\title{
MEDUSA-1.0: a new intermediate complexity plankton ecosystem model for the global domain
}

\author{
A. Yool, E. E. Popova, and T. R. Anderson \\ National Oceanography Centre, University of Southampton Waterfront Campus, European Way, \\ Southampton SO14 3ZH, UK
}

Received: 25 June 2010 - Published in Geosci. Model Dev. Discuss.: 29 October 2010

Revised: 28 March 2011 - Accepted: 9 April 2011 - Published: 10 May 2011

\begin{abstract}
The ongoing, anthropogenically-driven changes to the global ocean are expected to have significant consequences for plankton ecosystems in the future. Because of the role that plankton play in the ocean's "biological pump", changes in abundance, distribution and productivity will likely have additional consequences for the wider carbon cycle. Just as in the terrestrial biosphere, marine ecosystems exhibit marked diversity in species and functional types of organisms. Predicting potential change in plankton ecosystems therefore requires the use of models that are suited to this diversity, but whose parameterisation also permits robust and realistic functional behaviour. In the past decade, advances in model sophistication have attempted to address diversity, but have been criticised for doing so inaccurately or ahead of a requisite understanding of underlying processes. Here we introduce MEdus A-1.0 (Model of Ecosystem Dynamics, nutrient Utilisation, Sequestration and Acidification), a new "intermediate complexity" plankton ecosystem model that expands on traditional nutrient-phytoplankton-zooplanktondetritus (NPZD) models, and remains amenable to globalscale evaluation. MedusA-1.0 includes the biogeochemical cycles of nitrogen, silicon and iron, broadly structured into "small" and "large" plankton size classes, of which the "large" phytoplankton class is representative of a key phytoplankton group, the diatoms. A full description of MEDUSA1.0 's state variables, differential equations, functional forms and parameter values is included, with particular attention focused on the submodel describing the export of organic carbon from the surface to the deep ocean. MEDUsA-1.0 is used here in a multi-decadal hindcast simulation, and its biogeochemical performance evaluated at the global scale.
\end{abstract}

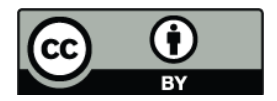

Correspondence to: A. Yool (axy@noc.ac.uk)

\section{Introduction}

Marine biota play a key role in the cycling and sequestering carbon in the ocean via the so-called "biological pump" (Raven and Falkowski, 1999). Fuelled by nutrients upwelled from the deep, phytoplankton produce organic matter via photosynthesis in the sunlit surface ocean. This is then processed by components of the marine ecosystem including grazing zooplankton, and a fraction exported back to depth via sinking detrital particles and dissolved organic matter. This biogenic flux of carbon into the deep ocean serves to elevate the ocean's storage of carbon beyond that sequestered through physics and chemistry alone. While the large-scale role of biology can be studied from its effects on tracer distributions (e.g. Gruber et al., 1996), mathematical modelling provides an important means of investigating the dynamics of the biological pump and its response to changing climate.

For many years, nutrient-phytoplankton-zooplanktondetritus (NPZD) models were the mainstay of basinand global-scale biogeochemical modelling studies (e.g. Sarmiento et al., 1993; Six and Maier-Reimer, 1996; Palmer and Totterdell, 2001). Today, aggregating the wide taxonomic and functional diversity of organisms in marine ecosystems into such an idealised model structure is generally considered too simplistic an approach. In the case of phytoplankton, for example, there are numerous different groups, so called plankton functional types (PFTs) such as diatoms, nitrogen fixers and coccolithophores, which undertake specific roles in marine biogeochemical cycles (Hood et al., 2006). A new generation of complex models that include multiple PFTs has accordingly been developed (e.g. Moore et al., 2004; Gregg et al., 2003; Le Quéré et al., 2005), yet complexity in models has associated difficulties including poorly understood ecology, lack of data for validation and sensitivity to the parameterisations involved (Anderson, 2005; Flynn, 2005). Additionally, on a practical level, the greater the complexity of an ecosystem model, the greater the

Published by Copernicus Publications on behalf of the European Geosciences Union. 
computation burden involved in its simulation, and therefore the less attractive the model is for long duration simulations of, for instance, future climate change (e.g. Cox et al., 2000).

The challenge is to derive model structures and parameterisations that are robust in the sense that the modelled ecosystem reacts realistically with the physico-chemical environment, yet which are based on sound mechanistic principles that maintain accuracy in prediction (Anderson, 2010). Here, we present a new ecosystem model, Medusa-1.0 (henceforth MEDUSA), and show results for its performance when incorporated into a global ocean general circulation model (GCM). The MEDUSA model is of intermediate complexity, building beyond the standard NPZD formulations, but without elaborating to the number of state variables and parameters in contemporary PFT models. The plankton ecosystem is divided into "small" and "large" portions, into which different planktonic components are organised. The small portion primarily includes (prokaryotic) nanophytoplankton and microzooplankton (protists and larval metazoans), together with small detrital particles that sink relatively slowly and are explicitly represented. The large portion primarily includes (eukaryotic) diatom phytoplankton and mesozooplankton (adult metazoans), together with large detrital particles that are assumed to sink sufficiently quickly that implicit representation is required. The phytoplankton components of MEDUsa include explicit representations of internal chlorophyll quotas, in order that light acclimation is permitted. The resulting plankton ecosystem is founded on the biogeochemical cycle of nitrogen, although the cycles of silicon and the micronutrient iron are also included.

The layout of the manuscript is as follows. First, MEDUSA's structure, differential equations, functional forms and parameterisation are fully described. Since MEDUSA has a particular focus on the biologically-driven sequestration of carbon in the deep ocean, the particulate flux submodels are described in detail. Next, MEDUSA is used in a standard control simulation for the period 1958 to 2005 (inclusive), and its performance assessed for the global ocean. This simulation makes use of a medium resolution instance of the Nucleus for European Modelling of the Ocean (NEMO) physical model (Madec, 2008) into which Medusa is embedded. Finally, the results of this simulation are discussed within the context of the need to move beyond NPZD models and to include additional factors associated with the biological carbon pump, such as ecosystem structure and multiple nutrient interaction.

\section{Medusa}

\subsection{State variables}

The model resolves 11 state variables distributed between the nitrogen (6), silicon (2) and iron (1) cycles. The remaining 2 state variables denote chlorophyll for each of the 2 phytoplankton classes. Nitrogen is the model's primary currency. The biogeochemical cycling of major elements in marine systems often exhibits relatively constant stoichiometry in which the ratios of utilisation of inorganic carbon, nitrogen and phosphorus by phytoplankton are matched by corresponding ratios of remineralisation in the deep ocean (Redfield, 1934). This has been particularly convenient for modellers because the cycling of nutrients by the marine ecosystem can be converted to carbon by simply multiplying by the so-called "Redfield ratio". Examples of this approach being used in GCMs include Six and Maier-Reimer (1996), Palmer and Totterdell (2001), Moore et al. (2004) and Le Quéré et al. (2005). We adopt the same approach here whereby the fluxes of carbon are calculated empirically from those of nitrogen without the need for explicit carbon tracers. Additional tracers for dissolved inorganic carbon (DIC) and alkalinity can be added for simulations that require a complete oceanic carbon cycle (e.g. for air-sea $\mathrm{CO}_{2}$ fluxes). Figure 1 presents a diagrammatic representation of MEDUSA's components and the relationships between them. The state variables are:

$\begin{array}{lll}\mathrm{Pn} & \text { Non-diatom phytoplankton } & \mathrm{mmol} \mathrm{N}^{-3} \\ \mathrm{Pd} & \text { Diatom phytoplankton } & \mathrm{mmol} \mathrm{N} \mathrm{m}^{-3} \\ \mathrm{Chl}_{\mathrm{Pn}} & \text { Chlorophyll in non-diatoms } & \mathrm{mg} \mathrm{chl} \mathrm{m}^{-3} \\ \mathrm{Ch}_{\mathrm{Pd}} & \text { Chlorophyll in diatoms } & \mathrm{mg} \mathrm{chl} \mathrm{m}^{-3} \\ \mathrm{Pd} & \text { Diatom phytoplankton (silicon) } & \mathrm{mmol} \mathrm{Si} \mathrm{m}^{-3} \\ \mathrm{Z} \mu & \text { Microzooplankton } & \mathrm{mmol} \mathrm{N} \mathrm{m}^{-3} \\ \mathrm{Zm} & \text { Mesozooplankton } & \mathrm{mmol} \mathrm{N} \mathrm{m}^{-3} \\ \mathrm{D} & \text { Slow-sinking detritus } & \mathrm{mmol} \mathrm{N} \mathrm{m}^{-3} \\ \mathrm{~N} & \text { Nitrogen nutrient } & \mathrm{mmol} \mathrm{N} \mathrm{m}^{-3} \\ \mathrm{~S} & \text { Silicic acid } & \mathrm{mmol} \mathrm{Si} \mathrm{m} \\ \mathrm{F} & \text { Iron nutrient } & \mathrm{mmol} \mathrm{Fe} \mathrm{m} \\ \end{array}$

The model includes a number of notable features. First, MEDUSA includes a stoichiometric representation of the trophic transfer of carbon and nitrogen during feeding by zooplankton, based on the C:N ratios in predator and prey, and derived from the model of Anderson and Hessen (1995) (based on the implementation in Anderson and Pondaven, 2003). Second, Medus A adds an explicit diatom silicon state variable $\left(\mathrm{Pd}_{\mathrm{Si}}\right)$ to allow diatom cells to have a dynamic $\mathrm{Si}: \mathrm{N}$ ratio, based on the model of Mongin et al. (2006). Third, Medusa includes both slow- and fast-sinking detrital pathways to represent the transport of particulate organic carbon in the ocean interior. The former is represented explicitly with a defined sinking rate, while the latter implicitly represents large particles that sink too quickly to be properly resolved within model time-stepping. The modifications adopted here for fast-sinking detritus are based on the ballast model of Armstrong et al. (2002), with the specific implementation derived largely from Dunne et al. (2007). Finally, Medus A adds an iron cycle submodel and explicit iron state variable $(\mathrm{F})$ to permit regional phytoplankton limitation by this important micronutrient. As remarked upon by Galbraith et al. (2010), iron submodels are still rudimentary, and there is significant uncertainty concerning the detail of the ocean's 


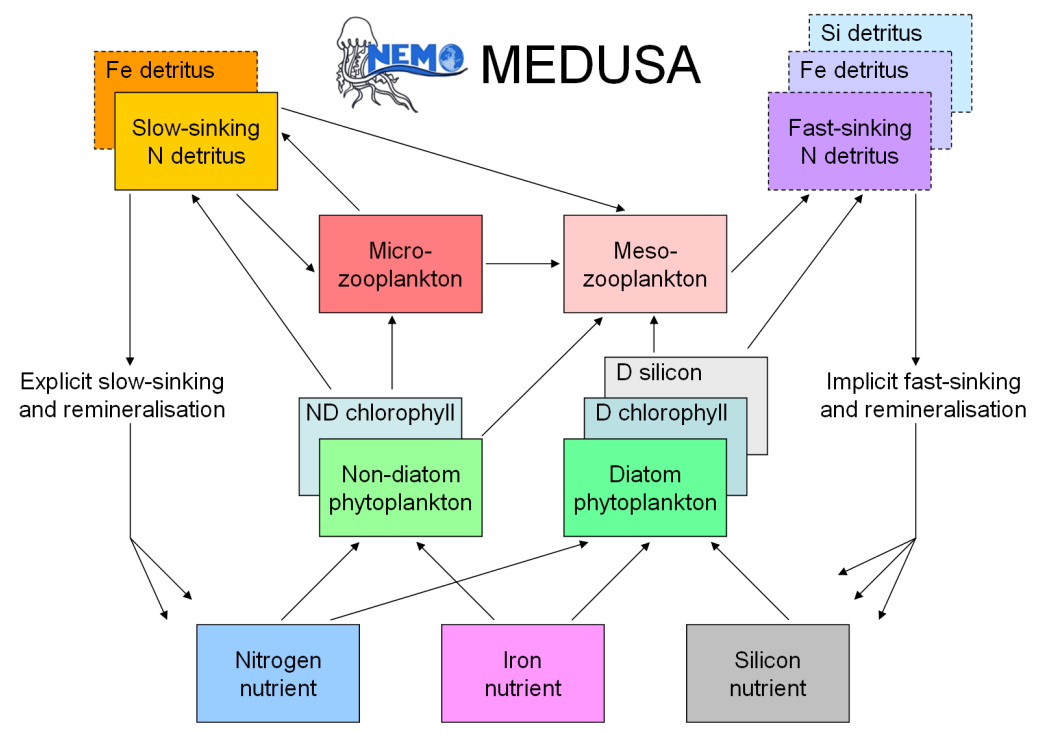

Fig. 1. Schematic diagram of the components and interactions in the MEDUSA model. Boxes with solid borders indicate explicitly modelled state variables, while boxes with dashed borders indicate implicitly modelled components. Overlapping boxes indicate components for which multiple currencies are modelled (e.g. different elements, chlorophyll).

iron cycle. Consequently, here we adopt the relatively simple iron submodel of Parekh et al. (2005) (based on the implementation in Dutkiewicz et al., 2005). In this, model iron is linked in a single fixed ratio to nitrogen throughout the ecosystem, but it also experiences processes that add (aeolian deposition) and remove (scavenging) it from the water column.

A key intention in this choice of framework is that MEDUSA separately represents populations of small phytoplankton that are strongly controlled by fast-growing microzooplankton, and those of large phytoplankton that are more weakly controlled by slower-growing mesozooplankton. Since diatoms form a key component of larger phytoplankton (Mann, 1999), Medusa assumes that they are synonymous with modelled "large phytoplankton". This assumption simplifies the real world situation in which even diatom species span a range of cell sizes (Furnas, 1990). Further assumptions concerning MEDUSA's phytoplankton include faster growth and better nutrient uptake kinetics of the small phytoplankton (Furnas, 1990), and similar size-linked growth patterns in zooplankton (Baird and Suthers, 2007). Appendix A1 describes a limited investigation of the significance of this disparity of growth rates between MEDUSA's non-diatom and diatom phytoplankton.

One potentially significant omission from MEDUSA is dissolved organic matter (DOM). This is often explicitly represented in contemporary ecosystem models that are implemented in OGCMs (e.g. Moore et al., 2004; Anderson et al., 2007; Okunishi et al., 2007; Lancelot et al., 2009), although this is not always the case (e.g. Christian et al., 2008; Liu and Chai, 2009). DOM cycling may cause stoichiometric imbalances within marine systems. Accumulation of dissolved organic carbon may, for example, contribute to seasonal drawdown of DIC and thereby impact on air-sea transfer of $\mathrm{CO}_{2}$ (Anderson and Pondaven, 2003; Prowe et al., 2009). Modelling studies have also implicated the potential importance of dissolved organic nutrients in fuelling primary production in the oligotrophic gyres of the ocean, particularly in the North Atlantic (Roussenov et al., 2006; Charria et al., 2008). Nevertheless, in comparing the global-scale performance of two versions of an ecosystem model (with and without DOM), Popova and Anderson (2002) found that the predicted distributions of nutrients and DIC were similar, as was the export flux which was driven primarily by sinking particles. Greater changes occurred in primary production and $f$-ratio . Similar findings were made by Schmittner et al. (2005) when examining the sensitivity of a global model of the marine ecosystem to DOM cycling. The very fact that the stoichiometry of deep ocean nutrients conforms relatively closely to Redfield indicates the dominance of particles in export (Kahler and Koeve, 2001). That is not to say that the flux of DOM is unimportant as it may contribute, for example, 5 to $29 \%$ of AOU below the euphotic zone in the North Atlantic (Carlson et al., 2010).

Whether or not to represent DOM in models is a typical issue relating to model complexity. Including DOM adds realism, but at a cost of error associated with its parameterisation. Assigning equations and parameter values for DOM cycling is fraught with difficulty given our limited understanding of interactions within microbial communities and of 
the physiology of heterotrophic bacteria (Christian and Anderson, 2002). Few estimates are available for the kinetic parameters defining the degradation of DOM in marine systems, particularly the semi-labile fraction, and it is therefore questionable how reliably it is possible to simulate this process in models (Christian and Anderson, 2002). Parameter estimates for DOM cycling are highly variable in models and require further validation. As such, given the apparent limited benefits of adding DOM tracers in terms of improved prediction, the difficulties of parameterisation and the computational overhead, we chose not to include DOM within MEdusA.

\subsection{Differential equations}

The following equations describe the tendency terms operating on the biogeochemical state variables in the model. Abbreviations used are: "PP" for primary production; " $\mu z o o "$ for microzooplankton; "mzoo" for mesozooplankton; "nonlin" for non-linear; "remin" for remineralisation. Functions and parameters are defined in Sects. 2.3 and 2.4.

$$
\begin{aligned}
& \frac{\partial \mathrm{Pn}}{\partial t}=+\underbrace{\left[\mathrm{PP}_{\mathrm{Pn}} \cdot \mathrm{Pn}\right]}_{\text {non-diatom PP }}-\underbrace{\left[\mathrm{G} \mu_{\mathrm{Pn}}\right]}_{\mu \text { zoo graze }}-\underbrace{\left[\mathrm{Gm} \mathrm{Pn}_{\mathrm{Pn}}\right]}_{\text {mzoo graze }} \\
& -\underbrace{\left[\mathrm{M} 1_{\mathrm{Pn}}\right]}_{\text {linear losses }}-\underbrace{[\mathrm{M} 2 \mathrm{Pn}]}_{\text {non-lin losses }} \\
& \frac{\partial \mathrm{Pd}}{\partial t}=+\underbrace{\left[\mathrm{PP}_{\mathrm{Pd}} \cdot \mathrm{Pd}\right]}_{\text {diatom PP }}-\underbrace{\left[\mathrm{Gm}_{\mathrm{Pd}}\right]}_{\text {mzoo graze }}-\underbrace{\left[\mathrm{M} 1_{\mathrm{Pd}}\right]}_{\text {linear losses }} \\
& -\underbrace{[\mathrm{M} 2 \mathrm{Pd}]}_{\text {non-lin losses }} \\
& \frac{\partial \mathrm{Chl}_{\mathrm{Pn}}}{\partial t}=\theta_{\mathrm{Pn}}{ }_{\mathrm{Chl}} \cdot \xi^{-1} \cdot(+\underbrace{\left[R_{\mathrm{Pn}} \cdot \mathrm{PP}_{\mathrm{Pn}} \cdot \mathrm{Pn}\right]}_{\text {non-diatom PP }} \\
& -\underbrace{\left[\mathrm{G} \mu_{\mathrm{Pn}}\right]}_{\text {Hzoo graze }}-\underbrace{[\mathrm{Gm} P \mathrm{Pn}}_{\text {mzoo graze }}]-\underbrace{\left[\mathrm{M} 1_{\mathrm{Pn}}\right]}_{\text {linear losses }} \\
& -\underbrace{[\mathrm{M} 2 \mathrm{Pn}]}_{\text {non-lin losses }}) \\
& \frac{\partial \mathrm{Chl}_{\mathrm{Pd}}}{\partial t}=\theta_{\mathrm{Pd}}^{\mathrm{Chl}} \cdot \xi^{-1} \cdot(+\underbrace{\left[R_{\mathrm{Pd}} \cdot \mathrm{PP}_{\mathrm{Pd}} \cdot \mathrm{Pd}\right]}_{\text {diatom PP }} \\
& -\underbrace{\left[\mathrm{Gm}_{\mathrm{Pd}}\right]}_{\text {mzoo graze }}-\underbrace{\left[\mathrm{M} 1_{\mathrm{Pd}}\right]}_{\text {linear losses }}-\underbrace{\left[\mathrm{M} 2_{\mathrm{Pd}}\right]}_{\text {non-lin losses }}) \\
& \frac{\partial \mathrm{Pd}_{\mathrm{Si}}}{\partial t}=+\underbrace{\left[\mathrm{PP}_{\mathrm{Pd}_{\mathrm{Si}}} \cdot \mathrm{Pd}_{\mathrm{Si}}\right]}_{\text {diatom PP }}-\underbrace{\left[\mathrm{Gm}_{\mathrm{Pd}_{\mathrm{Si}}}\right]}_{\text {mzoo graze }}-\underbrace{\left[\mathrm{M}_{\mathrm{Pd}_{\mathrm{Si}}}\right]}_{\text {linear losses }} \\
& -\underbrace{\left[\mathrm{M} 2 \mathrm{Pd}_{\mathrm{Si}}\right]}_{\text {non-lin losses }}-\underbrace{\left[\mathrm{DS}_{\mathrm{Pd}_{\mathrm{Si}}}\right]}_{\text {dissolution }}
\end{aligned}
$$

Geosci. Model Dev., 4, 381-417, 2011

$$
\begin{aligned}
& \frac{\partial \mathrm{Z} \mu}{\partial t}=+\underbrace{\left[F_{\mathrm{Z} \mu}\right]}_{\text {all grazing }}-\underbrace{\left[\mathrm{Gm}_{\mathrm{Z} \mu}\right]}_{\text {mzoo graze }}-\underbrace{\left[\mathrm{M} 1_{\mathrm{Z} \mu}\right]}_{\text {linear losses }} \\
& -\underbrace{[\mathrm{M} 2 \mathrm{Z \mu}]}_{\text {non-lin losses }} \\
& \frac{\partial \mathrm{Zm}}{\partial t}=+\underbrace{\left[F_{\mathrm{Zm}}\right]}_{\text {all grazing }}-\underbrace{\left[\mathrm{M} 1_{\mathrm{Zm}}\right]}_{\text {linear losses }}-\underbrace{\left[\mathrm{M} 2_{\mathrm{Zm}}\right]}_{\text {non-lin losses }} \\
& \frac{\partial \mathrm{D}}{\partial t}=+\underbrace{\left[\mathrm{M} 2_{\mathrm{Pn}}\right]}_{\text {non-diatom losses }}+\underbrace{\left[\left(1-\mathrm{D} 1_{\mathrm{frac}}\right) \cdot \mathrm{M} 2_{\mathrm{Pd}}\right]}_{\text {diatom losses }} \\
& +\underbrace{\left[\mathrm{M} 2_{\mathrm{Z \mu}}\right]}_{\mu \text { zoo losses }}+\underbrace{\left[\left(1-\mathrm{D} 2_{\mathrm{frac}}\right) \cdot \mathrm{M} 2_{\mathrm{Zm}}\right]}_{\text {mzoo losses }} \\
& +\underbrace{\left[\left(1-\beta_{\mathrm{N}}\right) \cdot \mathrm{IN}_{\mathrm{Z \mu}}\right]}_{\mu \text { zoo egestion }}+\underbrace{\left[\left(1-\beta_{\mathrm{N}}\right) \cdot \mathrm{IN}_{\mathrm{Zm}}\right]}_{\text {mzoo egestion }} \\
& -\underbrace{\left[\mathrm{G} \mu_{\mathrm{D}}\right]}_{\text {Hzoo graze }}-\underbrace{[\mathrm{Gm} \mathrm{D}]}_{\text {mzoo graze }}-\underbrace{\left[\mathrm{M}_{\mathrm{D}}\right]}_{\text {remin }}-\underbrace{\left[w_{\mathrm{g}} \cdot \frac{\partial \mathrm{D}}{\partial z}\right]}_{\text {sinking }} \\
& \frac{\partial \mathrm{N}}{\partial t}=-\underbrace{\left[\mathrm{PP}_{\mathrm{Pn}} \cdot \mathrm{Pn}\right]}_{\text {non-diatom PP }}-\underbrace{\left[\mathrm{PP}_{\mathrm{Pd}} \cdot \mathrm{Pd}\right]}_{\text {diatom PP }} \\
& +\underbrace{\left[\phi \cdot\left(\mathrm{G} \mu_{\mathrm{Pn}}+\mathrm{G} \mu_{\mathrm{D}}\right)\right]}_{\mu \text { zoo messy feeding }} \\
& +\underbrace{\left[\phi \cdot\left(\mathrm{Gm}_{\mathrm{Pn}}+\mathrm{Gm}_{\mathrm{Pd}}+\mathrm{Gm}_{\mathrm{Z} \mu}+\mathrm{Gm}_{\mathrm{D}}\right)\right]} \\
& \text { mzoo messy feeding } \\
& +\underbrace{\left[E_{\mathrm{Z} \mu}\right]}_{\mu \text { zoo excretion }}+\underbrace{\left[E_{\mathrm{Zm}}\right]}_{\text {mzoo excretion }} \\
& +\underbrace{\left[\mathrm{M} 1_{\mathrm{Pn}}\right]}_{\text {non-diatom losses }}+\underbrace{\left[\mathrm{M} 1_{\mathrm{Pd}}\right]}_{\text {diatom losses }}+\underbrace{\left[\mathrm{M} 1_{\mathrm{Z \mu}}\right]}_{\mu \mathrm{zoo} \text { losses }} \\
& +\underbrace{\left[\mathrm{M} 1_{\mathrm{Zm}}\right]}_{\text {mzoo losses }}+\underbrace{\left[\mathrm{M}_{\mathrm{D}}\right]}_{\text {remin }}+\underbrace{\left[\mathrm{LD}_{\mathrm{N}}(k)\right]}_{\text {fast } \mathrm{N} \text { detritus remin }} \\
& \frac{\partial \mathrm{S}}{\partial t}=-\underbrace{\left[\mathrm{PP}_{\mathrm{Pd}_{\mathrm{Si}}} \cdot \mathrm{Pd}_{\mathrm{Si}}\right]}_{\text {diatom PP }}+\underbrace{\left[\mathrm{M}_{\mathrm{Pd}_{\mathrm{Si}}}\right]}_{\text {linear losses }} \\
& +\underbrace{\left[\left(1-\mathrm{D} 1_{\text {frac }}\right) \cdot \mathrm{M} 2 \mathrm{Pd}_{\mathrm{Si}}\right]}_{\text {non-lin. losses }}+\underbrace{\left[\mathrm{DS}_{\mathrm{Pd}_{\mathrm{Si}}}\right]}_{\text {dissolution }} \\
& +\underbrace{\left[\left(1-\mathrm{D} 2_{\mathrm{frac}}\right) \cdot \mathrm{Gm}_{\left.\mathrm{Pd}_{\mathrm{Si}}\right]}\right]}_{\text {mzoo graze }}+\underbrace{\left[\mathrm{LD}_{\mathrm{Si}}(k)\right]}_{\text {fast Si detritus remin }} \\
& \frac{\partial \mathrm{F}}{\partial t}=-\underbrace{\left[R_{\mathrm{Fe}} \cdot \frac{\partial \mathrm{N}}{\partial t}\right]}_{\text {coupled to } \mathrm{N}}+\underbrace{\left[F_{\text {atmos }}\right]}_{\text {aeolian }}-\underbrace{\left[F_{\text {scavenge }}\right]}_{\text {scavenging }}
\end{aligned}
$$

These differential equations are applied to the biogeochemical state variables within every ocean grid cell in the physical model, regardless of horizontal or vertical position. This parallels the implementation of ecosystem models in 
some general circulation models (e.g. Yool et al., 2010), but is different from other studies in which different equations are applied at different depths, typically to separate the photic and aphotic zones (e.g. Popova et al., 2006).

\subsection{Interaction functional forms}

The following series of equations expand on the tendency terms described in the differential equations. Parameter definitions and values are described in Sect. 2.4.

\subsubsection{Non-diatom limitation and growth}

The chlorophyll and light-limited growth terms for nondiatom phytoplankton are derived from those in Taylor et al. (1997) and Fasham et al. (1990), and based on their implementation in Popova et al. (2006). As per Eppley (1972), maximum phytoplankton growth rate is a simple exponential function of temperature. Nutrient limitation is factored in through standard Michaelis-Menten terms.

$\begin{aligned} \theta_{\mathrm{Pn}}^{\mathrm{Chl}} & =\frac{\mathrm{Ch}_{\mathrm{Pn}} \cdot \xi}{\mathrm{Pn}} \\ \hat{\alpha}_{\mathrm{Pn}} & =\alpha_{\mathrm{Pn}} \cdot \theta_{\mathrm{Pn}}^{\mathrm{Chl}}\end{aligned}$

$\theta_{\mathrm{Pn}}^{\mathrm{Chl}}$ is the scaled chlorophyll to biomass ratio, while $\hat{\alpha}_{\mathrm{Pn}}$ scales the initial slope of the photosynthesis-irradiance $(P-I)$ curve, $\alpha_{\mathrm{Pn}}$, by this ratio so that phytoplankton with a high chlorophyll content have an elevated response to irradiance.

$V_{\mathrm{Pn}^{T}}=V_{\mathrm{Pn}} \cdot 1.066^{T}$

This term calculates maximum phytoplankton growth rate as an exponential function of temperature, $T$, and base growth rate at $0^{\circ} \mathrm{C}$.

$J_{\mathrm{Pn}}=\frac{V_{\mathrm{Pn}^{T}} \cdot \hat{\alpha}_{\mathrm{Pn}} \cdot I}{\left(V_{\mathrm{Pn}^{T}}^{2}+\hat{\alpha}_{\mathrm{Pn}}^{2} \cdot I^{2}\right)^{1 / 2}}$

Given the (chlorophyll-related) initial slope of the $P$ $I$ curve and (temperature-related) maximum phytoplankton growth rate, this function calculates realised growth rate given local irradiance, $I\left(\mathrm{~W} \mathrm{~m}^{-2}\right)$.

$$
\begin{aligned}
Q_{\mathrm{N}, \mathrm{Pn}} & =\frac{\mathrm{N}}{k_{\mathrm{N}, \mathrm{Pn}}+\mathrm{N}} \\
Q_{\mathrm{Fe}, \mathrm{Pn}} & =\frac{\mathrm{F}}{k_{\mathrm{Fe}, \mathrm{Pn}}+\mathrm{F}}
\end{aligned}
$$

Nutrient limitation of phytoplankton growth is specified here via standard, hyperbolic Michaelis-Menten terms that use ambient nutrient concentrations and parameters for the concentration at which phytoplankton growth is half its theoretical maximum.

$$
\mathrm{PP}_{\mathrm{Pn}}=J_{\mathrm{Pn}} \cdot Q_{\mathrm{N}, \mathrm{Pn}} \cdot Q_{\mathrm{Fe}, \mathrm{Pn}}
$$

Light- and nutrient-limitation factors are brought together in a multiplicative term that determines nutrient uptake and, via Redfield coupling, primary production. Appendix A2 investigates an alternative Liebig law of the minimum scheme for multiple nutrient limitation.

\subsubsection{Diatom limitation and growth}

Diatom phytoplankton growth terms are derived from the same sources as those of non-diatom phytoplankton. However, diatom growth is additionally coupled to the silicon cycle, and the submodel of silicon uptake and diatom growth from Mongin et al. (2006) has been adopted to represent these processes. This places contraints on growth and nutrient uptake based upon the $\mathrm{Si}: \mathrm{N}$ ratio of the modelled diatom cells.

$$
\begin{aligned}
\theta_{\mathrm{Pd}}^{\mathrm{Ch}} & =\frac{\mathrm{Ch}_{\mathrm{Pd}} \cdot \xi}{\mathrm{Pd}} \\
\hat{\alpha}_{\mathrm{Pd}} & =\alpha_{\mathrm{Pd}} \cdot \theta_{\mathrm{Pd}}^{\mathrm{Chl}} \\
V_{\mathrm{Pd}} T & =V_{\mathrm{Pd}} \cdot 1.066^{T} \\
J_{\mathrm{Pd}} & =\frac{V_{\mathrm{Pd}^{T}} \cdot \hat{\alpha}_{\mathrm{Pd}} \cdot I}{\left(V_{\mathrm{Pd}^{T}}^{2}+\hat{\alpha}_{\mathrm{Pd}}^{2} \cdot I^{2}\right)^{1 / 2}} \\
Q_{\mathrm{N}, \mathrm{Pd}} & =\frac{\mathrm{N}}{k_{\mathrm{N}, \mathrm{Pd}}+\mathrm{N}} \\
Q_{\mathrm{Si}} & =\frac{\mathrm{S}}{k_{\mathrm{Si}}+\mathrm{S}} \\
Q_{\mathrm{Fe}, \mathrm{Pd}} & =\frac{\mathrm{F}}{k_{\mathrm{Fe}, \mathrm{Pd}}+\mathrm{F}}
\end{aligned}
$$

As noted above, the growth of diatom phytoplankton is additionally limited by the availability of the macronutrient silicic acid.

$\begin{aligned} R_{\mathrm{Si}: \mathrm{N}} & =\frac{\mathrm{Pd}_{\mathrm{Si}}}{\mathrm{Pd}} \\ R_{\mathrm{N}: \mathrm{Si}} & =\frac{\mathrm{Pd}}{\mathrm{Pd}_{\mathrm{Si}}}\end{aligned}$

Silicon is largely used by diatom phytoplankton in the construction of their cell walls, or frustules, which can vary significantly in their ornamentation (e.g. spines, girdle bands; Martin-Jézéquel et al., 2000). As a result, diatoms have a degree of plasticity in their requirement for silicon, necessitating a separate state variable, and centred around the resulting stoichiometric ratios, $R_{\mathrm{Si}: \mathrm{N}}$ and $R_{\mathrm{N}: \mathrm{Si}}$.

$$
\begin{aligned}
& \text { If } R_{\mathrm{Si}: \mathrm{N}} \leq R_{\mathrm{Si}: \mathrm{N}}^{0} \text { then } \\
& \mathrm{PP}_{\mathrm{Pd}}=0
\end{aligned}
$$

else if $R_{\mathrm{Si}: \mathrm{N}}^{0}<R_{\mathrm{Si}: \mathrm{N}}<\left(3 \cdot R_{\mathrm{Si}: \mathrm{N}}^{0}\right)$ then

$$
\begin{aligned}
\mathrm{PP}_{\mathrm{Pd}}= & \left(J_{\mathrm{Pd}} \cdot Q_{\mathrm{N}, \mathrm{Pd}} \cdot Q_{\mathrm{Fe}, \mathrm{Pd}}\right) \\
& \cdot\left(U_{\infty} \cdot \frac{R_{\mathrm{Si}: \mathrm{N}}-R_{\mathrm{Si}: \mathrm{N}}^{0}}{R_{\mathrm{Si} \mathrm{N}}}\right)
\end{aligned}
$$


else if $R_{\mathrm{Si}: \mathrm{N}} \geq\left(3 \cdot R_{\mathrm{Si}: \mathrm{N}}^{0}\right)$ then

$\mathrm{PP}_{\mathrm{Pd}}=\left(J_{\mathrm{Pd}} \cdot Q_{\mathrm{N}, \mathrm{Pd}} \cdot Q_{\mathrm{Fe}, \mathrm{Pd}}\right)$

Here, the uptake of nitrogen (and iron) by diatom cells, $\mathrm{PP}_{\mathrm{Pd}}$, is governed by the $\mathrm{Si} \mathrm{N}$ ratio. If this falls below a critical value, $R_{\mathrm{Si}: \mathrm{N}}^{0}$, diatom cells cannot complete their cell division cycle and growth stops Martin-Jézéquel et al. (2000). Above this minimum ratio growth is scaled by a factor of the $\mathrm{Si}: \mathrm{N}$ ratio, and above 3 times this ratio, growth is unimpeded by silicon dynamics.

If $R_{\mathrm{Si}: \mathrm{N}}<\left(3 \cdot R_{\mathrm{Si}: \mathrm{N}}^{0}\right)^{-1}$ then

$\operatorname{PP}_{\mathrm{Pd}_{\mathrm{Si}}}=\left(J_{\mathrm{Pd}} \cdot Q_{\mathrm{Si}}\right)$

else if $\left(3 \cdot R_{\mathrm{Si}: \mathrm{N}}^{0}\right)^{-1} \leq R_{\mathrm{Si}: \mathrm{N}}<\left(R_{\mathrm{Si}: \mathrm{N}}^{0}\right)^{-1}$ then

$\mathrm{PP}_{\mathrm{Pd}_{\mathrm{Si}}}=\left(J_{\mathrm{Pd}} \cdot Q_{\mathrm{Si}}\right)$

$$
\cdot\left(U_{\infty} \cdot \frac{R_{\mathrm{N}: \mathrm{Si}}-R_{\mathrm{N}: \mathrm{Si}}^{0}}{R_{\mathrm{N}: \mathrm{Si}}}\right)
$$

else if $R_{\mathrm{Si}: \mathrm{N}} \geq\left(R_{\mathrm{Si}: \mathrm{N}}^{0}\right)^{-1}$ then

$\mathrm{PP}_{\mathrm{Pd}_{\mathrm{Si}}}=0$

Here, silicon uptake, $\mathrm{PP}_{\mathrm{Pd}_{\mathrm{Si}}}$, occurs at the maximum rate permitted by light and silicon availability whenever the Si:N ratio is below a critical threshold, $\left(3 \cdot R_{\mathrm{Si} N \mathrm{~N}}^{0}\right)^{-1}$. Above this ratio, silicon uptake is linearly decreased to another threshold value, $\left(R_{\text {Si:N }}^{0}\right)^{-1}$, above which no silicon is taken up by diatom cells. Figure 2 illustrates these equations by showing uptake of nitrogen and silicon by diatoms across a range of biomass $\mathrm{Si}: \mathrm{N}$ ratios.

\subsubsection{Chlorophyll growth scaling factors}

Both phytoplankton groups have separate chlorophyll state variables in addition to those of nitrogen biomass. This allows the modelled phytoplankton to dynamically alter their chlorophyll content under different light regimes. The following terms for this processes are taken from Taylor et al. (1997).

$$
\begin{aligned}
& R_{\mathrm{Pn}}=\frac{\theta_{\mathrm{max}, \mathrm{Pn}}^{\mathrm{Chl}}}{\theta_{\mathrm{Pn}}^{\mathrm{hl}}} \cdot \frac{\mathrm{PP}_{\mathrm{Pn}}}{\hat{\alpha}_{\mathrm{Pn}} \cdot I} \\
& R_{\mathrm{Pd}}=\frac{\theta_{\mathrm{max}, \mathrm{Pd}}^{\mathrm{Chl}}}{\theta_{\mathrm{Pd}}^{\mathrm{Chl}}} \cdot \frac{\mathrm{PP}_{\mathrm{Pd}}}{\hat{\alpha}_{\mathrm{Pd}} \cdot I}
\end{aligned}
$$

\subsubsection{Microzooplankton grazing}

Microzooplankton graze on smaller non-diatom phytoplankton and on particles of slow-sinking detritus. The ingestion function that balances the availability of these prey items with the preference microzooplankton have for them is drawn from the classic model of Fasham et al. (1990).
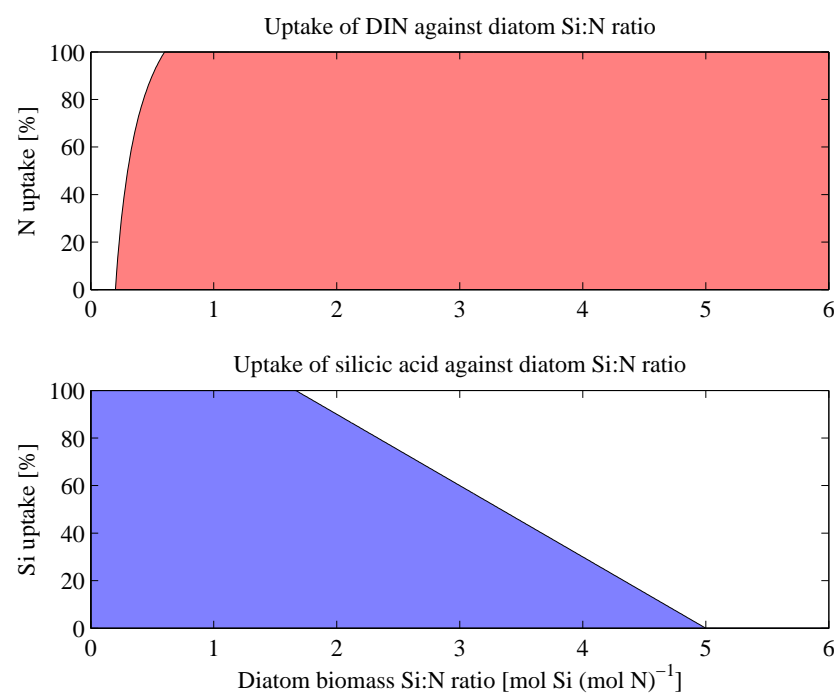

Fig. 2. Diatom uptake of nitrogen (top) and silicon (bottom) against the $\mathrm{Si}: \mathrm{N}$ ratio of diatom biomass.

$\mathrm{G} \mu_{X}=\frac{g_{\mu} \cdot p_{\mu X} \cdot X^{2} \cdot \mathrm{Z} \mu}{k_{\mu}^{2}+p_{\mu \mathrm{Pn}} \cdot \mathrm{Pn}^{2}+p_{\mu \mathrm{D}} \cdot \mathrm{D}^{2}}$

where $X$ is Pn or D. The above term is repeated for each separate prey item consumed by microzooplankton. The term is based around a sigmoid function in which the "substrate" is composed of the sum of the prey items scaled by the preference that microzooplankton have for them. It is assumed here that microzooplankton prefer non-diatom phytoplankton over detritus since they represent a higher quality food item.

$\mathrm{IN}_{\mathrm{Z} \mu}=(1-\phi) \cdot\left(\mathrm{G} \mu_{\mathrm{Pn}}+\mathrm{G} \mu_{\mathrm{D}}\right)$

$\mathrm{IC}_{\mathrm{Z} \mu}=(1-\phi) \cdot\left(\theta_{\mathrm{Pn}} \cdot \mathrm{G} \mu_{\mathrm{Pn}}+\theta_{\mathrm{D}} \cdot \mathrm{G} \mu_{\mathrm{D}}\right)$

Here, the separate quantities of nitrogen, $\mathrm{IN}_{Z \mu}$, and carbon, $\mathrm{IC}_{\mathrm{Z} \mu}$, ingested by microzooplankton are summed. Parameter $\phi$ relates to grazing inefficiency, so-called "messy feeding", that returns a fraction of the grazed material back to dissolved nutrient. For the material actually ingested, the resulting $\mathrm{C}: \mathrm{N}$ ratio, $\theta_{\mathrm{F} \mu}$, can be calculated.

$\theta_{\mathrm{F} \mu}=\frac{\mathrm{IC}_{\mathrm{Z} \mu}}{\mathrm{IN}_{\mathrm{Z} \mu}}$

Since grazed material may have a different $\mathrm{C}: \mathrm{N}$ ratio than that required for microzooplankton growth, the assimilation and metabolism submodel of Anderson and Pondaven (2003) is incorporated here to balance growth, excretion and respiration. The $\mathrm{C}: \mathrm{N}$ ratio of ingested food calculated above is 
then compared to the ideal ratio preferred by microzooplankton, $\theta_{\mathrm{F} \mu}^{*}$. This makes use of the assimilation efficiencies of nitrogen, $\beta_{\mathrm{N}}$, and carbon, $\beta_{\mathrm{C}}$, as well as the carbon growth efficiency, $k_{\mathrm{C}}$, of microzooplankton.

$\theta_{\mathrm{F} \mu}^{*}=\frac{\beta_{\mathrm{N}} \cdot \theta_{\mathrm{Z} \mu}}{\beta_{\mathrm{C}} \cdot k_{\mathrm{C}}}$

Either $\mathrm{C}$ or $\mathrm{N}$ limits production depending on whether $\theta_{\mathrm{F} \mu}$ is greater or lower than $\theta_{\mathrm{F} \mu}^{*}$, with any excess carbon respired, and any excess nitrogen excreted. Growth, $F_{\mathrm{Z} \mu}$, respiration, $R_{\mathrm{Z} \mu}$, and excretion, $E_{\mathrm{Z} \mu}$, are calculated as follows.

If $\theta_{\mathrm{F} \mu}>\theta_{\mathrm{F} \mu}^{*}$ then $\mathrm{N}$ is limiting and ...

$F_{\mathrm{Z} \mu}=\beta_{\mathrm{N}} \cdot \mathrm{IN}_{\mathrm{Z} \mu}$

$E_{\mathrm{Z} \mu}=0$

$R_{\mathrm{Z} \mu}=\left(\beta_{\mathrm{C}} \cdot \mathrm{IC}_{\mathrm{Z} \mu}\right)-\left(\theta_{\mathrm{Z} \mu} \cdot \mathrm{F}_{\mathrm{Z} \mu}\right)$

else if $\theta_{\mathrm{F} \mu}<\theta_{\mathrm{F} \mu}^{*}$ then $\mathrm{C}$ is limiting and ...

$F_{\mathrm{Z} \mu}=\frac{\beta_{\mathrm{C}} \cdot k_{\mathrm{C}} \cdot \mathrm{IC}_{\mathrm{Z} \mu}}{\theta_{\mathrm{Z} \mu}}$

$E_{\mathrm{Z} \mu}=\mathrm{IC}_{\mathrm{Z} \mu} \cdot\left(\frac{\beta_{\mathrm{N}}}{\theta_{\mathrm{F} \mu}}-\frac{\beta_{\mathrm{C}} \cdot k_{\mathrm{C}}}{\theta_{\mathrm{Z} \mu}}\right)$

$R_{\mathrm{Z} \mu}=\left(\beta_{\mathrm{C}} \cdot \mathrm{IC}_{\mathrm{Z} \mu}\right)-\left(\theta_{\mathrm{Z} \mu} \cdot \mathrm{F}_{\mathrm{Z} \mu}\right)$

Figure 3 shows the relative partitioning of carbon and nitrogen grazed by zooplankton depending upon food C:N ratio.

\subsubsection{Mesozooplankton grazing}

Mesozooplankton grazing follows that of microzooplankton with the exception that mesozooplankton have a broader range of prey items. For simplicity, parameters $\phi, \beta_{\mathrm{N}}, \beta_{\mathrm{C}}$, and $k_{\mathrm{C}}$ are identical to those used for microzooplankton.

$\mathrm{Gm}_{X}=\frac{g_{\mathrm{m}} \cdot p_{\mathrm{m} X} \cdot X^{2} \cdot \mathrm{Zm}}{k_{\mathrm{m}}^{2}+\mathrm{Fm}}$

where $X$ is $\mathrm{Pn}, \mathrm{Pd}, \mathrm{Z} \mu$ or $\mathrm{D}$.

$$
\begin{aligned}
\mathrm{Fm}= & \left(p_{\mathrm{mPn}} \cdot \mathrm{Pn}^{2}\right)+\left(p_{\mathrm{mPd}} \cdot \mathrm{Pd}^{2}\right) \\
+ & \left(p_{\mathrm{mZ} \mu} \cdot \mathrm{Z}^{2}\right)+\left(p_{\mathrm{mD}} \cdot \mathrm{D}^{2}\right) \\
\mathrm{Gm}_{\mathrm{Pd}_{\mathrm{Si}}}= & R_{\mathrm{Si} \mathrm{N}} \cdot \mathrm{Gm} \mathrm{Pd}_{\mathrm{Pd}} \\
\mathrm{IN}_{\mathrm{Zm}}= & (1-\phi) \cdot\left(\mathrm{Gm}_{\mathrm{Pd}}+\mathrm{Gm}_{\mathrm{Pn}}\right. \\
& \left.+\mathrm{Gm} \mathrm{Z} \mu+\mathrm{Gm}_{\mathrm{Pd}}\right) \\
\mathrm{IC}_{\mathrm{Zm}}= & (1-\phi) \cdot\left(\left(\theta_{\mathrm{Pd}} \cdot \mathrm{Gm}_{\mathrm{Pd}}\right)+\left(\theta_{\mathrm{Pn}} \cdot \mathrm{Gm}_{\mathrm{Pn}}\right)\right. \\
& \left.+\left(\theta_{\mathrm{Z} \mu} \cdot \mathrm{Gm}_{\mathrm{Z} \mu}\right)+\left(\theta_{\mathrm{D}} \cdot \mathrm{Gm}_{\mathrm{D}}\right)\right)
\end{aligned}
$$

www.geosci-model-dev.net/4/381/2011/
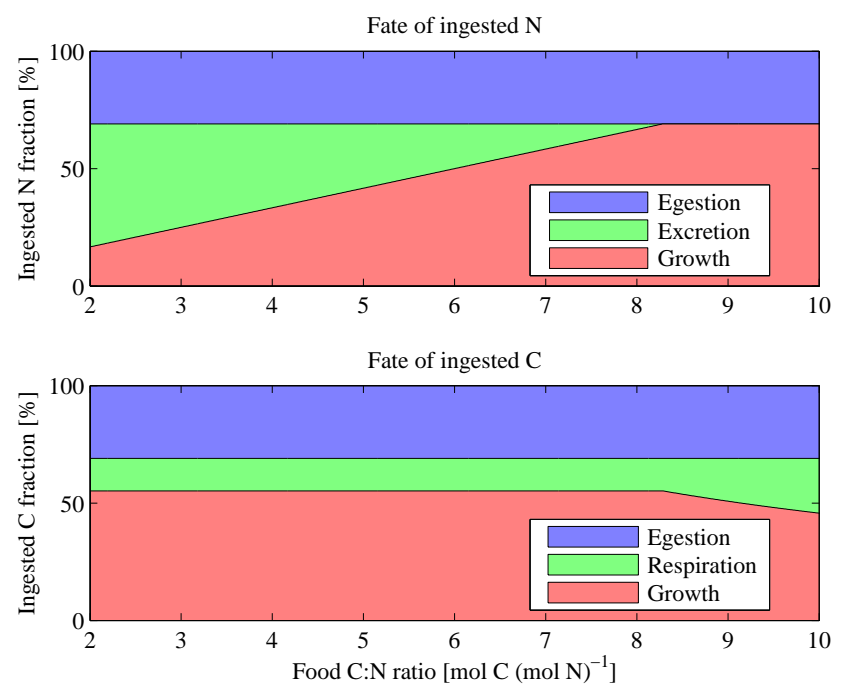

Fig. 3. Partitioning of nitrogen (top) and carbon (bottom) to egestion, excretion, respiration and growth against the $\mathrm{C}: \mathrm{N}$ ratio of ingested food. Since they share parameter values, the responses of both microzooplankton and mesozooplankton are identical.

$\theta_{\mathrm{Fm}}=\frac{\mathrm{IC}_{\mathrm{Zm}}}{\mathrm{IN} \mathrm{Zm}_{\mathrm{m}}}$

$\theta_{\mathrm{Fm}}^{*}=\frac{\beta_{\mathrm{N}} \cdot \theta_{\mathrm{Zm}}}{\beta_{\mathrm{C}} \cdot k_{\mathrm{C}}}$

if $\theta_{\mathrm{Fm}}>\theta_{\mathrm{Fm}}^{*}$ then $\mathrm{N}$ is limiting and ...

$F_{\mathrm{Zm}}=\beta_{\mathrm{N}} \cdot \mathrm{IN}_{\mathrm{Zm}}$

$E_{\mathrm{Zm}}=0$

$R_{\mathrm{Zm}}=\left(\beta_{\mathrm{C}} \cdot \mathrm{IC}_{\mathrm{Zm}}\right)-\left(\theta_{\mathrm{Zm}} \cdot F_{\mathrm{Zm}}\right)$

else if $\theta_{\mathrm{Fm}}<\theta_{\mathrm{Fm}}^{*}$ then $\mathrm{C}$ is limiting and ...

$F_{\mathrm{Zm}}=\frac{\beta_{\mathrm{C}} \cdot k_{\mathrm{C}} \cdot \mathrm{IC}_{\mathrm{Zm}}}{\theta_{\mathrm{Zm}}}$

$E_{\mathrm{Zm}}=\mathrm{IC}_{\mathrm{Zm}} \cdot\left(\frac{\beta_{\mathrm{N}}}{\theta_{\mathrm{Fm}}}-\frac{\beta_{\mathrm{C}} \cdot k_{\mathrm{C}}}{\theta_{\mathrm{Zm}}}\right)$

$R_{\mathrm{Zm}}=\left(\beta_{\mathrm{C}} \cdot \mathrm{IC}_{\mathrm{Zm}}\right)-\left(\theta_{\mathrm{Zm}} \cdot F_{\mathrm{Zm}}\right)$

Figure 3 shows the relative partitioning of carbon and nitrogen grazed by zooplankton depending upon food C:N ratio. 


\subsubsection{Plankton loss terms}

In addition to losses to grazing, all four living components of the plankton model incur smaller, secondary losses to other processes.

$$
\begin{aligned}
& \mathrm{M} 1_{\mathrm{Pn}}=\mu_{1, \mathrm{Pn}} \cdot \mathrm{Pn} \\
& \mathrm{M} 1_{\mathrm{Pd}}=\mu_{1, \mathrm{Pd}} \cdot \mathrm{Pd} \\
& \mathrm{M}_{\mathrm{Pd}_{\mathrm{Si}}}=R_{\mathrm{Si} \mathrm{N}} \cdot \mathrm{M} 1_{\mathrm{Pd}} \\
& \mathrm{M} 1_{\mathrm{Z} \mu}=\mu_{1, \mathrm{Z} \mu} \cdot \mathrm{Z} \mu \\
& \mathrm{M} 1_{\mathrm{Zm}}=\mu_{1, \mathrm{Zm}} \cdot \mathrm{Zm}
\end{aligned}
$$

The above functions are density-independent loss terms for processes such as metabolism that occur without reference to abundance.

$\mathrm{M} 2_{\mathrm{Pn}}=\mu_{2, \mathrm{Pn}} \cdot \frac{\mathrm{Pn}}{k_{\mathrm{Pn}}+\mathrm{Pn}} \cdot \mathrm{Pn}$

$\mathrm{M} 2_{\mathrm{Pd}}=\mu_{2, \mathrm{Pd}} \cdot \frac{\mathrm{Pd}}{k_{\mathrm{Pd}}+\mathrm{Pd}} \cdot \mathrm{Pd}$

$\mathrm{M} 2_{\mathrm{Pd}_{\mathrm{Si}}}=R_{\mathrm{Si}: \mathrm{N}} \cdot \mathrm{M} 2_{\mathrm{Pd}}$

$\mathrm{M} 2 \mathrm{Z} \mu=\mu_{2, \mathrm{Z} \mu} \cdot \frac{\mathrm{Z} \mu}{k_{\mathrm{Z} \mu}+\mathrm{Z} \mu} \cdot \mathrm{Z} \mu$

$\mathrm{M} 2_{\mathrm{Zm}}=\mu_{2, \mathrm{Zm}} \cdot \frac{\mathrm{Zm}}{k_{\mathrm{Zm}}+\mathrm{Zm}} \cdot \mathrm{Zm}$

The above functions are density-dependent loss terms for processes such as disease (e.g. viruses) and grazing by implicit higher trophic levels that occur at variable rates depending upon plankton abundance. Such terms are also favoured over linear mortality in ecosystem models because they provide a source of stabilising feedback (Steele and Henderson, 1992). In the default case, density-dependent losses are represented using a hyperbolic function of plankton concentration (Fasham, 1993), although switches in the model code (Table 5) permit linear, quadratic and sigmoid functions. As the best choice for mortality function is unclear but can have significant consequences for models (e.g. Steele and Henderson, 1992; Edwards and Yool, 2000; Fussmann and Blasius, 2005; Anderson et al., 2010), Appendix A3 investigates alternative functions for this mortality term.

\subsubsection{Miscellaneous losses}

Since silicic acid is at undersaturated concentrations throughout the modern ocean (Yool and Tyrrell, 2003), the silicon component of diatom phytoplankton is additionally vulnerable to dissolution. This is represented here by a simple linear loss rate, per Mongin et al. (2006).

$\mathrm{DS}_{\mathrm{Pd}_{\mathrm{Si}}}=\mathrm{Diss} \cdot \mathrm{Pd}_{\mathrm{Si}}$
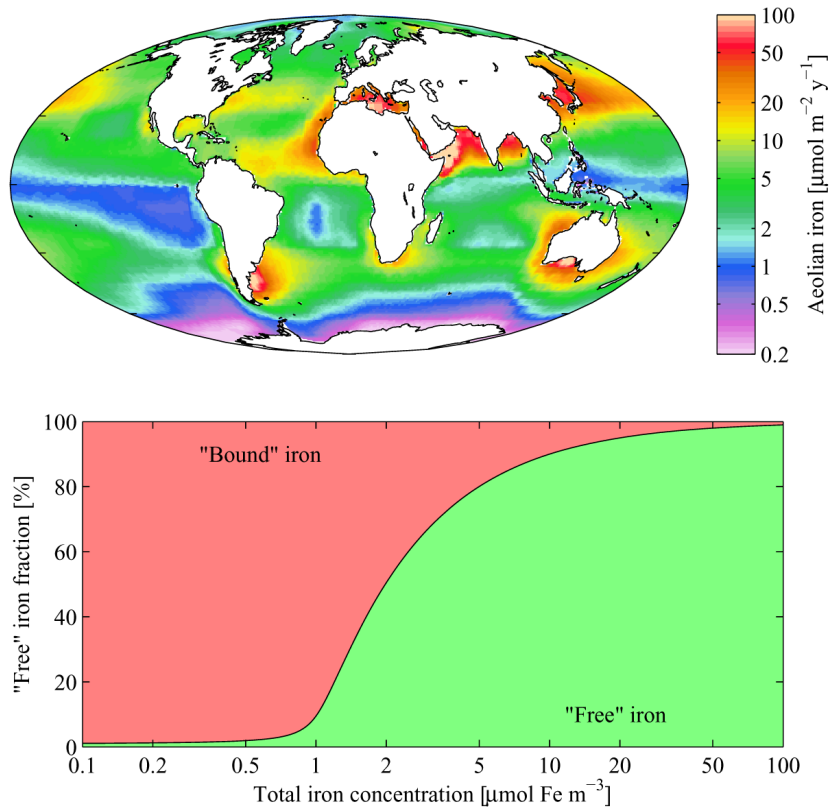

Fig. 4. The top panel shows mean annual aeolian iron input to the ocean (i.e. the quantity of iron that dissolves into seawater from deposited dust). The input is shown on a logarithmic scale in units of

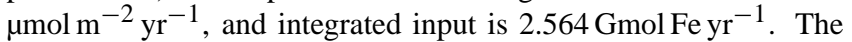
bottom panel shows the fractionation of total iron between "free" and ligand-bound forms across a logarithmic range of total iron concentrations.

Remineralisation of slow-sinking detrital particles to dissolved inorganic nitrogen occurs at a rate dependent on ambient temperature.

$\mathrm{M}_{\mathrm{D}}=\mu_{\mathrm{D}} \cdot 1.066^{T} \cdot \mathrm{D}$

\subsubsection{Iron supply and removal}

Following the submodel of Dutkiewicz et al. (2005), iron is added to the ocean by aeolian deposition of iron-carrying dust at the surface, and removed throughout by scavenging.

$F_{\text {atmos }}=$ spatially variable rate

Figure 4 shows a map of annual average iron deposition. Aeolian iron solubility was adjusted in Medusa such that the total dissolved iron addition to the ocean $\left(2.6 \mathrm{Gmol} \mathrm{yr}^{-1}\right)$ was the same as that of Dutkiewicz et al. (2005).

$F_{\text {scavenge }}=k_{\text {scav }} \cdot F_{\text {free }}$

Scavenging occurs at a fixed linear rate, $k_{\text {scav }}$, throughout the full volume of the ocean, but is assumed to only remove "free" iron, $F_{\text {free }}$.

$F_{\text {free }}=\mathrm{F}-F_{\text {ligand }}$ 
MEdusA's iron state variable, $\mathrm{F}$, represents total iron, and this is assumed to occur in two fractions: "free", $F_{\text {free}}$; and that bound to organic ligands, $F_{\text {ligand }}$ Gledhill and van den Berg (1994). In the ocean, it is estimated that more than $97 \%$ of total iron is complexed with ligands (Boye et al., 2003).

$F_{\text {ligand }}=L_{\text {total }}-L_{\text {free }}$

$L_{\text {free }}=0.5 \cdot \frac{\left(F_{1}+\sqrt{F_{2}}\right)}{k_{\mathrm{FeL}}}$

$F_{1}=k_{\mathrm{FeL}} \cdot\left(L_{\mathrm{total}}-\mathrm{F}\right)-1$

$F_{2}=\max \left(F_{1}^{2}+\left(4 \cdot k_{\mathrm{FeL}} \cdot L_{\text {total }}\right), 0\right)$

The complexation reactions between iron species and ligands occur rapidly, and it is assumed here that they reach equilibrium in a shorter period than model time-step Rose and Waite (2003). In the equations above, $L_{\text {total }}$ is the total ligand concentration of seawater, and is assumed to be globally constant; $k_{\mathrm{FeL}}$ is the ligand binding strength. Given these equations and parameters, Fig. 4 shows a diagram of the resulting partition between "free" and bound iron over a range of total iron concentration.

\subsubsection{Fast detritus}

Differential Eqs. (9) and (10) (and, implicitly, 11) include terms for the remineralisation of fast-sinking detrital material, $\mathrm{LD}_{\mathrm{N}}(k)$ and $\mathrm{LD}_{\mathrm{Si}}(k)$. These, together with the corresponding terms for the production of fast-sinking detritus (nitrogen, silicon, iron, organic carbon and calcium carbonate) are fully described in Section 3.2.

\subsection{Parameter values}

The Tables 1 to 4 list model parameters, a brief description of each, and their respective values and units. For ease of use, the ordering of parameters reflects their appearance in the namelist.trc.sms file in which they are specified (see Appendix B and accompanying model code).

In addition to the parameters above, MEDUSA includes a number of control parameters that allow the model to switch between different functional forms for a small number of processes. These appear in namelist.trc.sms and are listed in Table 5.

The parameters associated with the fast-sinking detritus submodel are described in a later section.

\section{Detritus}

Sinking detrital material occurs in Medusa in two forms that represent particles of different size and which are modelled in distinct ways.
Table 1. Phytoplankton growth parameters.

\begin{tabular}{|c|c|c|}
\hline$\xi$ & $\begin{array}{l}\text { Chl:N conversion factor } \\
\text { (Redfield ratio of } 6.625) \\
\mathrm{g} \mathrm{chl}(\mathrm{mol} \mathrm{N})^{-1}\end{array}$ & 0.01257 \\
\hline$\alpha_{\mathrm{Pn}}, \alpha_{\mathrm{Pd}}$ & $\begin{array}{l}\text { chl-specific initial slope of } \\
\text { P-I curve } \\
\mathrm{gC}(\mathrm{g} \mathrm{chl})^{-1}\left(\mathrm{~W} \mathrm{~m}^{-2}\right)^{-1} \mathrm{~d}^{-1}\end{array}$ & $15.0,11.25$ \\
\hline$V_{\mathrm{Pn}}, V_{\mathrm{Pd}}$ & $\begin{array}{l}\text { maximum phytoplankton } \\
\text { growth rate at } 0^{\circ} \mathrm{C} \\
\mathrm{d}^{-1}\end{array}$ & $0.53,0.50$ \\
\hline$\theta_{\max , P n}^{\mathrm{Chl}}, \theta_{\max , \mathrm{Pd}}^{\mathrm{Chl}}$ & $\begin{array}{l}\operatorname{maximum} \text { chl:C ratio } \\
\mathrm{g} \text { chl }(\mathrm{g} \mathrm{C})^{-1}\end{array}$ & $0.05,0.05$ \\
\hline$R_{\mathrm{Si}: \mathrm{N}}^{0}$ & $\begin{array}{l}\text { minimum diatom Si:N ratio } \\
\mathrm{mol} \mathrm{Si}(\mathrm{mol} \mathrm{N})^{-1}\end{array}$ & 0.2 \\
\hline$R_{\mathrm{N}: \mathrm{Si}}^{0}$ & $\begin{array}{l}\operatorname{minimum} \text { diatom } \mathrm{N}: \mathrm{Si} \text { ratio } \\
\mathrm{molN}(\mathrm{mol} \mathrm{Si})^{-1}\end{array}$ & 0.2 \\
\hline$U_{\infty}$ & $\begin{array}{l}\text { hypothetical growth ratio at } \infty \\
\text { Si:N ratio } \\
\text { - }\end{array}$ & 1.5 \\
\hline$k_{\mathrm{N}, \mathrm{Pn}}, k_{\mathrm{N}, \mathrm{Pd}}$ & $\begin{array}{l}\mathrm{N} \text { nutrient uptake } \\
\text { half-saturation constants } \\
\mathrm{mmol} \mathrm{N} \mathrm{m}{ }^{-3}\end{array}$ & $0.50,0.75$ \\
\hline$k_{\mathrm{Si}}$ & $\begin{array}{l}\text { Si nutrient uptake } \\
\text { half-saturation constant } \\
\mathrm{mmol} \mathrm{Si} \mathrm{m}^{-3}\end{array}$ & 0.75 \\
\hline$k_{\mathrm{Fe}, \mathrm{Pn}}, k_{\mathrm{Fe}, \mathrm{Pd}}$ & $\begin{array}{l}\text { Fe nutrient uptake } \\
\text { half-saturation constants } \\
\mathrm{mmol} \mathrm{Fe} \mathrm{m}^{-3}\end{array}$ & $\begin{array}{l}0.33 \times 10^{-3} \\
0.67 \times 10^{-3}\end{array}$ \\
\hline
\end{tabular}

- Small particles are assumed to sink slowly relative to the model timestep, and their elemental concentration is modelled explicitly as a state variable (detrital nitrogen, D).

- Large particles are assumed to sink quickly relative to the model timestep, and their elemental concentration is implicitly remineralised down the water column (nitrogen, carbon, silicon).

Iron cycle changes associated with the remineralisation of both classes of sinking detrital material are assumed to occur in a strict Redfieldian relationship with those of nitrogen, so neither class includes an explicit consideration of iron concentrations.

\subsection{Small particles}

Small particles sink down the water column at a prescribed rate and are remineralised to utilisable nutrients at a rate dependent on ambient temperature (Eq. 72). This takes the form of $Q_{10}$-type relationships for the implicitly modelled remineralisation processes (i.e. heterotrophic bacteria are not explicitly modelled), and allows faster recycling of detritus in warm tropical waters to support the microbial loop (Pomeroy, 1974). Small particles are also be consumed by 
Table 2. Zooplankton grazing parameters.

\begin{tabular}{|c|c|c|}
\hline$g_{\mu}, g_{\mathrm{m}}$ & $\begin{array}{l}\text { maximum zooplankton } \\
\text { grazing rate } \\
\mathrm{d}^{-1}\end{array}$ & $2.0,0.5$ \\
\hline$k_{\mu}, k_{\mathrm{m}}$ & $\begin{array}{l}\text { zooplankton grazing } \\
\text { half-saturation con- } \\
\text { stants } \\
\text { mmol N m }\end{array}$ & $0.8,0.3$ \\
\hline$\phi$ & $\begin{array}{l}\text { zooplankton grazing } \\
\text { inefficiency } \\
\text { - }\end{array}$ & 0.20 \\
\hline$\beta_{\mathrm{N}}$ & $\begin{array}{l}\text { zooplankton } \mathrm{N} \\
\text { assimilation efficiency } \\
\text { - }\end{array}$ & 0.69 \\
\hline$\beta_{\mathrm{C}}$ & $\begin{array}{l}\text { zooplankton } \mathrm{C} \\
\text { assimilation efficiency } \\
\text { - }\end{array}$ & 0.69 \\
\hline$k_{\mathrm{C}}$ & $\begin{array}{l}\text { zooplankton net } \mathrm{C} \\
\text { growth efficiency } \\
-\end{array}$ & 0.80 \\
\hline$p_{\mu \mathrm{Pn}}, p_{\mu \mathrm{D}}$ & $\begin{array}{l}\text { microzooplankton } \\
\text { grazing preferences } \\
-\end{array}$ & $0.75,0.25$ \\
\hline$p_{\mathrm{mPn}}, p_{\mathrm{mPd}}$, & $\begin{array}{l}\text { mesozooplankton } \\
\text { grazing preferences }\end{array}$ & $0.15,0.35$ \\
\hline$p_{\mathrm{mZ}} \mu, p_{\mathrm{mD}}$ & - & $0.35,0.15$ \\
\hline
\end{tabular}

both micro- and mesozooplankton which accelerates the return of nitrogen and iron to utilisable forms. Equation (80) below repeats the full differential equation (Eq. 8) to indicate the sinking and remineralisation terms.

$$
\frac{\partial \mathrm{D}}{\partial t}=\ldots-\underbrace{\left[\mathrm{M}_{\mathrm{D}}\right]}_{\text {remin }}-\underbrace{\left[w_{\mathrm{g}} \cdot \frac{\partial \mathrm{D}}{\partial z}\right]}_{\text {sinking }}
$$

\subsection{Large particles}

Large particles of detritus can have sinking velocities that cannot be resolved given the time and space scales of the physical models in which ecosystem models are commonly embedded. To resolve this here, large detritus is handled in an implicit fashion in which pools of fast sinking detritus, one for each elemental or biomineral species, are added to (through production) and depleted (through remineralisation) level by level down the water column. As well as sidestepping issues related to the Courant-Friedrichs-Lewy (CFL) condition, this removes the need for additional (and computationally costly) model tracers. The remineralisation of large detrital particles uses a variant of the ballast model of Armstrong et al. (2002). This model divides sinking material
Table 3. Plankton and detritus loss parameters.

\begin{tabular}{|c|c|c|}
\hline$\mu_{1, \mathrm{Pn}}, \mu_{1, \mathrm{Pd}}$ & $\begin{array}{l}\text { phytoplankton loss } \\
\text { rates } \\
\mathrm{d}^{-1}\end{array}$ & $0.02,0.02$ \\
\hline$\mu_{1, \mathrm{Z} \mu}, \mu_{1, \mathrm{Zm}}$ & $\begin{array}{l}\text { zooplankton loss rates } \\
\mathrm{d}^{-1}\end{array}$ & $0.02,0.02$ \\
\hline$\mu_{2, \mathrm{Pn}}, \mu_{2, \mathrm{Pd}}$ & $\begin{array}{l}\text { phytoplankton } \\
\text { maximum loss rates } \\
\mathrm{d}^{-1}\end{array}$ & $0.1,0.1$ \\
\hline$k_{\mathrm{Pn}}, k_{\mathrm{Pd}}$ & $\begin{array}{l}\text { phytoplankton loss } \\
\text { half-saturation } \\
\text { constants } \\
\text { mmol N m }\end{array}$ & $0.5,0.5$ \\
\hline$\mu_{2, \mathrm{Z} \mu}, \mu_{2, \mathrm{Zm}}$ & $\begin{array}{l}\text { zooplankton maximum } \\
\text { loss rates } \\
\mathrm{d}^{-1}\end{array}$ & $0.5,0.75$ \\
\hline$k_{\mathrm{Z} \mu}, k_{\mathrm{Zm}}$ & $\begin{array}{l}\text { zooplankton loss } \\
\text { half-saturation } \\
\text { constants } \\
\text { mmol } \mathrm{N} \mathrm{m}^{-3}\end{array}$ & $0.2,0.75$ \\
\hline$\mu_{\mathrm{D}}$ & $\begin{array}{l}\text { detrital } \mathrm{N} \\
\text { remineralisation rate at } \\
0^{\circ} \mathrm{C} \\
\mathrm{d}^{-1}\end{array}$ & 0.016 \\
\hline
\end{tabular}

into organic and mineral components and assumes that a fraction of the organic material is "protected" from degradation by the mineral material. A full description is given in Sect. 3.2.2.

\subsubsection{Detritus production}

In the case of the nitrogen and silicon cycles, the following equations describe the level by level addition of material to the detrital pools of these elements, $T_{\mathrm{N}}(k)$ and $T_{\mathrm{Si}}(k)$. These pools are initialised to zero at the ocean surface, and accumulate (through production) and lose (through remineralisation) material down the water column. Note that $\delta z(k)$ denotes the thickness of model layer $k$.

$$
\begin{aligned}
T_{\mathrm{N}}(k+1)= & T_{\mathrm{N}}(k)+\left(\left(\mathrm{D} 1_{\mathrm{frac}} \cdot \mathrm{M} 2_{\mathrm{Pd}}\right)\right. \\
& \left.+\left(\mathrm{D} 2_{\mathrm{frac}} \cdot \mathrm{M} 2_{\mathrm{Zm}}\right)\right) \cdot \delta z(k) \\
T_{\mathrm{Si}}(k+1)= & T_{\mathrm{Si}}(k)+\left(\left(\mathrm{D} 1_{\mathrm{frac}} \cdot \mathrm{M} 2_{\mathrm{Pd}_{\mathrm{Si}}}\right)\right. \\
& \left.+\left(\mathrm{D} 2_{\mathrm{frac}} \cdot \mathrm{Gm}_{\mathrm{Pd}_{\mathrm{Si}}}\right)\right) \cdot \delta z(k)
\end{aligned}
$$

Large nitrogenous detritus is derived from fractions of the losses of diatoms and mesozooplankton, $\mathrm{D} 1_{\text {frac }}$ and $\mathrm{D} 2_{\text {frac }}$ respectively. As these losses produce large particles of detritus 
Table 4. Miscellaneous parameters.

\begin{tabular}{|c|c|c|}
\hline$\theta_{\mathrm{Pn}}, \theta_{\mathrm{Pd}}$ & $\begin{array}{l}\text { phytoplankton C:N ratio } \\
\text { mol C }(\mathrm{mol} \mathrm{N})^{-1}\end{array}$ & 6.625 \\
\hline$\theta_{\mathrm{Z} \mu}, \theta_{\mathrm{Zm}}$ & $\begin{array}{l}\text { zooplankton } \mathrm{C}: \mathrm{N} \text { ratio } \\
\text { mol C }(\mathrm{mol} \mathrm{N})^{-1}\end{array}$ & 6.625 \\
\hline$\theta_{\mathrm{D}}$ & $\begin{array}{l}\text { detritus C:N ratio } \\
\operatorname{mol} C(\operatorname{mol~N})^{-1}\end{array}$ & 6.625 \\
\hline$R_{\mathrm{Fe}}$ & $\begin{array}{l}\text { phytoplankton } \mathrm{Fe}: \mathrm{N} \\
\text { uptake ratio } \\
\mathrm{mmol} \mathrm{Fe}(\mathrm{mol} \mathrm{N})^{-1} \mathrm{~m}\end{array}$ & $30.0 \times 10^{-3}$ \\
\hline$L_{\text {total }}$ & $\begin{array}{l}\text { total ligand } \\
\text { concentration } \\
\mathrm{mmol} \mathrm{m}^{-3}\end{array}$ & $1.0 \times 10^{-3}$ \\
\hline$k_{\mathrm{FeL}}$ & $\begin{array}{l}\text { dissociation constant for } \\
(\mathrm{Fe}+\text { ligand }) \\
\left(\mathrm{mmol} \mathrm{m}^{-3}\right)^{-1}\end{array}$ & $100.0 \times 10^{3}$ \\
\hline$k_{\text {scav }}$ & $\begin{array}{l}\text { scavenging rate of "free" } \\
\mathrm{Fe} \\
\mathrm{d}^{-1}\end{array}$ & 0.001 \\
\hline Diss & $\begin{array}{l}\text { diatom frustule } \\
\text { dissolution rate } \\
\mathrm{d}^{-1}\end{array}$ & 0.006 \\
\hline$w_{\mathrm{g}}$ & $\begin{array}{l}\text { detrital sinking rate } \\
\mathrm{m} \mathrm{d}^{-1}\end{array}$ & 3.0 \\
\hline
\end{tabular}

that fuel the fast-sinking detritus submodel, these parameters are assumed to take values close to unity. As diatom cells are both smaller than the mesozooplankton that graze them, and since diatoms themselves span a range of sizes, $\mathrm{D} 1_{\text {frac }}$ is assigned a smaller value (0.75) than $\mathrm{D} 2_{\text {frac }}$ (1.00) so that a minor fraction of diatom losses is channelled to small detritus. Fast detrital silicon is similarly derived from loss processes though, since biogenic silica produced by diatoms is not utilised by zooplankton, one of the sources in MEdusA is the egested remains of diatom cells rather than mesozooplankton mortality. Parameters $\mathrm{D} 1_{\text {frac }}$ and $\mathrm{D} 2_{\text {frac }}$ are again utilised to control the distribution of losses to fast detritus. However, since the fate of ingested diatom silicon is more associated with zooplankton egestion in faecal pellets than zooplankton losses such as mortality, the arrangement could arguably be altered such that biogenic silicon is directly channelled to fast detritus without reference to $\mathrm{D} 2_{\text {frac }}$ (perhaps via $\mathrm{D} 3_{\text {frac }}$ instead). However, since D2 frac already has value 1.00 , for simplicity this embellishment has not currently been adopted. Note that, since there is no silicon component to small detritus, the small fraction of diatom losses that is not channelled to fast detritus is returned directed to dissolved silicic acid.
Table 5. MEDUSA switches.

\begin{tabular}{|c|c|}
\hline jphy & $\begin{array}{l}\text { switches phytoplankton maximum growth } \\
\text { between temperature independence }(=0) \\
\text { and dependence }(=1) \text {; the default is } \\
\text { jphy }=1\end{array}$ \\
\hline jmpn & $\begin{array}{l}\text { switches non-diatom phytoplankton } \\
\text { density-dependent mortality between } \\
\text { linear }(=1) \text {, quadratic }(=2) \text {, hyperbolic } \\
(=3) \text { and sigmoid }(=4) \text { forms; the } \\
\text { default is jmpn }=3\end{array}$ \\
\hline jmpd & as jmpn but for diatom phytoplankton \\
\hline jmzmi & as jmpn but for microzooplankton \\
\hline jmzme & as jmpn but for mesozooplankton \\
\hline jmd & $\begin{array}{l}\text { as jphy but for detrital remineralisation; } \\
\text { the default is } j \mathrm{md}=1\end{array}$ \\
\hline
\end{tabular}

As it is not explicitly simulated in the current version of MedusA, organic carbon is implicitly associated with the sources of large detritus, and is calculated as follows using the prescribed $\mathrm{C}: \mathrm{N}$ ratios of the diatoms and mesozooplankton, $\theta_{\mathrm{Pd}}$ and $\theta_{\mathrm{Zm}}$.

$$
\begin{aligned}
T_{\mathrm{C}}(k+1)= & T_{\mathrm{C}}(k)+\left(\left(\theta_{\mathrm{Pd}} \cdot \mathrm{D} 1_{\mathrm{frac}} \cdot \mathrm{M} 2_{\mathrm{Pd}}\right)\right. \\
& \left.+\left(\theta_{\mathrm{Zm}} \cdot \mathrm{D} 2_{\mathrm{frac}} \cdot \mathrm{M} 2_{\mathrm{Zm}}\right)\right) \cdot \delta z(k)
\end{aligned}
$$

A quantitatively important component of sinking particles in the ocean (and one which frames the so-called ballast hypothesis; Armstrong et al., 2002) is the biomineral calcium carbonate $\left(\mathrm{CaCO}_{3}\right)$. This is used in the shells of certain types of both phytoplankton and zooplankton, but the factors controlling its production are not fully understood (cf. Hood et al., 2006). Consequently, there is wide diversity in the approaches taken to modelling the production of calcium carbonate, with models variously grounding it in primary production (e.g. Moore et al., 2002; Gehlen et al., 2007; Yool et al., 2010), export production (e.g. Zahariev et al., 2008; Ridgwell et al., 2007) or phytoplankton biomass (e.g. Tyrrell and Taylor, 1996).

Reviewing this diversity, and testing it in a common model framework against observational data from the Bay of Biscay, Kelly-Gerreyn et al. (2009) found no strong support for any one approach over its rivals. Consequently, MedusA largely follows Dunne et al. (2007) and models calcium carbonate production as a function of fast detritus production (i.e. only indirectly related to either primary production or the biomass of phytoplankton). This simplified approach suits Medusa since its current version does not include a complete representation of the carbon cycle (and completely omits ocean alkalinity), and calcium carbonate is used in the model solely in the context of fast detritus. 


$$
\begin{aligned}
T_{\mathrm{CaCO}_{3}}(k+1)= & T_{\mathrm{CaCO}_{3}}(k)+ \\
& \left(\left(\theta_{P d} \cdot \mathrm{D} 1_{\text {frac }} \cdot \mathrm{M} 2_{\mathrm{Pd}}\right)+\right. \\
& \left.\left(\theta_{\mathrm{Zm}} \cdot \mathrm{D} 2_{\mathrm{frac}} \cdot \mathrm{M} 2_{\mathrm{Zm}}\right)\right) . \\
& \delta z(k) \cdot f c(\text { lat })
\end{aligned}
$$

where $f c$ (lat) $\left(\mathrm{mol} \mathrm{CaCO}_{3}(\mathrm{molC})^{-1}\right)$ is a simple function that relates the rain ratio of calcium carbonate production $\left(\mathrm{C}_{\mathrm{CaCO}_{3}}: \mathrm{C}_{\text {org }}\right)$ to latitude, lat. Reviewing this relationship, Dunne et al. (2007) found that, on a molar basis, this is approximately 0.09 to 0.10 at the equator, and 0.04 at high latitudes, and that it is systematically lower in the North Atlantic (0.02) than the North Pacific (0.06). Here, we neglect differences between basins and use globally uniform equatorial $\left(f c\left(0^{\circ}\right)\right)$ and polar values $\left(f c\left(90^{\circ}\right)\right)$.

$$
\begin{aligned}
f_{c}(\text { lat })= & f_{c}\left(90^{\circ}\right)+ \\
& \left(f_{c}\left(0^{\circ}\right)-f_{c}\left(90^{\circ}\right) \cdot \frac{(90-\mid \text { lat } \mid)}{90}\right)
\end{aligned}
$$

As an aside, another unmodelled component of sinking material is lithogenic material such as wind-borne dust that is picked up from the land and settles into the ocean from the atmosphere. Similarly to the biominerals calcium carbonate and biogenic silica, this is proposed to affect export production in the ballast hypothesis (Armstrong et al., 2002). Although the iron component of dust is already included in MEDUs A to affect phytoplankton growth, at this point the role of dust in export production is not included.

\subsubsection{Ballast model}

As noted above, one interpretation concerning the sinking flux of material in the ocean is the ballast hypothesis of Armstrong et al. (2002). This posits that a fraction of the sinking organic material is quantitatively associated with sinking inorganic material (calcium carbonate, biogenic silica, lithogenic material), and that this provides "protection" for the organic matter, allowing it to penetrate deeper into the water column than might be expected from remineralisation rates. Armstrong et al. (2002) originally treated the hypothesis in rather theoretical terms, but it was subsequently parameterised by Klaas and Archer (2002) in a study that synthesised a global dataset of sediment trap measurements. This latter study has subsequently been used as the basis for other work, and its implementation within the model of Dunne et al. (2007) is that adopted here.

Given the pools of organic carbon and ballast minerals in the large detritus class, the ballast model first calculates the fraction of organic carbon that is "protected" by the minerals. The remainder, known as "excess" (and initially the majority), is subject to remineralisation, performed here in an exponential manner similar to that proposed by Martin et al.
(1987). Since the minerals themselves are subject to dissolution as the particle flux descends through the water column, the amount of organic carbon that can be "protected" also falls, although this occurs at a considerably slower rate than that at which the "excess" is remineralised. As a result, implementing the ballast scheme is done level-by-level down the modelled water column to account for the gradual differential attenuation of the components of the sinking flux.

The proportioning of the fast detrital flux of organic carbon into "protected", $\mathrm{TC}_{\text {protect }}=\left(\mathrm{TC}_{\mathrm{bSi}}+\mathrm{TC}_{\mathrm{bCaCO}}\right)$, and "excess", $\mathrm{TC}_{\text {excess, }}$, portions is calculated as follows.

$$
\begin{aligned}
& \mathrm{TC}_{\mathrm{bSi}}=T_{\mathrm{Si}}(k) \cdot \frac{\mathrm{M}_{\mathrm{Si}}}{\mathrm{M}_{\mathrm{org}}} \cdot f_{\mathrm{Si}} \\
& \mathrm{TC}_{\mathrm{bCaCO}_{3}}=T_{\mathrm{CaCO}_{3}}(k) \cdot \frac{\mathrm{M}_{\mathrm{CaCO}_{3}}}{\mathrm{M}_{\mathrm{org}}} \cdot f_{\mathrm{CaCO}_{3}} \\
& \mathrm{TC}_{\text {protect }}=\left(\mathrm{TC}_{\mathrm{bSi}}+\mathrm{TC}_{\mathrm{bCa}}\right) \\
& \mathrm{TC}_{\text {excess }}=T_{\mathrm{C}}(k)-\mathrm{TC}_{\text {protect }}
\end{aligned}
$$

Where $\mathrm{M}_{\mathrm{Si}}$ and $\mathrm{M}_{\mathrm{CaCO}_{3}}$ convert molar silicon and calcium carbonate ballast into mass equivalents that can then be used with mass-based organic carbon protection ratios $f_{\mathrm{Si}}$ and $f_{\mathrm{CaCO}_{3}}$. The "protected" fraction passes through unscathed to the next level down the water column, while the "excess" fraction is attenuated across a particular level, with a corresponding release of inorganic carbon. Not all "excess" carbon is remineralised in a given level, and the surviving portion, $\mathrm{TC}_{\text {survive }}$, is calculated as follows.

$\mathrm{TC}_{\text {survive }}=\mathrm{TC}_{\text {excess }} \cdot \exp \left(-\frac{\delta z(k)}{d_{\text {excess }}}\right)$

Leaving aside that added through production (see Eq. (83)), the quantity of fast detritus reaching the next model layer, $T_{\mathrm{C}}(k+1)$, is then as follows.

$T_{\mathrm{C}}(k+1)=\mathrm{TC}_{\text {protect }}+\mathrm{TC}_{\text {survive }}$

The flux of remineralised carbon to level $k$ is then simply:

$\mathrm{LD}_{\mathrm{N}}(k)=\frac{\mathrm{TC}_{\text {excess }}-\mathrm{TC}_{\text {survive }}}{\delta z(k)}$

The remineralisation fluxes of nitrogen and iron follow that of carbon, with the same fraction of sinking material "protected" by ballasting minerals. By contrast, the sinking fluxes of both biogenic silica, $T_{\mathrm{Si}}(k)$, and calcium carbonate, $T_{\mathrm{CaCO}_{3}}(k)$, attenuate with depth independently of organic carbon. In the case of biogenic silica, since silicic acid occurs at undersaturating concentrations throughout the World Ocean, this attenuation occurs globally at all depths. Calcium carbonate, by contrast, is not generally soluble in surface waters because of the supersaturating concentrations of the carbonate ion. However, at depth, specifically below the 
lysocline, concentrations become undersaturating and dissolution can occur. In MEdusA, the depth of the lysocline, lysocline(lat, lon), is precalculated and used to regulate the spatial distribution of dissolution.

$T_{\mathrm{Si}}(k+1)=T_{\mathrm{Si}}(k) \cdot \exp \left(-\frac{\delta z(k)}{d_{\mathrm{Si}}}\right)$

if $z(k)<$ lysocline(lat, lon)

$T_{\mathrm{CaCO}_{3}}(k+1)=T_{\mathrm{CaCO}_{3}}(k) \cdot \exp \left(-\frac{\delta z(k)}{d_{\mathrm{CaCO}_{3}}}\right)$

else

$T_{\mathrm{CaCO}_{3}}(k+1)=T_{\mathrm{CaCO}_{3}}(k)$

The dissolution fluxes of biogenic silica and calcium carbonate are then simply:

$\mathrm{LD}_{\mathrm{Si}}(k)=\frac{T_{\mathrm{Si}}(k)-T_{\mathrm{Si}}(k+1)}{\delta z(k)}$

$\mathrm{LD}_{\mathrm{CaCO}_{3}}(k)=\frac{T_{\mathrm{CaCO}_{3}}(k)-T_{\mathrm{CaCO}_{3}}(k+1)}{\delta z(k)}$

Figure 5 shows idealised results from this model, and in the left panel compares these to the classic empirical model derived by Martin et al. (1987):

$F_{\mathrm{C}}(z)=F_{\mathrm{C}}(100) \cdot\left(\frac{z}{100}\right)^{-0.858}$

In the upper $300 \mathrm{~m}$ of the water column, both models show similar fractional declines in sinking organic carbon, with approximately $40 \%$ of the $100 \mathrm{~m}$ flux surviving to this depth. Generally, the Dunne et al. (2007) model exhibits greater remineralisation, such that by $1000 \mathrm{~m}$ it estimates an organic carbon sinking flux less than one third of that of Martin et al. (1987). The right panel shows the decline of the biominerals with depth. Because of a longer dissolution length scale, a greater proportion of calcium carbonate reaches the seafloor than that of biogenic silicon (relative to the fluxes at $100 \mathrm{~m}$ ). Also, while silicic acid is present at undersaturated concentrations throughout the water column and so biogenic silicon dissolves at all depths, calcium carbonate is saturated in shallower waters and only dissolves when it becomes undersaturated at greater depths. The saturation horizon used in Fig. 5 is $2700 \mathrm{~m}$, the global average depth calculated from World Ocean Atlas and GLODAP sources, and the ballasting fraction of calcium carbonate only begins to attenuate below this depth. Figure 6 shows the global distribution of the calcite saturation horizon (cf. Feeley et al., 2004). This is calculated as the shallowest depth at which $\Omega_{\text {calcite }}$ is less than 1 . The three dimensional field of $\Omega_{\text {calcite }}$ is calculated using the CSYS package (Zeebe and Wolf-Gladrow, 2001) together with fields of ocean properties from the World Ocean Atlas (Locarnini et al., 2006; Antonov et al., 2006; temperature and
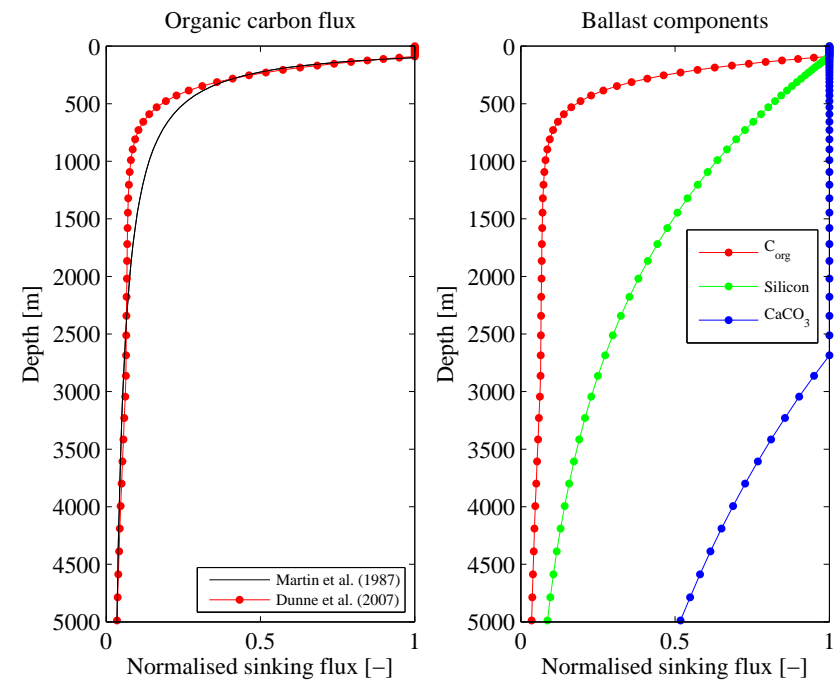

Fig. 5. Vertical attenuation of the sinking flux. The left panel compares the Dunne et al. (2007; red) parameterisation for organic carbon with that of Martin et al. (1987; black). The right panel shows the attenuation of organic carbon (red), biogenic silicon (green) and calcium carbonate (blue). In all cases, fluxes are normalised to those at $100 \mathrm{~m}$. Dots indicate NEMO physical model levels at which fluxes calculated.

salinity) and GLODAP (Key et al., 2004; DIC and alkalinity) climatologies. The geographical pattern occurs because deep water masses gradually accumulate DIC as they transit along the ocean's thermohaline circulation. This material is provided by the biological pump, and its influence gradually shifts the balance of DIC speciation in seawater towards lower carbonate ion $\left(\mathrm{CO}_{3}^{2-}\right)$ concentrations. "Young", recently ventilated waters, such as those in the North Atlantic, have accumulated the least material, and $\mathrm{CO}_{3}^{2-}$ concentrations are supersaturated for most of the water column. By contrast, "old" waters that have been isolated from the atmosphere for centuries or more, such as those in the North Pacific, have accumulated the most material, and $\mathrm{CO}_{3}^{2-}$ concentrations are largely undersaturated. This horizontal field shown in Fig. 6 is used in Medus a to control the depth at which dissolution begins in different regions of the World Ocean.

Based on a survey of vertical fluxes of calcium carbonate, it has been suggested that biological activity may be able to cause the dissolution of calcium carbonate above the calcite saturation horizon (Milliman et al., 1999). Proposed mechanisms include dissolution in the acidic guts of zooplankton (Harris, 1994; Pond et al., 1995), and respiration-driven low $\mathrm{pH}$ conditions within sinking particles (Milliman et al., 1999). Such activity would effectively shoal the horizon shown in Fig. 6 by more rapidly attenuating the "protection" offered by biomineral ballasting, with the result that the remineralisation of organic material would occur at shallower 

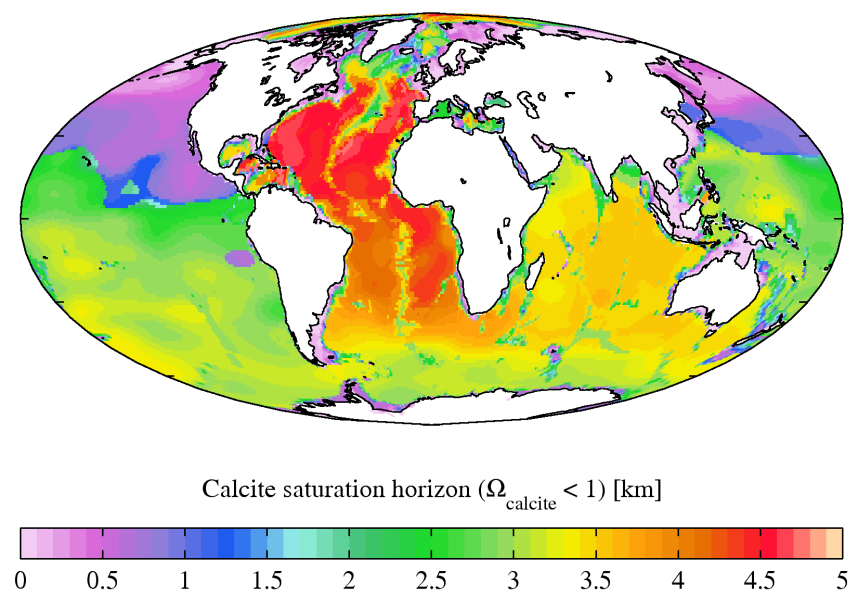

Fig. 6. The global distribution of the depth of the calcite saturation horizon. Interpolation (prior to the calculation of $\Omega_{\text {calcite }}$ ) has been used to fill gaps in the GLODAP climatology including the Arctic, Caribbean, Mediterranean seas and the Malay Archipelago.

depths. However, subsequent work has instead suggested that such additional mechanisms may be unnecessary, and that conventional dissolution kinetics together with consideration of sinking velocity may explain the fluxes observed (Greenwood, 2009). Consequently, MEDUSA does not consider dissolution above the calculated saturation horizon at this stage.

The parameters used in this implementation of the Dunne et al. (2007) model are listed in Table 6.

\subsubsection{Computation}

In Dunne et al. (2007) the input to the ballast model (i.e. sinking particulate organic matter) is a product of primary production and particle export algorithms. The former algorithms estimate the synthesis of organic matter by primary producers (via multiple algorithms: Behrenfeld and Falkowski, 1997; Carr, 2002; Marra et al., 2003), while the latter algorithm estimates the conversion of this into sinking particles (via: Dunne et al., 2005). The elemental contents of this sinking flux are then redistributed down the water column according to the ballast model formulation. This procedure does not calculate the vertical distribution of particle production, but essentially assumes that it takes place above a particular depth horizon, below which the particles are remineralised.

In the case of MEDUSA, its structure dictates that particle production has a vertical distribution that is dependent upon the locations of various plankton state variables and ecological processes. As a result, unlike Dunne et al. (2007) there is no single depth horizon separating particle production and remineralisation, and instead both coincide down the water column. As described above, and partly because of the organisation of calculations in the model code, fast
Table 6. Fast detritus submodel parameters.

\begin{tabular}{|c|c|c|}
\hline $\mathrm{D} 1_{\text {frac }}$ & $\begin{array}{l}\text { fast detritus fraction of } \\
\text { diatom losses } \\
\text { - }\end{array}$ & 0.75 \\
\hline $\mathrm{D} 2_{\mathrm{frac}}$ & $\begin{array}{l}\text { fast detritus fraction of } \\
\text { mesozooplankton losses } \\
\text { - }\end{array}$ & 1.00 \\
\hline$f c\left(90^{\circ}\right)$ & 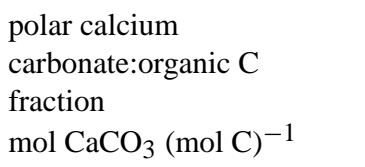 & 0.02 \\
\hline$f_{c}\left(0^{\circ}\right)$ & 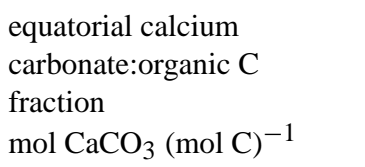 & 0.10 \\
\hline $\mathbf{M}_{\text {org }}$ & $\begin{array}{l}\text { organic carbon mass:mole } \\
\text { ratio, } \mathrm{C} \\
\mathrm{g}(\mathrm{mol} \mathrm{C})^{-1}\end{array}$ & 12.011 \\
\hline $\mathrm{M}_{\mathrm{CaCO}_{3}}$ & $\begin{array}{l}\text { calcium carbonate } \\
\text { mass:mole ratio, } \mathrm{CaCO}_{3} \\
\mathrm{~g}(\mathrm{~mol} \mathrm{C})^{-1}\end{array}$ & 100.086 \\
\hline $\mathrm{M}_{\mathrm{Si}}$ & $\begin{array}{l}\text { biogenic } \mathrm{Si} \text { mass:mole } \\
\text { ratio, } \mathrm{SiO}_{2} \\
\mathrm{~g}(\mathrm{~mol} \mathrm{Si})^{-1}\end{array}$ & 60.084 \\
\hline$f_{\mathrm{CaCO}_{3}}$ & $\begin{array}{l}\text { calcium carbonate } \\
\text { protection ratio } \\
\mathrm{gC}(\mathrm{g} \mathrm{C})^{-1}\end{array}$ & 0.070 \\
\hline$f_{\mathrm{Si}}$ & $\begin{array}{l}\text { biogenic Si protection ratio } \\
\mathrm{g} \mathrm{C}\left(\mathrm{g} \mathrm{Si}^{-1}\right.\end{array}$ & 0.026 \\
\hline$d_{\text {excess }}$ & $\begin{array}{l}\text { excess organic carbon } \\
\text { dissolution length scale } \\
\mathrm{m}\end{array}$ & 188 \\
\hline$d_{\mathrm{CaCO}_{3}}$ & $\begin{array}{l}\text { calcium carbonate } \\
\text { dissolution length scale } \\
\mathrm{m}\end{array}$ & 3500 \\
\hline$d_{\mathrm{Si}}$ & $\begin{array}{l}\text { biogenic Si dissolution } \\
\text { length scale } \\
\mathrm{m}\end{array}$ & 2000 \\
\hline
\end{tabular}

detritus production and remineralisation take place on a level by level basis. In the surface level, production is the only process that takes place, since there is no material to remineralise. In subsequent, deeper layers, fast detritus entering a level is both subject to remineralisation within that level, and can be "added to" by production processes as it leaves the level. This approach avoids the aphysical vertical redistribution of fast detritus that would occur if all production was first integrated and then dispersed. In practice, since the remineralisation of all components of fast detritus occurs over relatively long e-folding length scales, the majority of remineralisation takes place below its production. 
Additional explanation of this scheme can be found in commentary within the accompanying model source code.

\subsubsection{Alternative models}

Although the ballast model has been selected for use here, it is only one of a number of competing models that describe the attenuation of sinking particulate organic material in the ocean, and there is still considerable observational uncertainty concerning export production (e.g. Buesseler et al., 2007). Alternative models include variants of the original Martin et al. (1987) formulation (e.g. Parekh et al., 2005), models that consider the size spectra of sinking material (e.g. Kriest and Evans, 1999), and those that explicitly include the aggregation of sinking particles (e.g. Burd and Jackson, 2009). Furthermore, the particular parameterisation of the ballast model employed here is also only one among a number of subtly different variants. Alternatives include those of Moore et al. (2004) and Oka et al. (2008).

However, at the present time there is still considerable uncertainty surrounding water column remineralisation (e.g. Buesseler et al., 2007), and the most appropriate choice of export production model is unclear. To this end, the ballast model has been favoured for MEDUSA largely because of its relative simplicity, and because of its intrinsic connection with the silicon cycle.

\section{Default simulation}

The following section describes a simulation and evaluation of Medusa using the default equations, functional forms and parameter values described previously.

\subsection{Physical model}

The underlying physical model used in this simulation is version 3.2 of NEMO (Madec, 2008). This is comprised of an ocean general circulation model, OPA9 (Madec et al., 1998; Madec, 2008), coupled with a sea-ice model, Louvainla-Neuve Ice Model version 2 (LIM2; Timmermann et al., 2005). This physical framework is configured at approximately $1^{\circ} \times 1^{\circ}$ horizontal resolution $(292 \times 362$ grid points $)$, with a focusing of resolution around the equator to improve the representation of equatorial upwelling. Vertical space is divided into 64 levels, which increase in thickness with depth, from approximately $6 \mathrm{~m}$ at the surface to $250 \mathrm{~m}$ at $6000 \mathrm{~m}$. To improve the representation of deep water circulation, partial level thicknesses are used in the specification of bottom topography. Vertical mixing is parameterised using the turbulent kinetic energy (TKE) scheme of Gaspar et al. (1990), with modifications by Madec (2008).

The model is forced at the ocean surface using DFS4.1 fields developed by the European DRAKKAR collaboration (DRAKKAR Group, 2007). DFS combines elements from two sources: the CORE forcing dataset (Large and Yeager,
2004), from which precipitation and downward short- and long-wave radiation are extracted; and the ERA40 reanalysis, from which $10 \mathrm{~m}$ wind and $2 \mathrm{~m}$ air temperature and humidity are extracted. The latter fields are used in conjunction with the bulk formulae proposed by Large and Yeager (2004) to compute air/sea and air/sea-ice energy and freshwater fluxes. The frequency of DFS4.1 is monthly for precipitation, daily for radiation and 6-hourly for the turbulent variables. Climatological monthly runoff (Dai and Trenberth, 2002) is applied along the coastline of the land mask.

The sea-ice submodel used here, LIM2, is based upon viscous-plastic ice rheology (Hibler, 1979) and three layer (two layers of sea-ice, one layer of snow) thermodynamics (Semtner, 1976), with a number of updated physical processes (see Timmermann et al., 2005; and references therein). Model sea-ice is coupled to the ocean every 5 ocean timesteps through the non-linear quadratic drag law of the shear between sea-ice and ocean surface velocity (Timmermann et al., 2005). Freshwater exchange between the ocean and sea-ice is calculated from precipitation and ice formation/melting (Fichefet and Morales Maqueda, 1997), where sea-ice salinity is assumed to be 4 psu and rain/snow are assumed fresh. The heat flux between the sea-ice and ocean is proportional to the departure in temperature from salinitydependent freezing point and the friction velocity at the iceocean interface. Solar radiation can penetrate sea-ice not covered by snow, and is dissipated by brine pockets within the ice where it increases latent heat storage (Fichefet and Morales Maqueda, 1997).

Temperature and salinity fields are initialised here from a monthly climatology that combines the World Ocean Atlas climatology with the PHC2.1 database (Steele et al., 2001; high latitudes) and the Medatlas climatology (Jourdan et al., 1998; Mediterranean Sea). To prevent unacceptable drifts in salinity caused by deficiencies in freshwater forcing, sea surface salinity is relaxed towards monthly mean climatology values. The relaxation timescale is 180 days for the open ocean, and 12 days under sea-ice. Further details concerning model configuration can be found in Barnier et al. (2006), Penduff et al. (2007) and Penduff et al. (2010), but note that these describe higher resolution instances of NEMO.

\subsection{Spinup and simulation}

Before Medusa was added to NEMO, a short, physicsonly simulation was performed to provide a "moving" ocean circulation field into which the biogeochemistry could be added. The physical model was simulated from rest from the beginning of the forcing dataset (1 January 1958) for a period of $8 \mathrm{yr}$ (to 31 December 1965). This period is insufficient for the thermohaline circulation to be fully established, but it is long enough for strong transient behaviour to decline. In early tests with MEDUSA, it was found that the model's behaviour was broadly similar between simulations initialised 

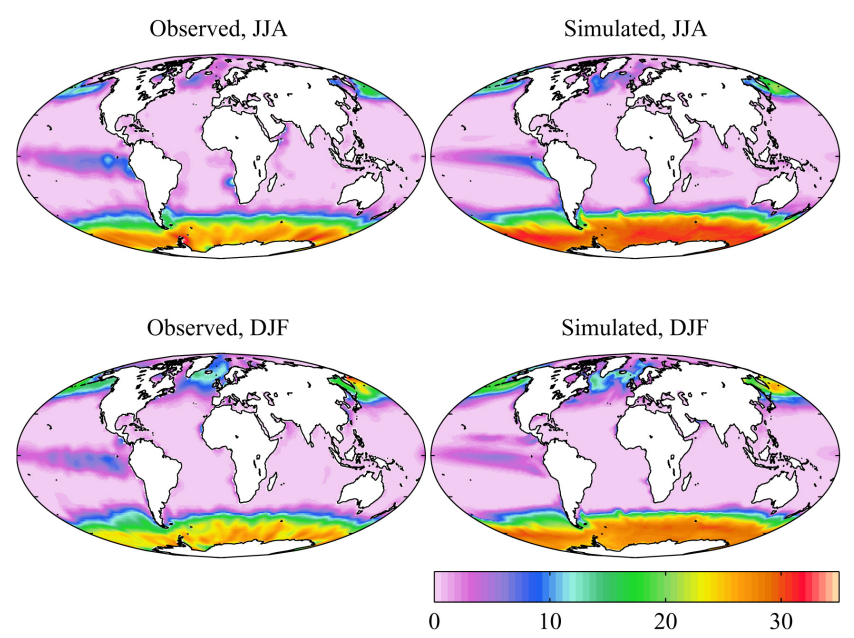

Fig. 7. Observational (World Ocean Atlas, 2005; left) and simulated (right) surface dissolved inorganic nitrogen for northern summer (June-July-August; top) and northern winter (December-JanuaryFebruary; bottom). Concentrations in $\mathrm{mmol} \mathrm{N} \mathrm{m}^{-3}$.

with physical states that had experienced significantly different spin-up periods.

After this initial phase, MEdusa was coupled to the resulting physical state and the simulation was integrated a further $40 \mathrm{yr}$ (to 31 December 2005). For this latter phase, Medusa was initialised using the World Ocean Atlas climatology for dissolved inorganic nitrogen and silicic acid concentrations, and using an iron field derived from a longduration simulation of a lower resolution GCM (Parekh et al., 2005; Dutkiewicz et al., 2005). All other model tracers were initialised to arbitrary small values.

In addition to the biogeochemical dynamics described previously, the concentrations of dissolved inorganic nitrogen and silicic acid were relaxed towards World Ocean Atlas climatology values in grid cells within $100 \mathrm{~km}$ of land. This was done to emulate unresolved coastal processes such as the input of these nutrients by riverine sources. Since there is, as yet, no corresponding climatology for iron, this nutrient was not relaxed anywhere in the ocean. Appendix A4 examines the significance of the relaxation of macronutrients in MedusA.

\subsection{Results}

In this section, a selection of model results are presented with the aim of providing a brief overview of MEDUSA's performance. In the first instance, model outputs that can be compared to observational fields are presented. These are followed by Taylor diagrams that aim to more comprehensively evaluate performance (cf. space and time). Next, model fields of interesting but unmeasured (or unmeasureable) properties are shown to illuminate notable aspects of
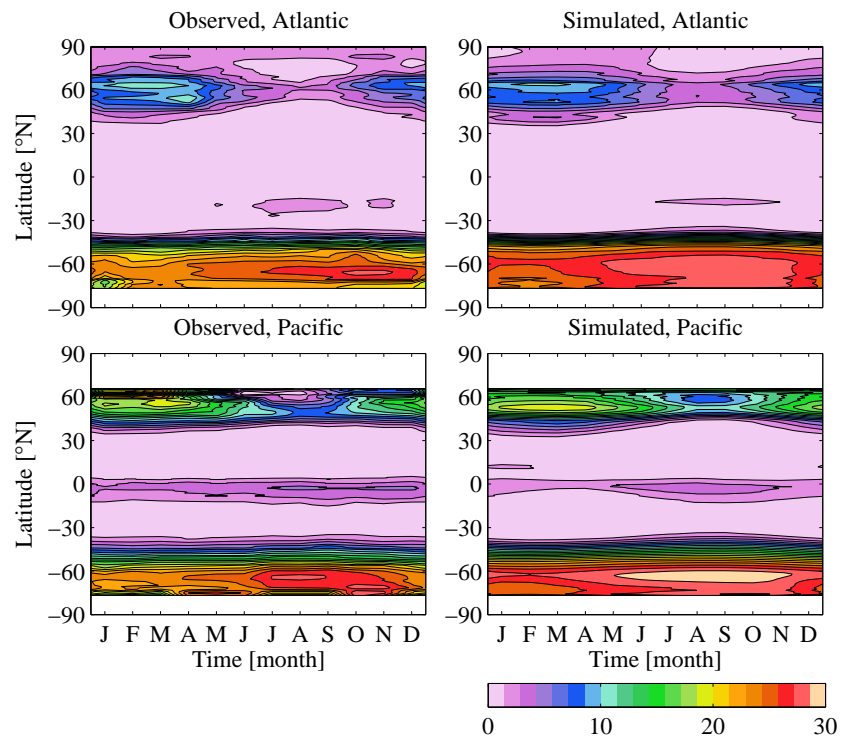

Fig. 8. Hovmöller diagrams of observational (World Ocean Atlas, 2005; left) and simulated (right) monthly surface dissolved inorganic nitrogen, averaged zonally for the Atlantic (top) and Pacific (bottom) basins. Concentrations in $\mathrm{mmol} \mathrm{N} \mathrm{m}^{-3}$.

Medusa. Finally, some plots of the time-evolution of modelled nutrients are shown to illustrate MEDUSA's stability and drift. Note that where geographical plots are shown, the Mollweide equal area projection has been used in order that ocean regions are presented without undue emphasis.

Regarding observational fields, these comprise the World Ocean Atlas 2005 nutrients (Garcia et al., 2006), SeaWiFS chlorophyll (O'Reilly et al., 1998) and estimated primary production. The latter is represented here by three empirical models: the VGPM (Behrenfeld and Falkowski, 1997), Eppley-VGPM (Carr et al., 2006) and CbPM (Westberry et al., 2008) productivity models. Three models are included since each predicts quite different productivity from the same chlorophyll input. The observational fields of chlorophyll and productivity used here represent averages over the same $5 \mathrm{yr}$ period from 2000 to 2004 inclusive, and this same period is used throughout the following analysis as a standard interval.

Figures 7 and 9 compare MEDUSA's performance in representing, respectively, surface concentrations of the macronutrients DIN and silicic acid. In both cases MEDUSA shows similar patterns of agreement (and disagreement). The seasonal patterns of high northern latitudes are well resolved, but nutrients are noticeably lower in equatorial upwelling regions, while significantly higher in the Southern Ocean. This latter discrepancy is particularly marked in the case of silicic acid. Figures 8 and 10 show corresponding, basin-averaged Hovmöller diagrams of DIN and silicic acid for the Atlantic and Pacific Oceans. 

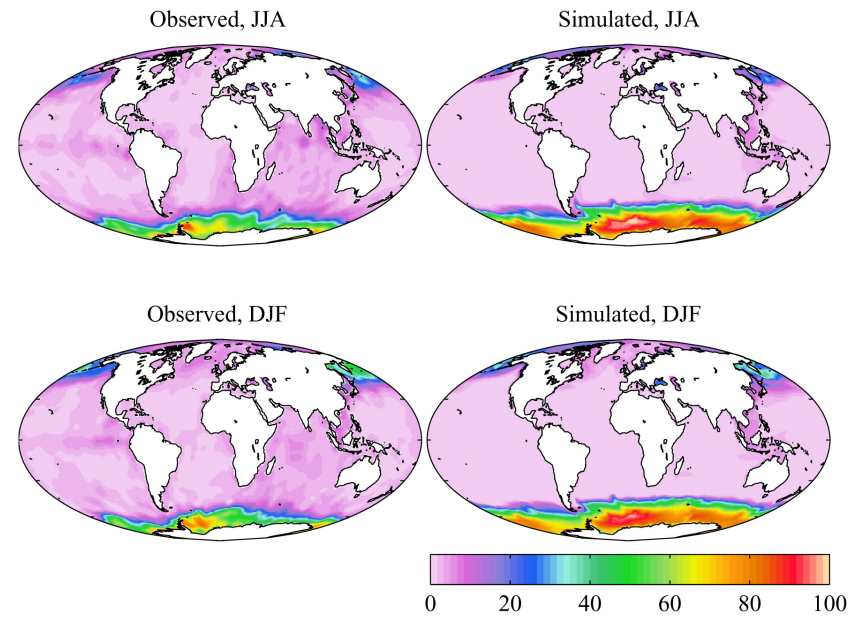

Fig. 9. Observational (World Ocean Atlas, 2005; left) and simulated (right) surface silicic acid for northern summer (June-July-August; top) and northern winter (December-January-February; bottom). Concentrations in $\mathrm{mmol} \mathrm{Si} \mathrm{m}^{-3}$.
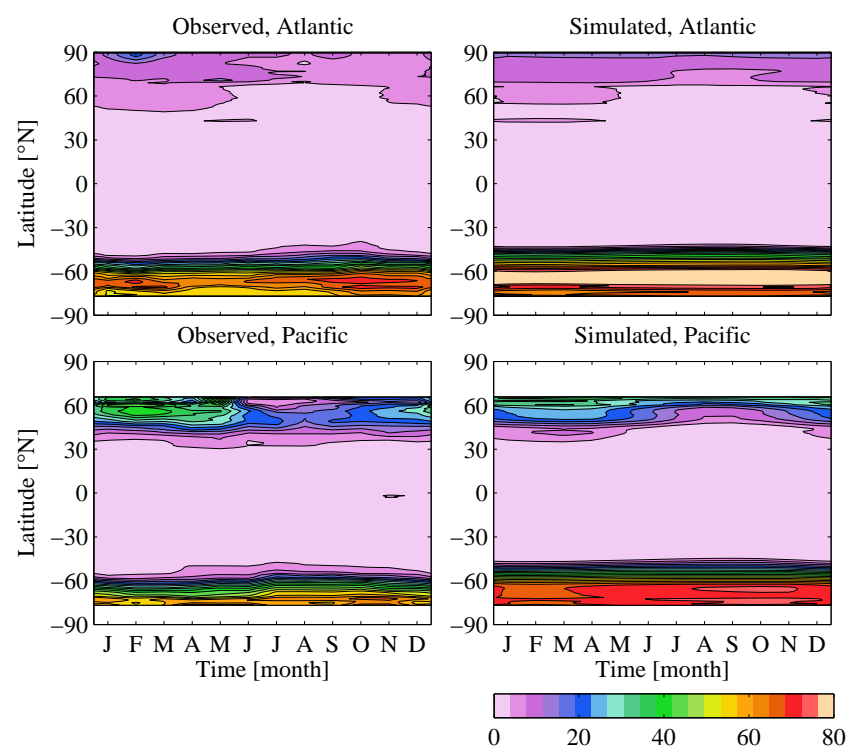

Fig. 10. Hovmöller diagrams of observational (World Ocean Atlas, 2005; left) and simulated (right) monthly surface silicic acid, averaged zonally for the Atlantic (top) and Pacific (bottom) basins. Concentrations in $\mathrm{mmol} \mathrm{Si} \mathrm{m}^{-3}$.

Figures 11 and 12 compare MEDUSA's simulated total chlorophyll (non-diatom plus diatom) to corresponding SeaWiFS fields. Note that a logarithmic colour scale is used to best represent the large range in ocean colour. Not uncommonly for ocean models, MEDUSA's representation of chlorophyll exhibits significant discrepancies with observations. MEDUSA shows much less pronounced seasonality, spatial boundaries that are significantly more sharply defined and consistently lower "background" chlorophyll
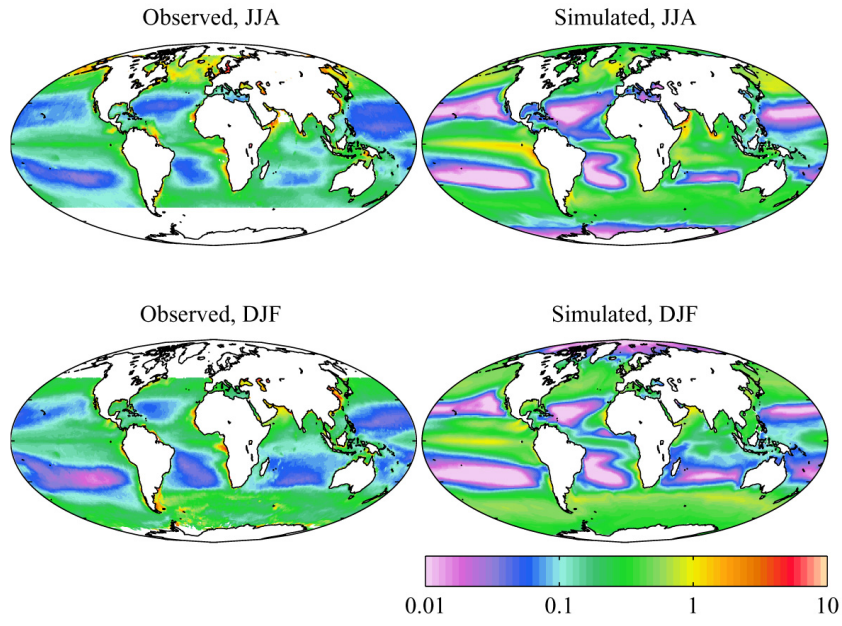

Fig. 11. Observational (SeaWiFS ; left) and simulated (right) surface chlorophyll for northern summer (June-July-August; top) and northern winter (December-January-February; bottom). Concentrations in $\mathrm{mg}$ chl. $\mathrm{m}^{-3}$, and plotted on a logarithmic scale.
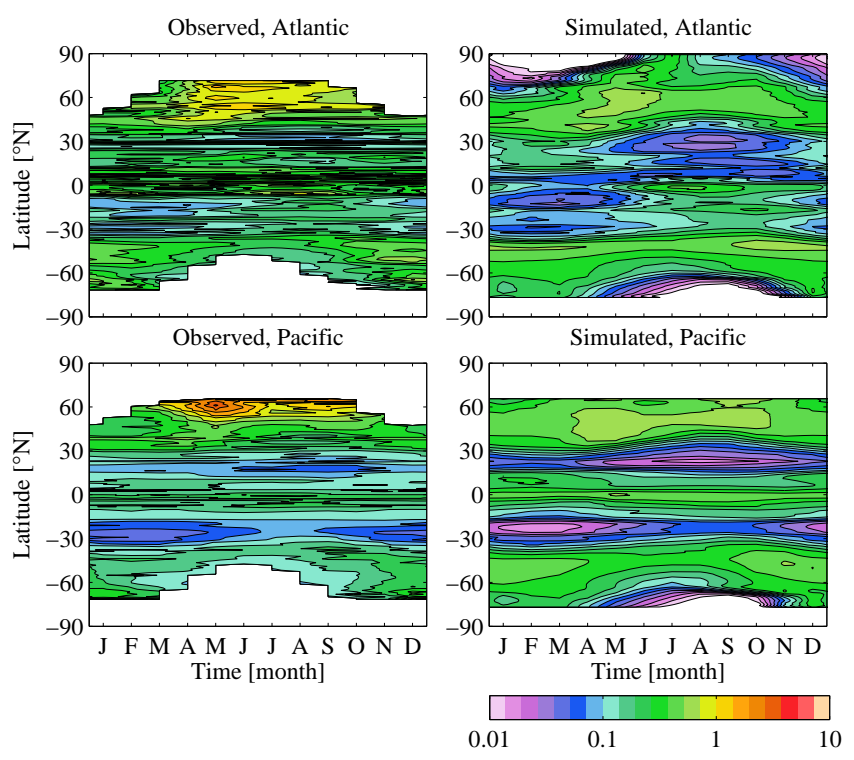

Fig. 12. Hovmöller diagrams of observational (SeaWiFS; left) and simulated (right) monthly surface chlorophyll, averaged zonally for the Atlantic (top) and Pacific (bottom) basins. Concentrations in $\mathrm{mg}$ chl. $\mathrm{m}^{-3}$, and plotted on a logarithmic scale.

concentrations in the ocean gyres. While the latter regions are not productive areas of the ocean, they represent a significant fraction of its total area. Part of the reason for the modeldata mismatches in this area may lie with the assumption of geographically invariant nutrient kinetics, which prevents model phytoplankton from adapting to oligotrophic conditions. In the real world, nutrient uptake kinetics are more 
Observed, VGPM, JJA
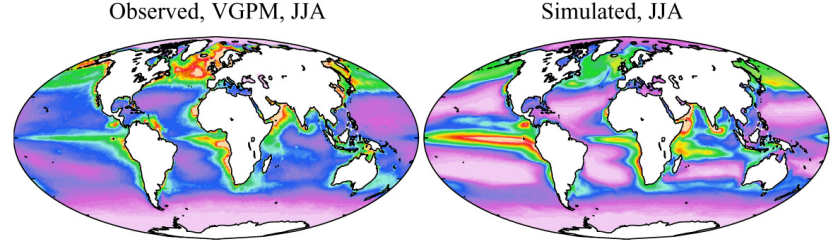

Observed, VGPM, DJF
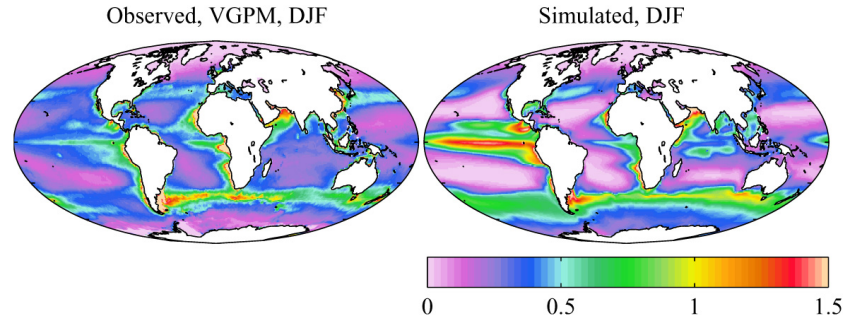

Fig. 13. Observational (VGPM model; left) and simulated (right) integrated primary production for northern summer (June-JulyAugust; top) and northern winter (December-January-February; bottom). The observational field here is estimated using the VGPM model and SeaWiFS chlorophyll observations. Production in $\mathrm{g} \mathrm{C} \mathrm{m}^{-2} \mathrm{~d}^{-1}$.
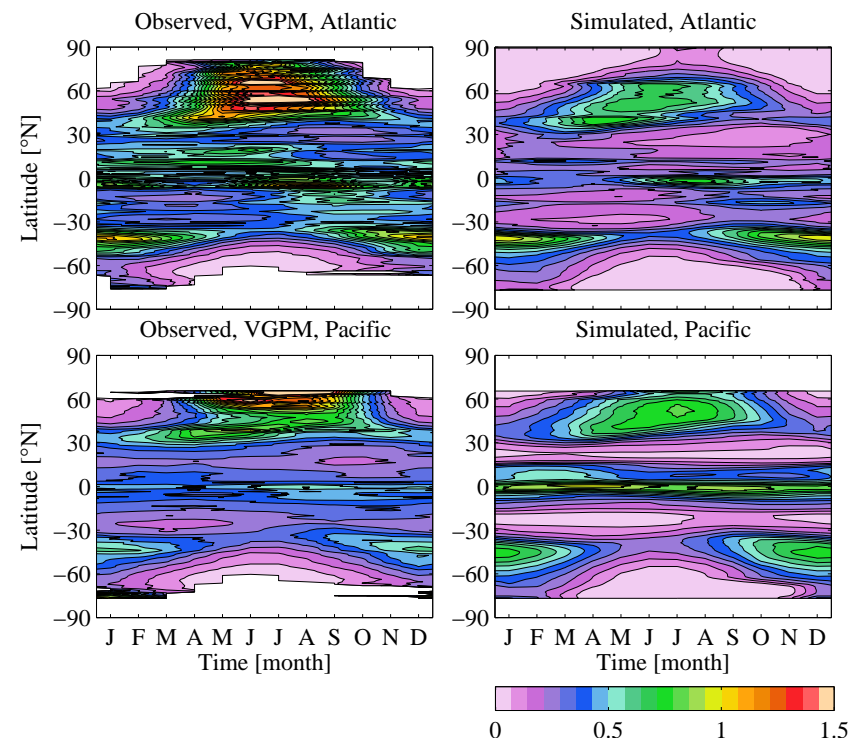

Fig. 14. Hovmöller diagrams of observational (VGPM; left) and simulated (right) monthly vertically-integrated primary production, averaged zonally for the Atlantic (top) and Pacific (bottom) basins. Production in $\mathrm{g} \mathrm{C} \mathrm{m}^{-2} \mathrm{~d}^{-1}$.

plastic, thereby permitting higher concentrations and productivity in the gyres (e.g. Smith et al., 2009).

Figures 13 to 14 compare MEDUSA's simulated total primary production (non-diatom plus diatom) to the estimates of the VGPM, Eppley-VGPM and CbPM models. While MEDUsA does not show strong correlations with any of the
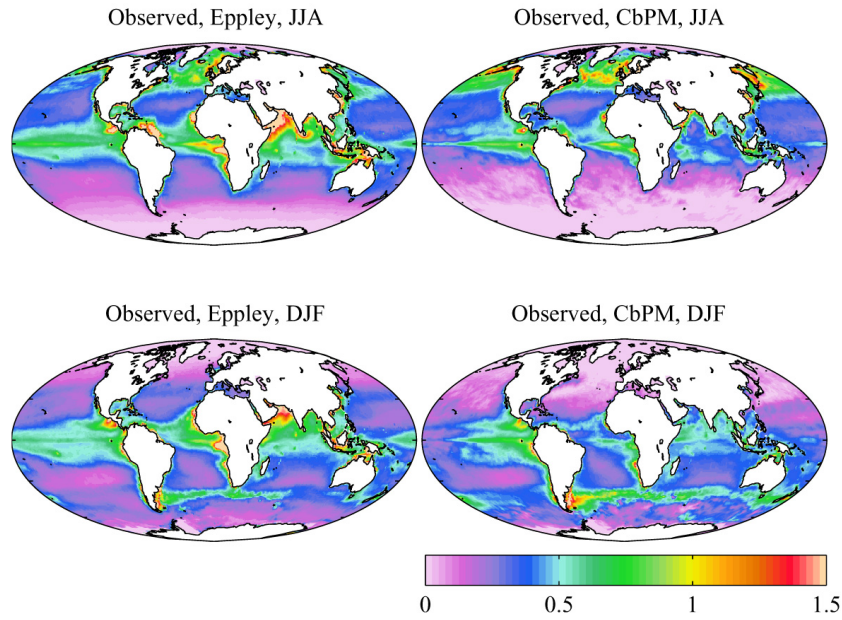

Fig. 15. Observational integrated primary production as per Fig. 13 but for the Eppley-VGPM (left) and CbPM (right) models. Production in $\mathrm{g} \mathrm{C} \mathrm{m}^{-2} \mathrm{~d}^{-1}$.
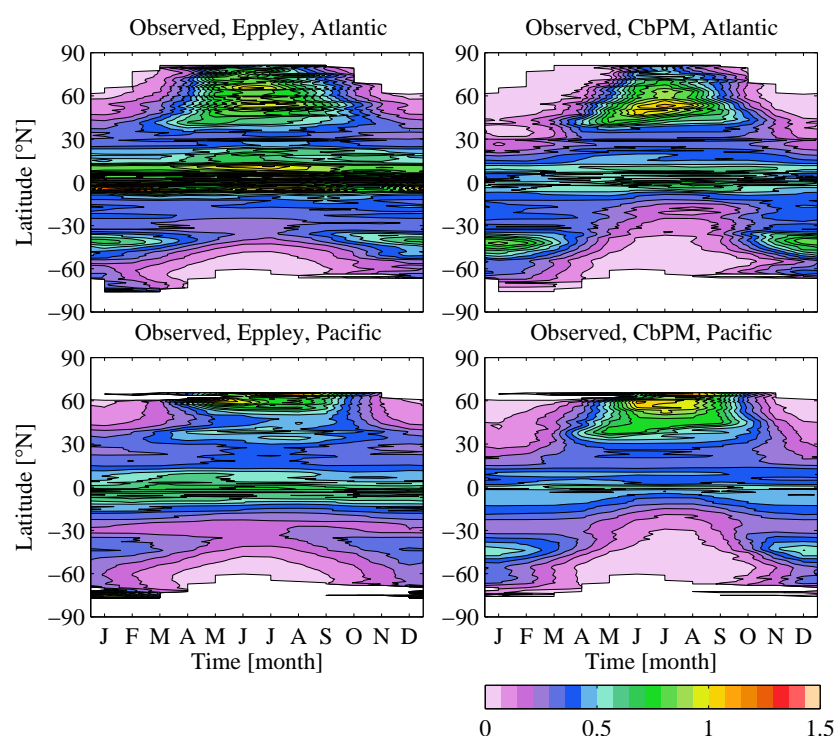

Fig. 16. As Fig. 14 but showing Hovmöller diagrams of observational vertically-integrated primary production estimated using the Eppley-VGPM and CbPM productivity models. Production in $\mathrm{g} \mathrm{C} \mathrm{m}^{-2} \mathrm{~d}^{-1}$.

estimates, the estimates do not strongly correlate with one another either. However, MEDUS A does still show systematic differences with the estimates. These include: consistently low subtropical gyre productivity; and elevated productivity in iron-limited regions including the Southern Ocean, equatorial Pacific and (seasonally) North Pacific. In terms of total oceanic primary production (and averaging over the final $10 \mathrm{yr}$ of the simulation), MEDUSA predicts $45.7 \mathrm{Gt} \mathrm{C} \mathrm{yr}^{-1}$, a value at the bottom of the broad range of the observational estimates, 58.8, 60.4 and $46.3 \mathrm{Gt} \mathrm{C} \mathrm{yr}^{-1}$ respectively. 

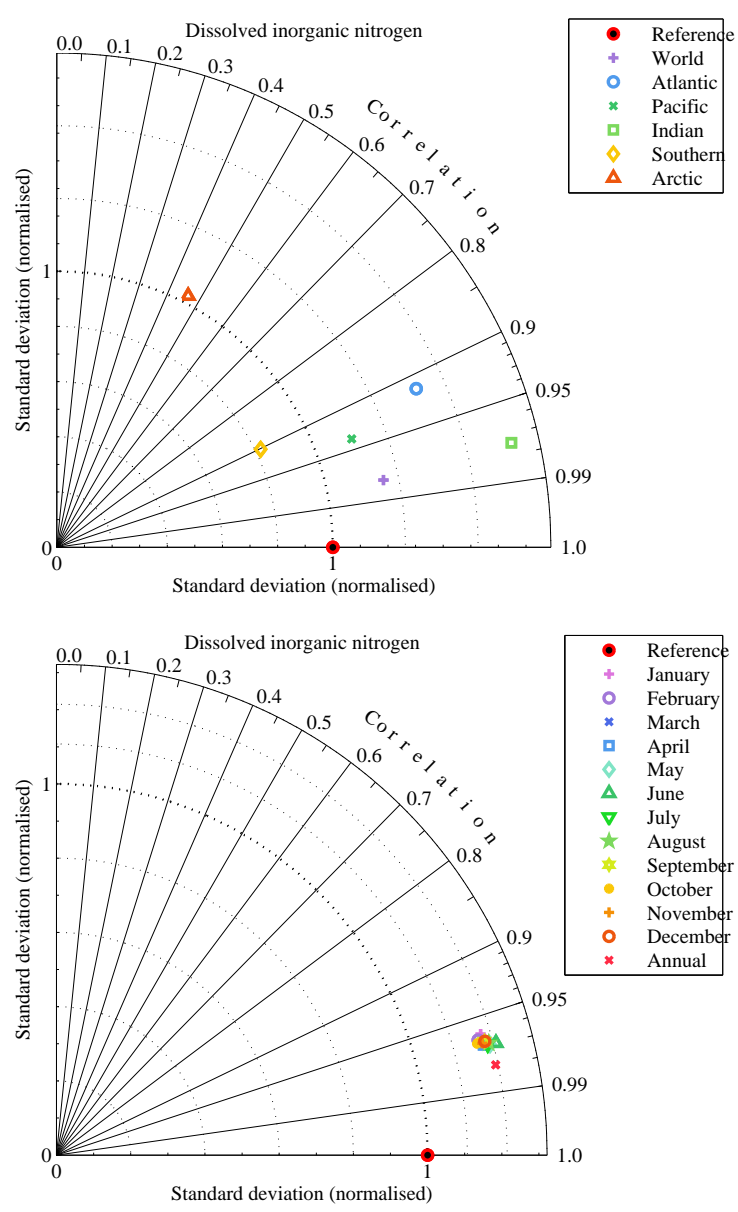

Fig. 17. Taylor diagrams of spatial (top) and temporal (bottom) model-observation comparisons for surface dissolved inorganic nitrogen. In the upper panel, simulated annual means for different regions are compared to corresponding observational fields. In the lower panel, simulated global average means for different months are compared to corresponding observational fields.

Figures 17 to 22 show the corresponding modelobservational comparisons using Taylor diagrams. These illustrate both the correlation between (circumference axis) and relative variability (radial axis) of model and observations. For each comparison two plots are shown. The first uses annually average fields, but separates the analysis between ocean regions; the second uses globally average fields, but separates the analysis between months. In all cases, model-observation is greater the closer plotted data are to the red/black bullseye on the horizontal axis.

Best agreement occurs for MEDUSA's nutrient fields, particularly those of dissolved inorganic nitrogen. While there remains sigificant scatter, MEDUSA generally shows good correlation with World Ocean Atlas 2005 fields, and comparable magnitudes of variability. This agreement is very weak in the case of chlorophyll, where the model both correlates
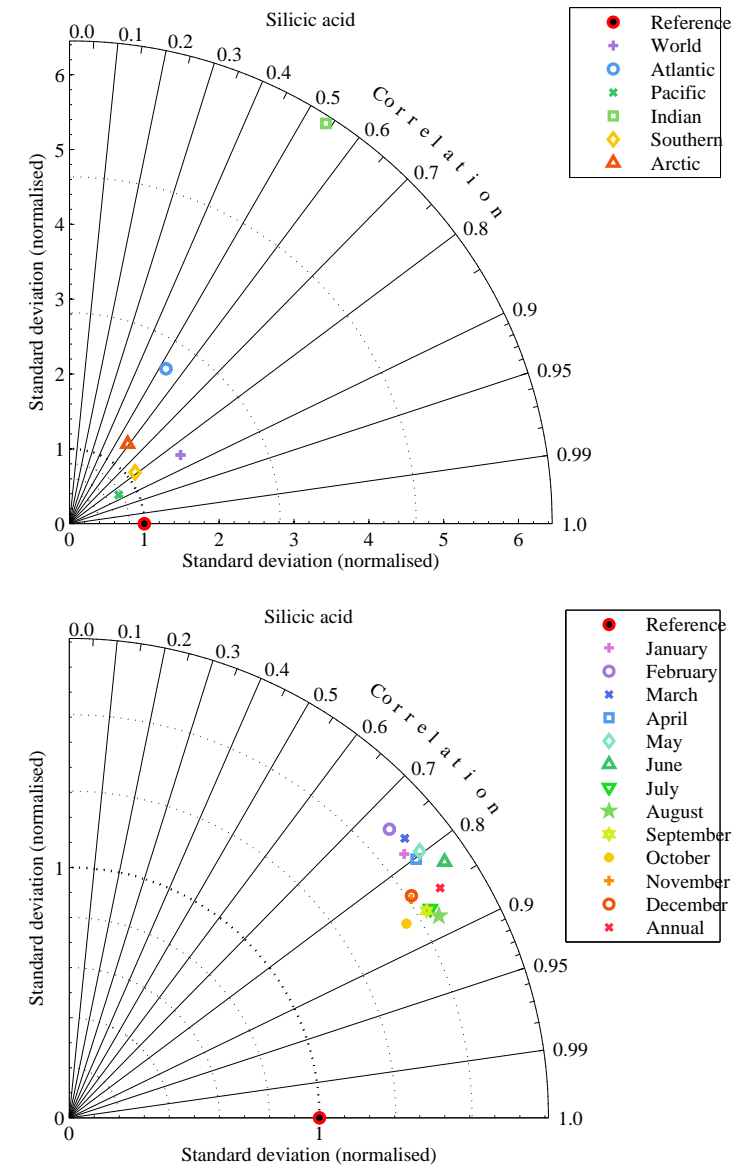

Fig. 18. Taylor diagrams of spatial (top) and temporal (bottom) model-observation comparisons for surface silicic acid. In the upper panel, simulated annual means for different regions are compared to corresponding observational fields. In the lower panel, simulated global average means for different months are compared to corresponding observational fields.

poorly and shows much less variability that the observed SeaWiFS fields. Although estimated productivity is based on the same SeaWiFS chlorophyll fields, MEDUSA's agreement with the three productivity models is actually greater. The CbPM model agrees best, although correlations are still relatively weak.

Figures 23 to 32 show model properties of relevance to MEDUSA's structure, but for which there is little or no observational information.

Figure 23 illustrates the difference in seasonality in the populations of diatom and non-diatom phytoplankton. The former show strongly seasonal behaviour, with high bloom concentrations in spring-summer and near-absence in winter. While the latter also show seasonality, it is considerably more modulated, with small but significant populations during the winter. 

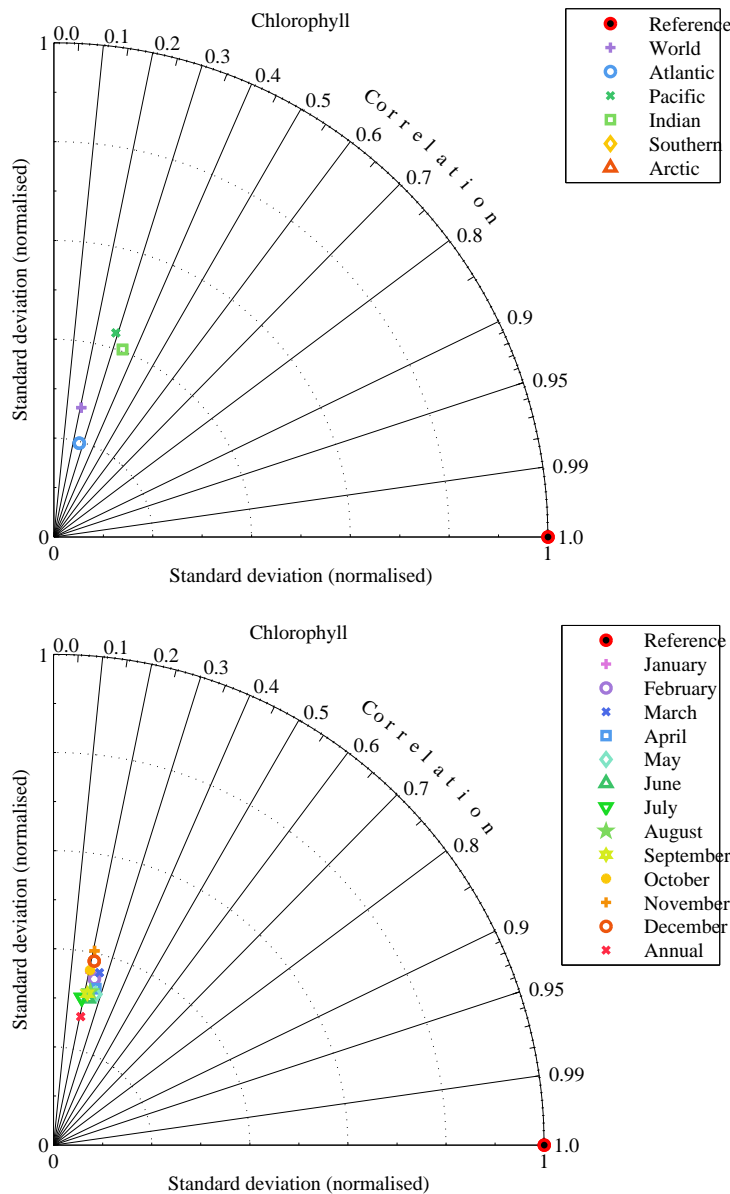

Fig. 19. Taylor diagrams of spatial (top) and temporal (bottom) model-observation comparisons for surface chlorophyll. In the upper panel, simulated annual means for different regions are compared to corresponding observational fields. In the lower panel, simulated global average means for different months are compared to corresponding observational fields.

Unsurprisingly, this pattern is repeated in Fig. 24, which shows the separate primary production of both groups. Integrating, the diatoms are responsible for $16.3 \%$ of total primary production in MEDUSA. Estimates of this fraction in the real world are not common. Several estimates for specific locations exist and range from 13 to $34 \%$ (Nelson and Brzezinski, 1997; Blain et al., 1997; Brzezinski et al., 1998), though these estimates do not cover the full range of ocean ecosystems. Global estimates are rarer, though a survey by Mann (1999) suggested 40 to $45 \%$, greater than that from the local studies, and much greater than that estimated by MEDUSA.

Although diatom primary production appears at the low end of literature estimates, biogenic opal production by MEdusA slightly higher than that estimated. Figure 26 shows the global distribution of opal production, which
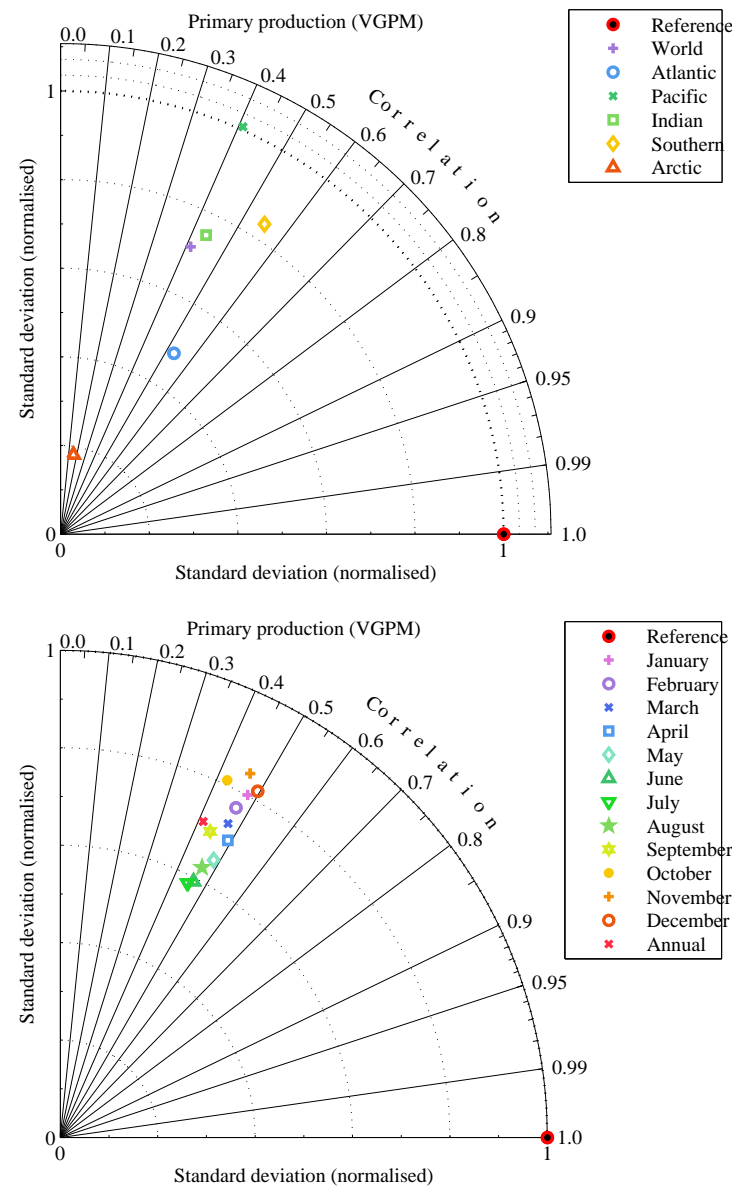

Fig. 20. Taylor diagrams of spatial (top) and temporal (bottom) model-observation comparisons for integrated primary production (VGPM estimated). In the upper panel, simulated annual means for different regions are compared to corresponding observational fields. In the lower panel, simulated global average means for different months are compared to corresponding observational fields.

largely follows diatom production, though areas such as the North Pacific and Southern Ocean show elevated production because of higher Si:N ratios (see Fig. 25). Globally integrated opal production is $222.4 \mathrm{Tmol} \mathrm{Si} \mathrm{yr}^{-1}, 7 \%$ lower than

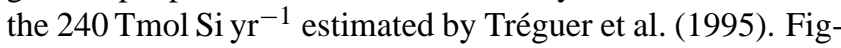
ure 26 also shows the corresponding production of calcium carbonate. Though this is in part linked to the diatoms (and mesozooplankton) through its association with the production of fast detritus, calcium carbonate production is focused more strongly in the equatorial region. This reflects the latitudinal scaling of $f_{c}$ (lat).

Figure 27 shows the split between primary production in the mixed layer and that deeper in the water column. The fraction is greatest at high latitudes in both summer and (especially) winter. Lower latitudes show much lower fractions especially in the oligotrophic subtropical gyres where nutrients are permanently limiting. Globally, $73.2 \%$ of primary 

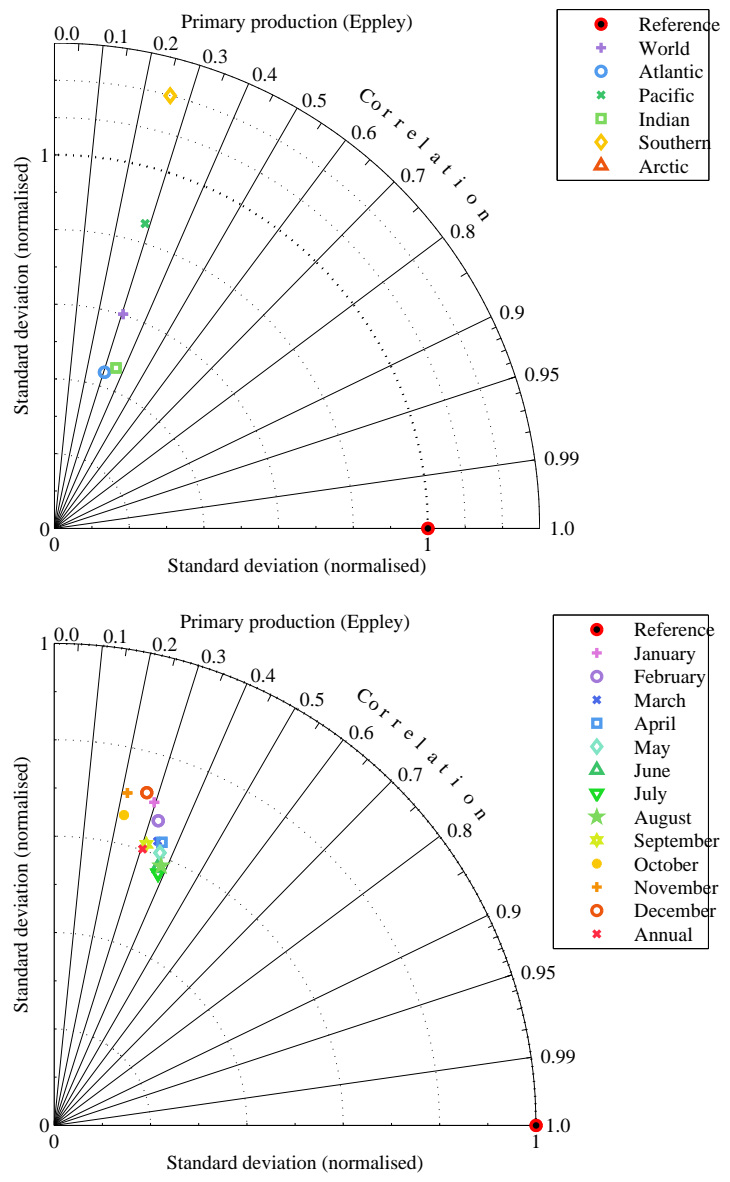

Fig. 21. Taylor diagrams of spatial (top) and temporal (bottom) model-observation comparisons for integrated primary production (Eppley-VGPM estimated). In the upper panel, simulated annual means for different regions are compared to corresponding observational fields. In the lower panel, simulated global average means for different months are compared to corresponding observational fields.

production occurs in the mixed layer. Following up on nutrient limitation, Fig. 29 shows summertime average limitations for both phytoplankton. Averaging spatially, non-diatoms are slightly more limited by iron (0.579) than nitrogen (0.636). Diatoms are most limited by iron (0.412), followed by silicon (0.511) then nitrogen (0.568). Figure 30 shows the overall scale of summertime nutrient limitation on both phytoplankton groups, together with maps that indicate the geographical distribution of "most limiting nutrient". Although less factors are considered in this analysis, the factors most limiting phytoplankton correspond fairly well to those identified by the BEC model of Moore et al. (2004). In the case of non-diatom phytoplankton, both models identify nitrogen as the most limiting nutrient in oligotrophic gyre regions, and iron in the equatorial Pacific and high latitude regions. In the case of diatom phytoplankton, the picture is somewhat different. BEC's diatoms are stressed in a similar pattern to its non-diatoms, with additional silicon stress around the
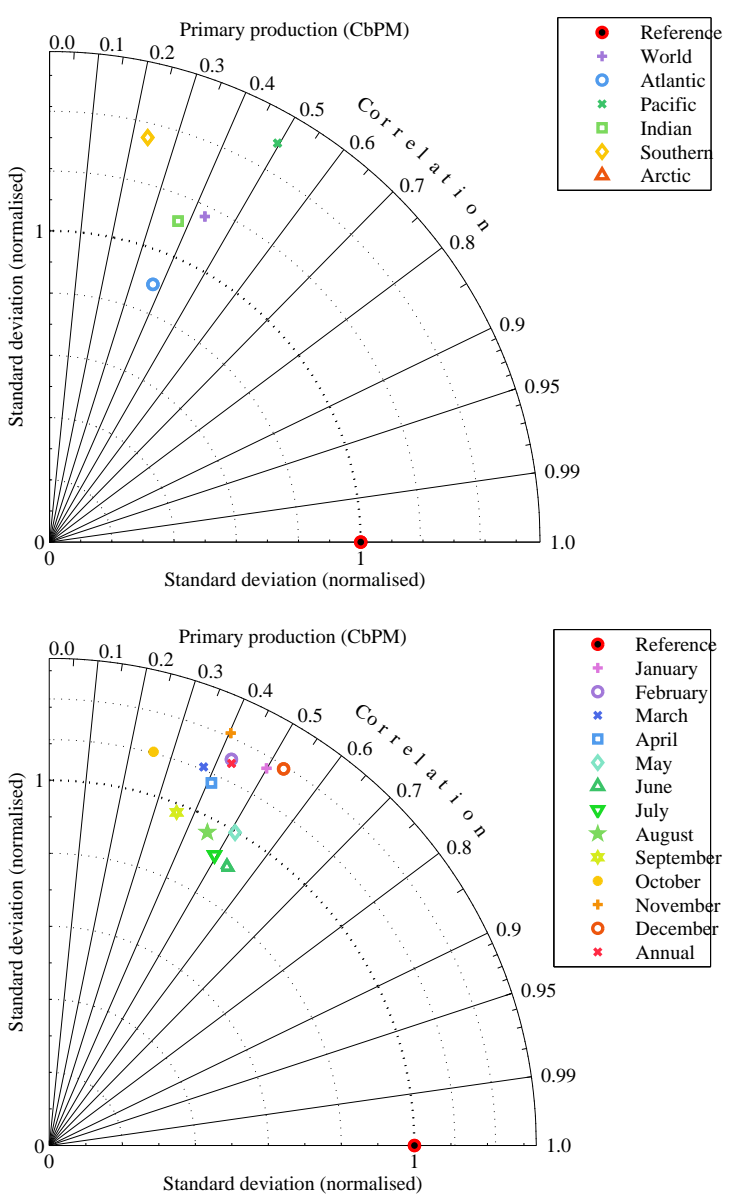

Fig. 22. Taylor diagrams of spatial (top) and temporal (bottom) model-observation comparisons for integrated primary production (CbPM estimated). In the upper panel, simulated annual means for different regions are compared to corresponding observational fields. In the lower panel, simulated global average means for different months are compared to corresponding observational fields.

region of iron stress in the equatorial Pacific and in the high North Atlantic. While Medus A shows a simliar pattern, its diatoms are also silicon-stressed in broad fringes around the oligotrophic gyre regions. Although these regions are not especially important for primary production, the extreme silicon stress in MEDUSA, at least relative to BEC, may point to excessively efficient export of silicon relative to nitrogen.

Largely following the availability of their favoured prey, Fig. 28 shows the seasonal distributions of micro- and mesozooplankton. The former closely matches the availability of the small, non-diatom phytoplankton. However, although the mesozooplankton have a preference for microzooplankton equal to diatoms, their distribution closely resembles diatoms, with generally low concentrations elevated wherever diatoms are blooming. However, while the diatoms are the smaller fraction of the phytoplankton community, their grazers make up $55.5 \%$ of total surface zooplankton. 

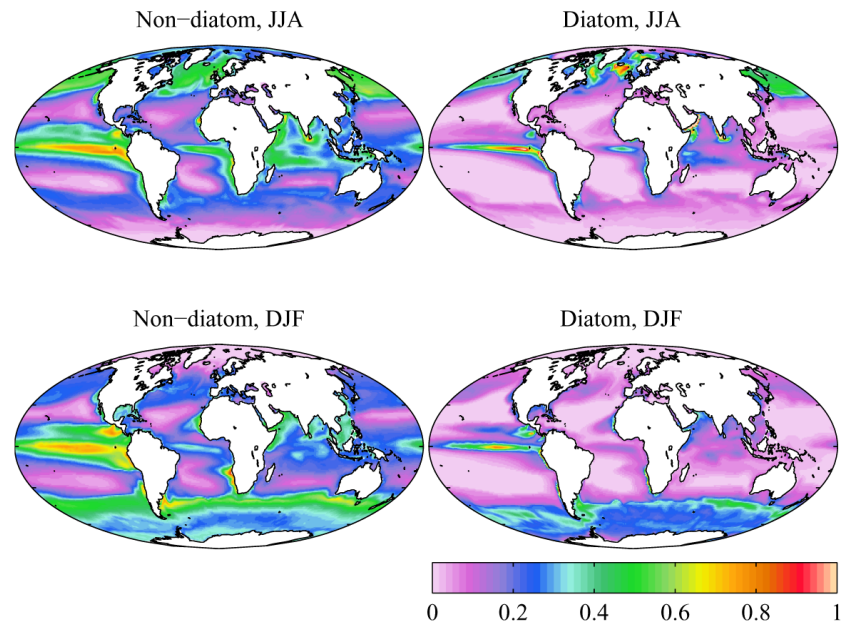

Fig. 23. Simulated surface non-diatom phytoplankton (left) and diatom phytoplankton (right) concentrations for northern summer (June-July-August; top) and northern winter (December-JanuaryFebruary; bottom). Concentrations in $\mathrm{mmol} \mathrm{N} \mathrm{m}^{-3}$.
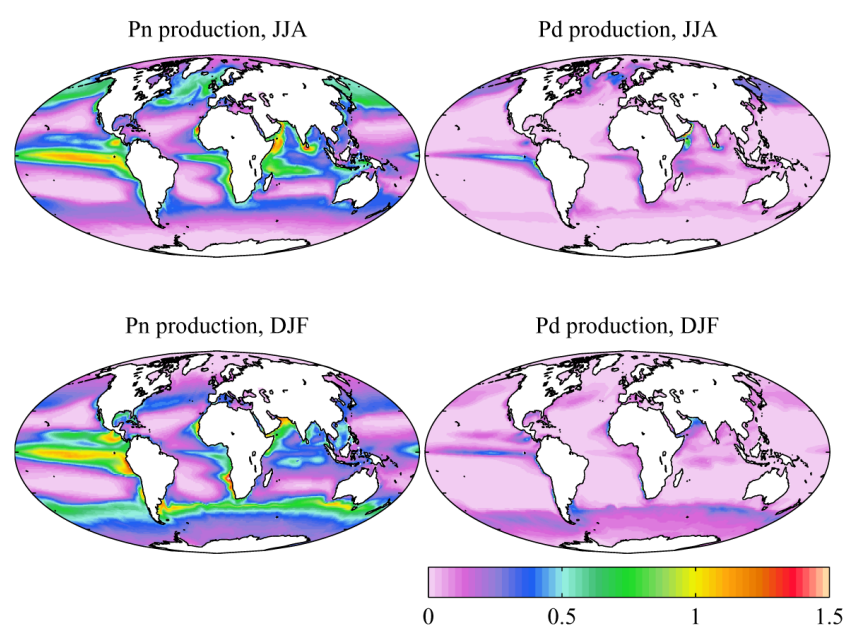

Fig. 24. Simulated non-diatom (left) and diatom (right) primary production for northern summer (June-July-August; top) and northern winter (December-January-February; bottom). Production in $\mathrm{g} \mathrm{C} \mathrm{m}^{-2} \mathrm{~d}^{-1}$.

Another size-based aspect of Medusa lies in slow- and fast-sinking detritus. Figure 31 shows the production of both classes of detritus. Unsurprisingly, given MEDUsA's foodweb, the distribution of slow-sinking detritus largely resembles that of the the smaller scale portion of the ecosystem, while fast-sinking detritus follows diatoms and mesozooplankton. In terms of production, $73.3 \%$ of detrital particles are small but, as Fig. 32 shows, by $100 \mathrm{~m}$ the total sinking flux has fallen to $27.7 \%$ of the $29.7 \mathrm{Gt} \mathrm{Cyr}^{-1}$ produced, of
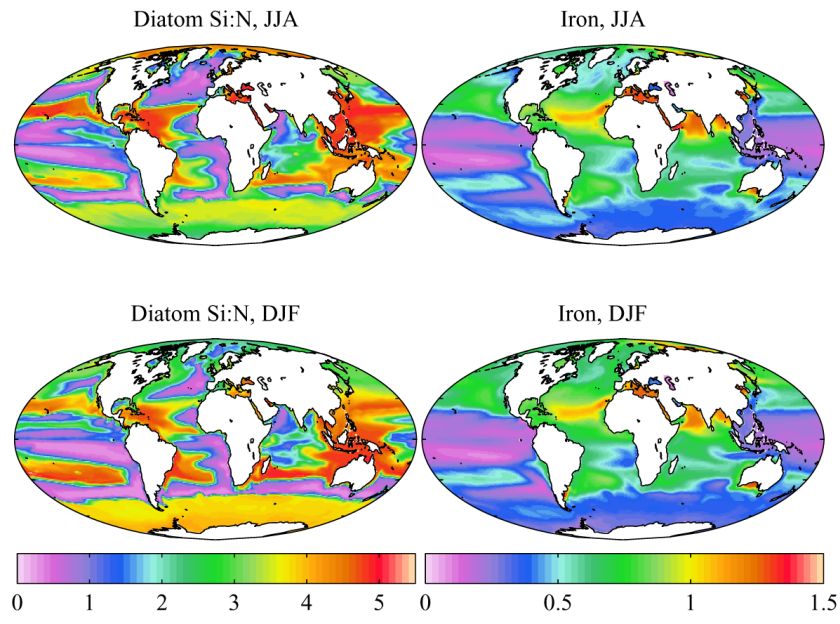

Fig. 25. Simulated surface diatom phytoplankton $\mathrm{Si}: \mathrm{N}$ ratio (left) and iron concentration (right) for northern summer (June-JulyAugust; top) and northern winter (December-January-February; bottom). Ratio in mol Si $(\mathrm{mol} \mathrm{N})^{-1}$; concentration in $\mu \mathrm{mol} \mathrm{Fe} \mathrm{m}^{-3}$.
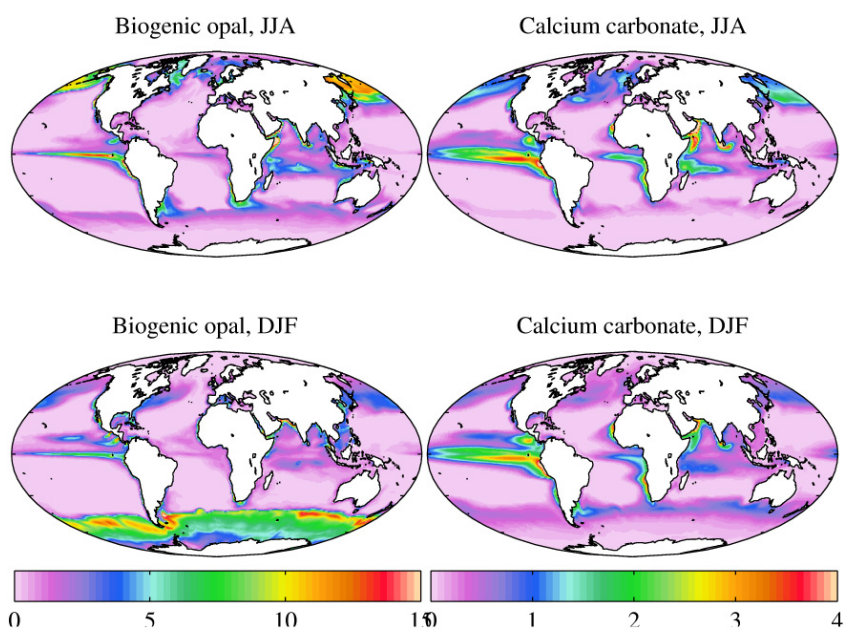

Fig. 26. Simulated diatom biogenic opal (left) and calcium carbonate (right) production for northern summer (June-July-August; top) and northern winter (December-January-February; bottom). Biogenic opal production in mol $\mathrm{Si} \mathrm{m}^{-2} \mathrm{~d}^{-1}$; calcium carbonate production in $\mathrm{mmol} \mathrm{C}^{-2} \mathrm{~d}^{-1}$.

which only $37.4 \%$ is made up of small particles. Figure 27 shows the corresponding magnitude of the sinking flux that reaches the model seafloor.

Figures 33 to 35 show the time evolution of regionally averaged nutrient profiles across the whole simulated period. These are plotted to quantify the scale of vertical nutrient redistribution that occurs during MEDUSA simulations, and to assess the extent to which the model has equilibriated by the end of the simulated period. Since the resupply of surface 

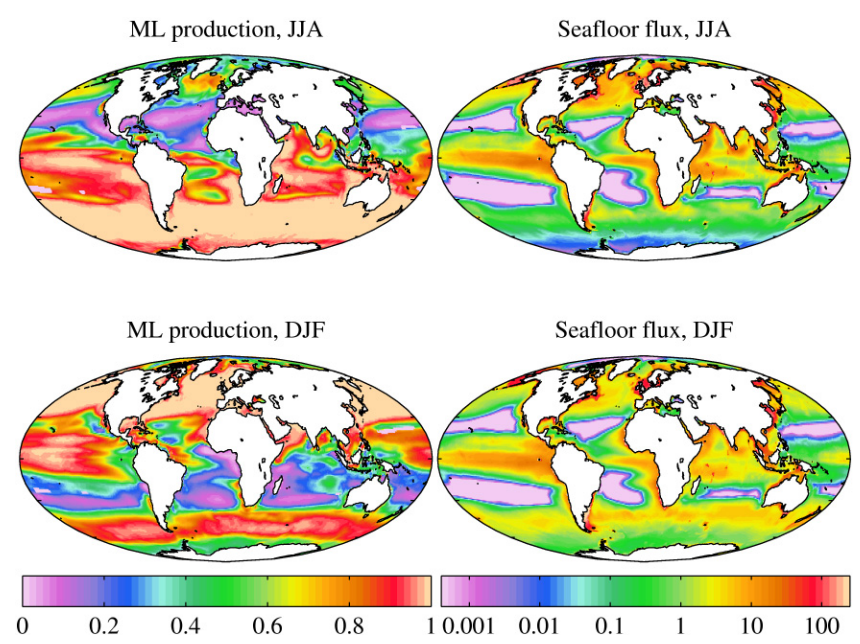

Fig. 27. Simulated mixed layer primary production fraction (left) and seafloor detrital flux (right) for northern summer (June-JulyAugust; top) and northern winter (December-January-February; bottom). Production fraction is dimensionless; seafloor detrital flux in $\mathrm{mg} \mathrm{C} \mathrm{m}^{-2} \mathrm{~d}^{-1}$, and shown on a logarithmic scale.
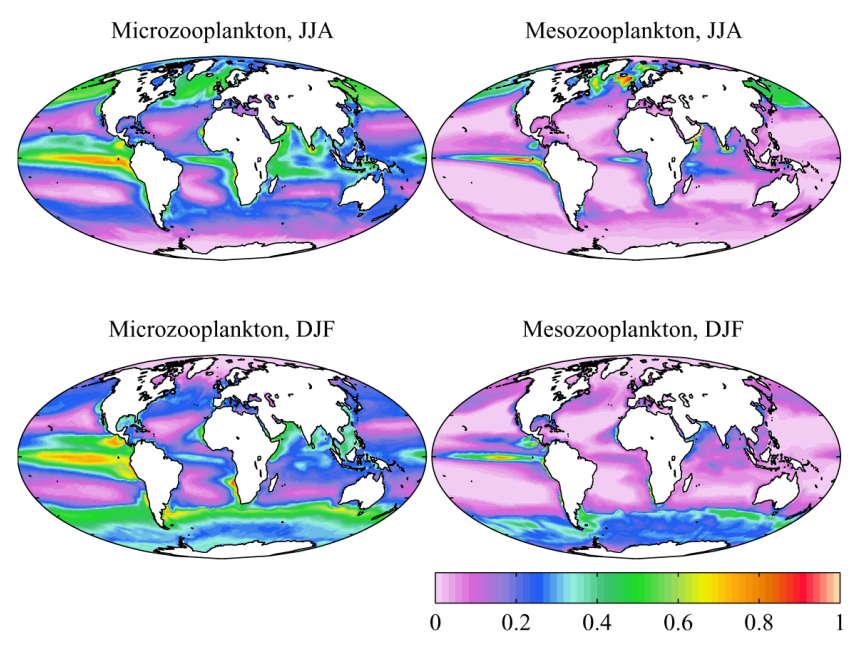

Fig. 28. Simulated surface microzooplankton (left) and mesozooplankton (right) concentrations for northern summer (June-JulyAugust; top) and northern winter (December-January-February; bottom). Concentrations in $\mathrm{mmol} \mathrm{N} \mathrm{m}^{-3}$.

nutrients is dependent on vertical gradients, changes in these wrought by the model can be very important.

Of the two macronutrients, nitrogen and silicon, profiles change only slightly during the simulation. The most striking changes occur in the Southern Ocean where both show strong shifts in the vertical gradients of nutrient concentration. As already seen in the fields shown in Figs. 7 and 9, surface concentrations in this region increase significantly relative to
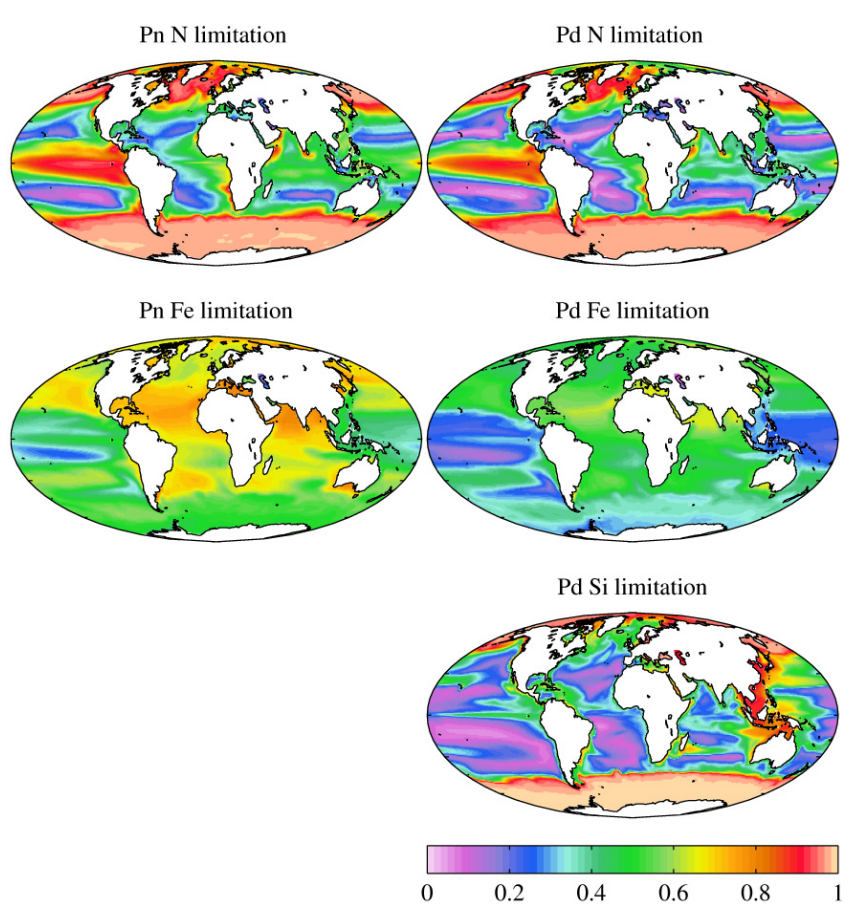

Fig. 29. Simulated summertime average non-diatom (left) and diatom (right) limitation factors for nitrogen (top), iron (middle) and silicon (bottom) nutrients. Limitation is weighted by biomass and integrated for the full water column. Limitation is dimensionless.

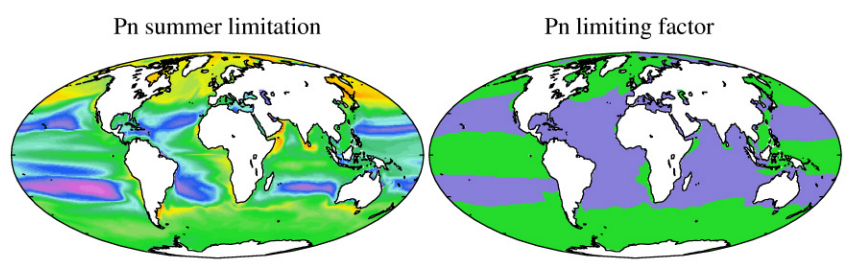

Pd summer limitation
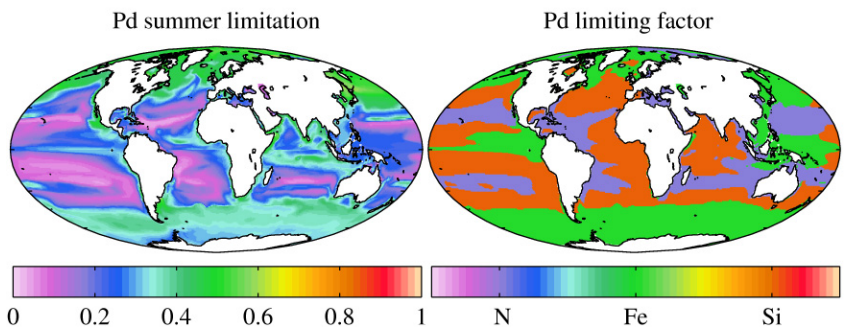

Fig. 30. Simulated summertime average non-diatom (top) and diatom (bottom) integrated nutrient limitation (left) and most-limiting nutrient (right). Limitation is weighted by biomass and integrated for the full water column. Limitation is dimensionless.

the World Ocean Atlas. By the end of the simulation these rises have slowed significantly, but they suggest a systematic problem with either physical or biogeochemical fluxes in this ocean region. 

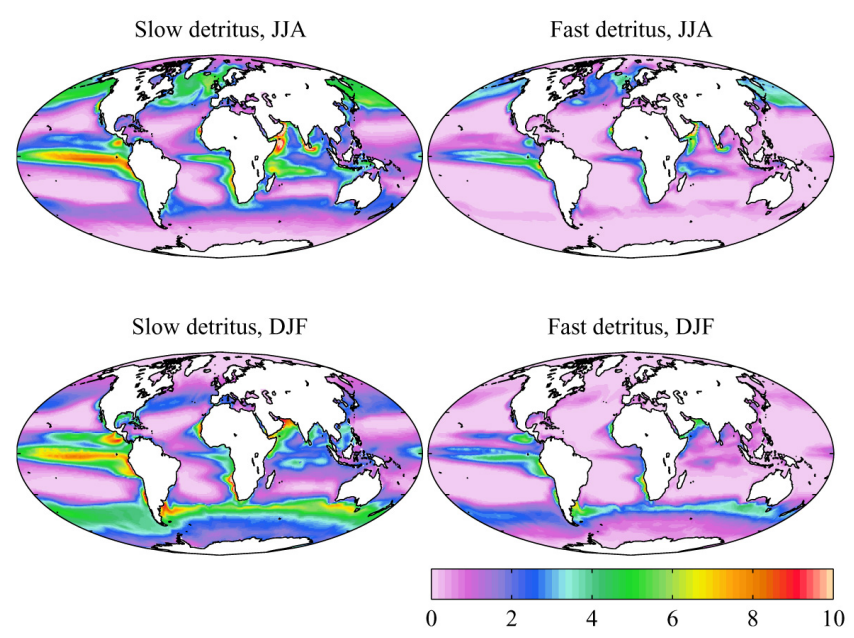

Fig. 31. Simulated slow (left) and fast (right) detritus production for northern summer (June-July-August; top) and northern winter (December-January-February; bottom). Detritus production in $\mathrm{mmol} \mathrm{N} \mathrm{m}{ }^{-2} \mathrm{~d}^{-1}$.
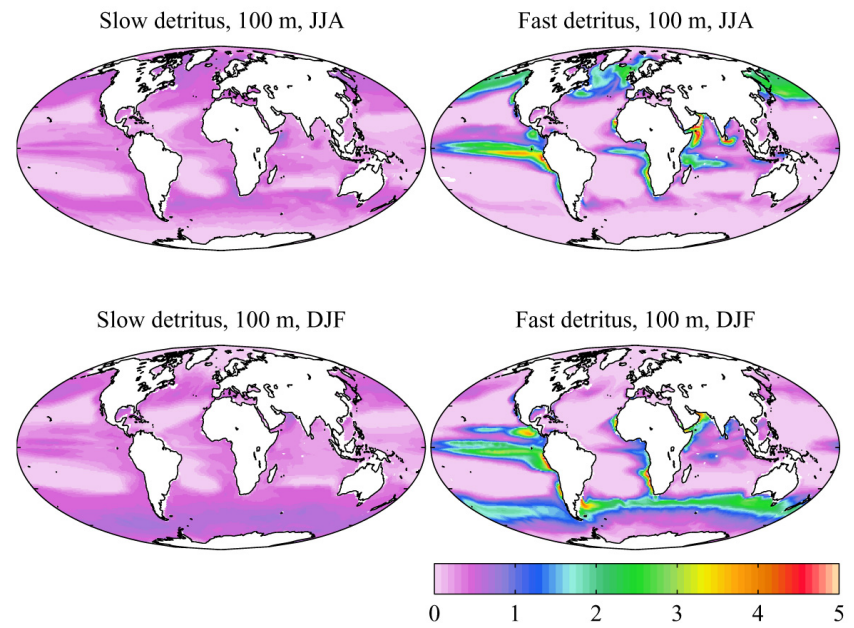

Fig. 32. Simulated slow (left) and fast (right) detrital sinking fluxes at $100 \mathrm{~m}$ for northern summer (June-July-August; top) and northern winter (December-January-February; bottom). Detritus production in $\mathrm{mmol} \mathrm{N} \mathrm{m} \mathrm{m}^{-2} \mathrm{~d}^{-1}$.

In the case of iron, in which the initial condition is from model output rather than an observational climatology, any changes that occur in basin profiles are less clearly erroneous. A general pattern is for iron concentrations to fall slightly in the surface $100 \mathrm{~m}$ within the first decade of simulation, and then to stabilise to a repeating annual cycle afterwards. This quick equilibriation is unsurprising, since surface iron concentrations are strongly controlled by aeolian deposition and biological activity. However, below around $1000 \mathrm{~m}$ iron
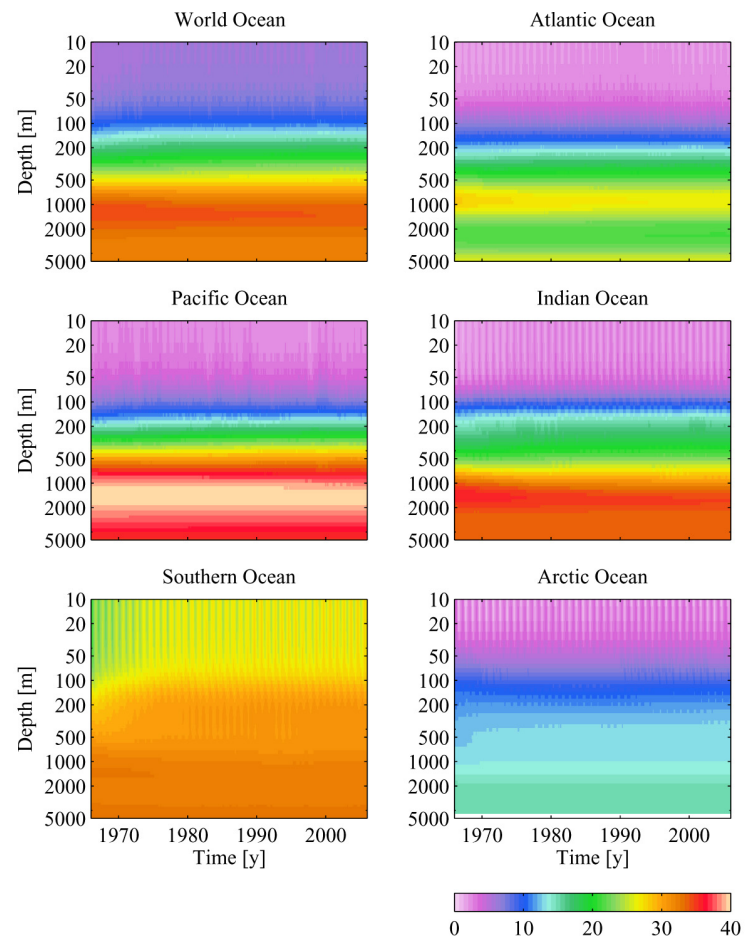

Fig. 33. Simulated vertical profiles of dissolved inorganic nitrogen concentration averaged for the World Ocean (top left) and 5 major regions. Concentrations in $\mathrm{mmol} \mathrm{N} \mathrm{m}^{-3}$. Note that depth is shown on a logarithmic scale.

concentrations are clearly drifting slowly downwards on a much longer time-scale. This difference between the iron and the nitrogen cycles is initially surprising, since the former is largely slaved to the latter, though it stems in part from the inclusion of iron scavenging, a biogeochemical pathway that has no analogue in the nitrogen cycle. Some iron cycle models stop scavenging below a fixed concentration (e.g. Aumont et al., 2003), while others tie it to the concentration of biological particles (e.g. Moore et al., 2004; Galbraith et al., 2010) both of which would act to decrease the deep drift found in MedusA. However, other studies also use lower resolution GCMs and much longer spin-up periods $(4000 \mathrm{yr}$, Aumont et al., 2003; 3000 yr, Dutkiewicz et al., 2005; 3000 yr, Moore and Doney, 2007; $1000 \mathrm{yr}$, Galbraith et al., 2010), and the drift in MEDUSA may simply stem from the short spin-up used in this study.

Finally, Fig. 36 complements earlier results by showing globally averaged time-series of the surface fields that are compared above to observations. The panels illustrate both the monthly variability across the simulation, and the interannual trends as it progresses. As already noted, the surface concentrations of both macronutrients show a common pattern of initial rise, followed by a gradual plateauing as their distributions come into equilibrium with physical and 

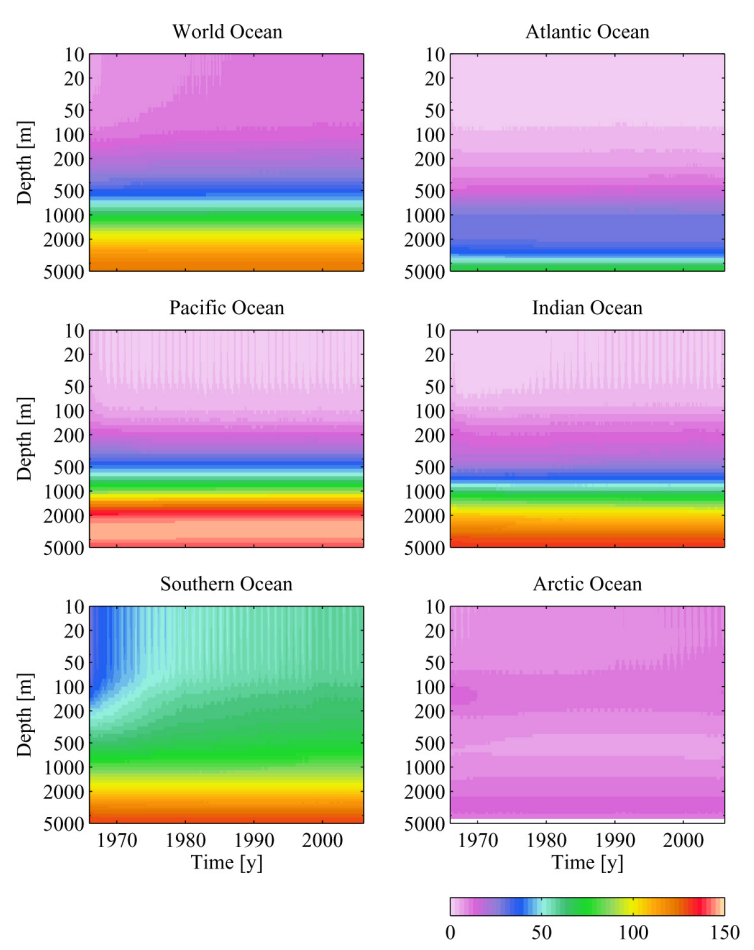

Fig. 34. Simulated vertical profiles of silicic acid concentration averaged for the World Ocean (top left) and 5 major regions. Concentrations in $\mathrm{mmol} \mathrm{Si} \mathrm{m}{ }^{-3}$. Note that depth is shown on a logarithmic scale.

biogeochemical fluxes. In contrast, both surface chlorophyll and primary production are relatively constant, and show no systematic drift. Inter-annual variability occurs, but there is no strong trend to increased or decreased biological activity. Assuming that NEMO's physical behaviour is realistic (which is supported by NEMO's good agreement with observational fields), this suggests that MEDUSA has a systematic deficiency that permits the accumulation of nutrients in the surface waters of (largely) the Southern Ocean.

\section{Discussion}

A significant factor in the adoption of increasingly complex models is the growing awareness of how ongoing anthropogenic changes to the Earth system will impact plankton ecosystems in a disparate number of ways. The most wellknown of these changes is the warming of the Earth's climate by the accumulation of the climatically-active gas $\mathrm{CO}_{2}$ in the atmosphere. This warming has led to a concommitant warming of the (surface) ocean (e.g. Lyman et al., 2010), and it is believed that this will primarily impact plankton systems through changes to surface nutrient concentrations driven by increasing water column stratification (e.g. Bopp et al., 2005). This change in the availability of raw materials
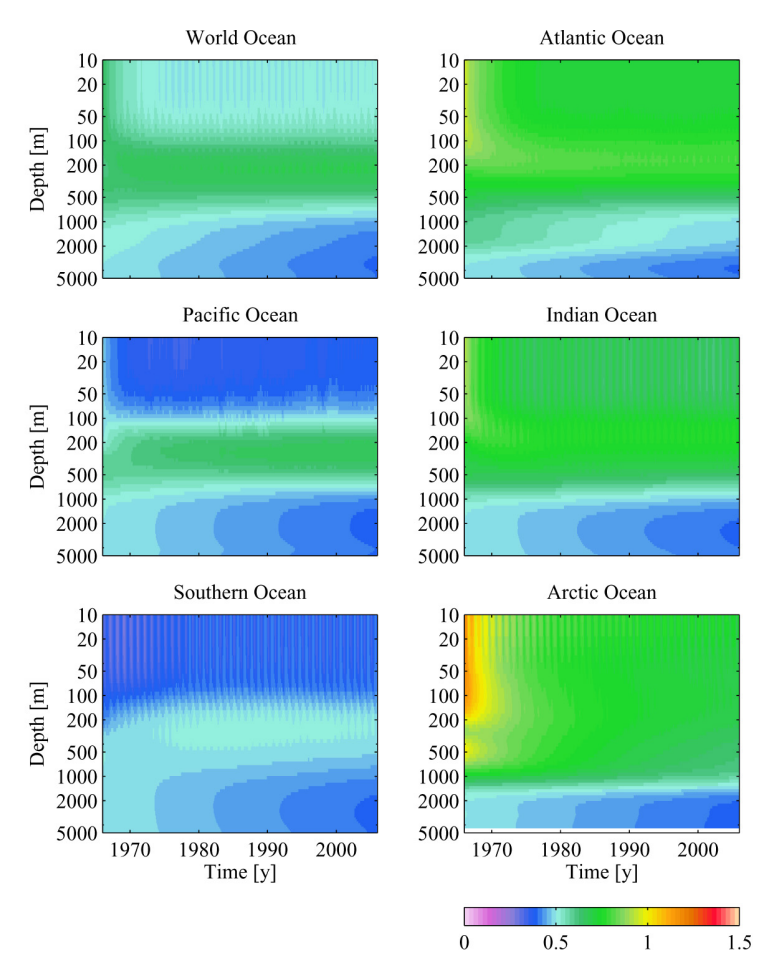

Fig. 35. Simulated vertical profiles of iron concentration averaged for the World Ocean (top left) and 5 major regions. Concentrations in $\mu \mathrm{mol} \mathrm{Fe} \mathrm{m}^{-3}$. Note that depth is shown on a logarithmic scale.

for phytoplankton growth is a fundamental one for plankton systems, and is amenable to study using even relatively simplified NPZD models. However, a number of other ongoing changes require more sophisticated treatments of marine ecology. For example, although increasing ocean stratification will lead to decreasing vertical nutrient supply to the surface ocean, not all nutrient species will be affected similarly because of differences in their distributions. Nitrogen and phosphorus nutrients, for instance, are known to covary strongly in a Redfield relationship (Tyrrell, 1999). However, silicic acid is regenerated much deeper in the water column (Yool and Tyrrell, 2003), and is liable to be affected differently by increasing stratification. Since this nutrient plays a crucial role in the ecology of the diatoms, a key phytoplankton group (Mann, 1999) with an important role in export production (Dugdale and Wilkerson, 1998), wider ecosystem functioning is liable to change if the diatoms become disadvantaged.

Similarly, also in part related to the change in surface nutrient conditions, another anticipated impact lies with the occurrence and distribution of nitrogen fixation (Capone et al., 2005). This process is an important source of fixed nitrogen for oligotrophic regions of the surface ocean, and offsets its consumption through denitification (Tyrrell, 1999). A declining supply of physically-supplied fixed nitrogen from 

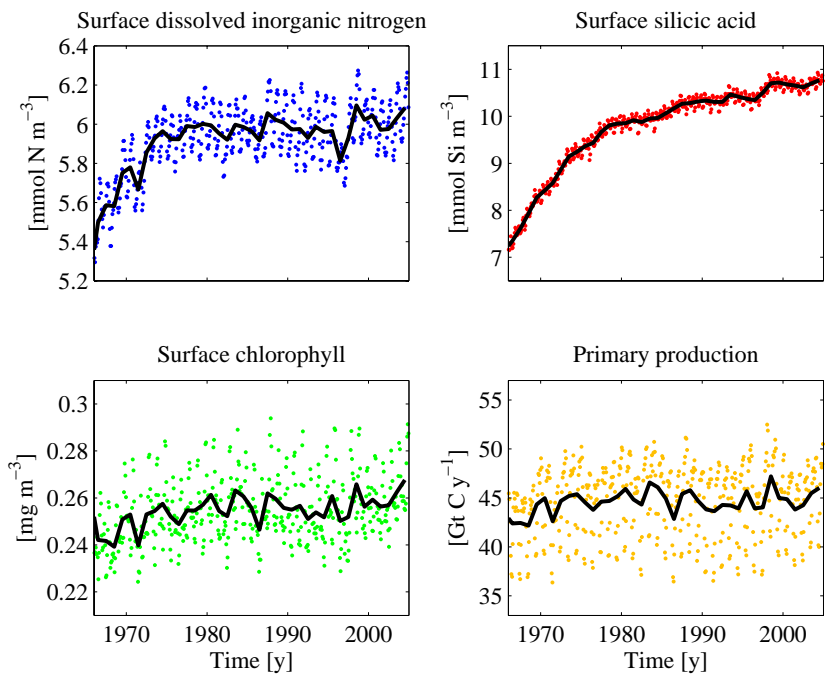

Fig. 36. Globally averaged surface dissolved inorganic nitrogen (top left), surface silicic acid (top right), surface chlorophyll (bottom left) and integrated primary production (bottom right). Solid black lines are annual averages/integral; individual points are individual months. Note that individual monthly primary production values have been normalised so that they appear on the same scale as annual integrals.

depth driven by increasing stratification and, potentially, increasing anoxia-mediated denitrification (cf. Deutsch et al., 2007), may act to shift phytoplankton community structure in favour of groups capable of utilising dissolved dinitrogen gas. The invasion of the ocean by anthropogenic $\mathrm{CO}_{2}$ is increasing dissolved inorganic carbon concentrations (Key et al., 2004), and altering the $\mathrm{pH}$ of seawater. This process, known as ocean acidification (Caldeira and Wickett, 2003; Orr et al., 2005), is predicted to have a number of different effects on ocean biota (Raven et al., 2005), but a major one will be the increasing solubility of the biomineral calcium carbonate in surface (and deep) waters. Since a large number of planktonic species utilise this mineral for structural purposes, changes in seawater chemistry that accelerate its dissolution are liable have a significant impact.

These latter changes to the ocean system mitigate in favour of ecosystem models that include more sophistication than conventional NPZD models, so that their consequences can be assessed. However, although research has outlined the ecosystem processes described above, there are still large gaps that preclude robust and reliable predictions. For instance, in the case of nitrogen fixation, there are a number of different phylogenetic groups engaged in this process (e.g. cyanobacteria, diatoms, even some metazoans; Kneip et al., 2007), with the result that functional behaviour is diverse and difficult to model within the confines of a single state variable. There are potentially even issues concerning seemingly established ideas about the correlation of nitrogen fixation with warm waters (cf. Le Quéré et al., 2005) that may be incorrect (cf. Monteiro et al., 2010). Similarly, while calcification may be expected to be straightforwardly related to the saturation state of calcium carbonate, experimental and field work has found a wide range of responses that, again, preclude simple modelling (e.g. Riebesell et al., 2000; IglesiasRodriguez et al., 2008).

Within this context, MEdusA aims to expand upon classical NPZD models, while restricting itself to biogeochemical cycles and biological functional groups that are more completely understood (cf. Anderson, 2005; Flynn, 2005). Hence, MEdusA's incorporation of diatoms and the silicon cycle (cf. Smetacek, 1985; Dugdale and Wilkerson, 1998), and a microbial loop of smaller phytoplankton and zooplankton (cf. Pomeroy, 1974; Azam et al., 1983). However, as noted by Hood et al. (2006), even these expansions are not without uncertainty. The silicon cycle, for instance, ignores the contributions to opal production of both the silicoflagellates and (more significantly) the radiolarians. Furthermore, MedusA also omits a detailed consideration of internal cell physiology (cf. Flynn, 2001). Nonetheless, the intention of MEDUSA is to provide a post-NPZD plankton ecosystem model, with a parameterisation that is robust, and whose major state variables are amenable to analysis and comparison with observational data throughout the global domain.

In general, MEDUSA's performance is acceptable, with global patterns of nutrients and productivity that follow those observed. Major features such as oligotrophic gyres and the seasonal progression of plankton blooms and nutrient depletion are reproduced. And at the global scale, MEDUSA's productivity falls well within the range estimated from observations, both in terms of organic carbon and biogenic opal. Furthermore, although indirect, the multi-decadal stability of vertical macronutrient gradients (except in the Southern Ocean; see below) suggests that MEDUSA's export production successfully balances nutrient resupply by physical mechanisms. Drifts in deep iron concentrations suggest an insufficient spin-up period, but surface gradients equilibriate quickly as with the macronutrients. However, there are a number of significant discrepancies between MEDUSA and observations that should be noted.

Firstly, MEDUSA tends to accumulate nutrients, especially silicic acid, in the surface waters of the Southern Ocean. Since MEdusA's productivity is similar to that estimated from satellite observations, this tends to suggest that either the export fraction of MEDUSA is too low in this region (i.e. the biological pump does not transfer organic material deep enough), or that NEMO's upwelling is too strong (i.e. excessive quantities of nutrient are upwelled, and cannot be processed by surface biology). Given the good agreement between NEMO and observed physical fields, the former explanation may guide future improvement.

Secondly, the oligotrophic gyres in MEdus a have lower concentrations of chlorophyll and are less productive than observed. Again, this may be the result of either biological 
or physical deficiencies in the model. For instance, the low nutrient concentrations in these regions may be insufficient to permit even slow growth of MEDUSA's phytoplankton on recycled nutrients. Alternatively, the resolution of NEMO used here may omit mesoscale processes that supply nutrients to the surface ocean (e.g. McGillicuddy et al., 2003). As noted already, the former suggestion is supported by work that permits adaptation of model phytoplankton to oligotrophic conditions (Smith et al., 2009). The latter suggestion may be investigated in future using higher resolution instances of NEMO.

As noted, both of these deficiencies may have biogeochemical roots. At present, MEdusA has not been objectively tuned to more closely match observational fields. Current parameterisation is instead derived from literature values and from subjective "tuning" where parameter values have been found to cause systematic errors. Previous studies have found that the localised optimisation of a biogeochemical model at particular locations can be successful at improving model performance when the model is then simulated in 3-D at large scale (Oschlies and Schartau, 2005). Consequently, objective tuning, coupled to validation in 3-D, may be a future avenue to improve the performance of MEDUSA and to diminish the most significant current errors.

On a separate but related point, some of MEdusA's deficiencies may stem from deeper, structural issues such as the forms of growth and mortality terms. To examine this, albeit incompletely, Appendix A describes a series of four sensitivity analyses that explore several key aspects of MEDUSA's formulation. In general, these do not find strong dependence of the default simulation's results on particular features of MEDUSA, though in the case of coastal nutrient relaxation this is found to operate in an unintended fashion in some locations.

A further issue with the simulation of MEDUSA examined here is the suggestion that the spin-up period used is insufficient, most clearly apparent in the drift of deep iron concentrations, but also in the more gradual adjustment of DIN and silicic acid distributions. In the specific case of iron, given an initial condition derived from a different model, the operation of iron scavenging throughout the model domain, and the long ventilation timescale of the deep ocean (2000 yr; Ostlund and Stuiver, 1980), this is perhaps unsurprising. The medium resolution used here, as well as the high resolution used in other applications of MEDUSA (e.g. Popova et al., 2010), preclude spin-ups of more than a few decades. However, lower resolution instances of the NEMO GCM are available, and future investigation of upscaled MEDUS A output from longer spin-ups of coarser grids may provide one solution to this problem. This approach, or similar, will be of particular relevance in the case of investigations at centennial-scale duration (e.g. climate change forecast simulations) where drifts in biogeochemical properties may be comparable to, or even obscure, actual forced trends. In such cases either a parallel (and expensive) control, or a more completely spun-up model is essential. Nonetheless, and as noted already, despite deep ocean drifts, the biogeochemical cycles of MEDUSA's surface ocean, where most biological activity takes place, reach quasi-equilibrium well within the time-scale of the simulation described here.

In summary, despite the deficiencies noted above, we believe that MEDUSA represents a valuable tool for global scale simulations of the plankton ecosystem. One that is intermediate between the simplicity of NPZD models, and the expensive complexity of PFT models, but whose complexity provides a "good fit" with our current ability to validate models at the global scale. Future work with MEDUSA will include its application to a range of contemporary topics, including Arctic climate change (Kwok and Rothrock, 2009) and ocean acidification (Orr et al., 2005).

\section{Conclusions}

- Medusa, a novel, size-based plankton ecosystem model of the nitrogen, silicon and iron cycles for the global ocean is introduced.

- The performance of MEDUSA is evaluated using globalscale observational fields following a multi-decadal simulation (1966 to 2005 inclusive).

- Medusa reliably produces global patterns of surface nutrients and productivity, and (generally) preserves vertical nutrient gradients.

- MedusA's major deficiencies are excessive surface nutrients in the Southern Ocean (especially silicic acid), and low productivity in oligotrophic gyres.

- Medusa estimates that surface productivity is dominated by small plankton, but that the deep biological pump is driven by large plankton.

\section{Appendix A}

\section{Sensitivity analysis}

As described in Sect. 5, a series of sensitivity analyses were undertaken to explore particular assumptions made in the default MEdusA simulation. This section provides a full description of the changes to MEDUSA for each of the different analyses, together with a brief summary of the results obtained.

In each case the model state of the default run at the end of year 2001 was used as an initial condition for a $4 \mathrm{yr}$ repeat of the period 2002-2005 inclusive. This period is not long enough for the altered model to reach full equilibrium, but it was found to be sufficient for general behaviour to be established (from experience during the development of MedusA). The first $3 \mathrm{yr}$ of this repeat period (2002-2004) 

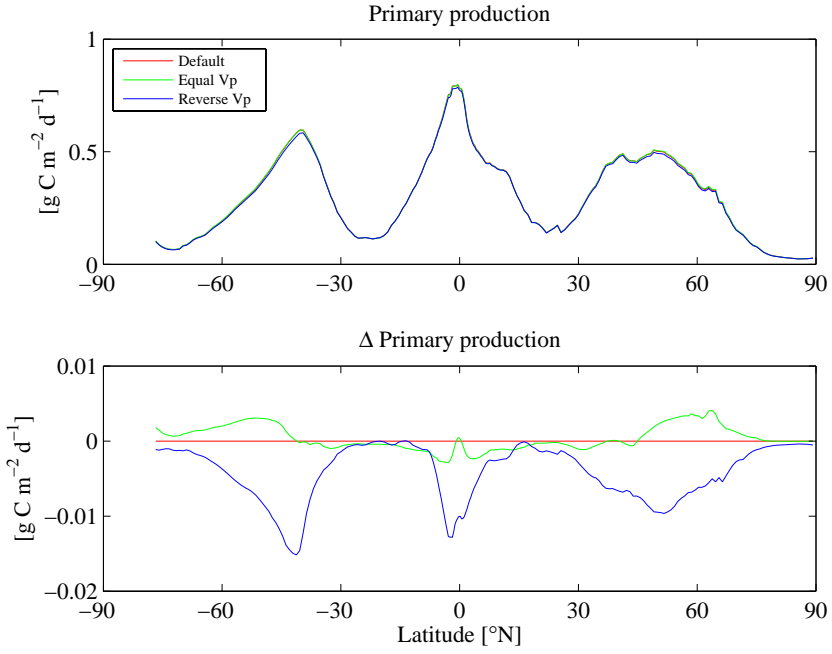

Fig. A1. Zonal average primary production $\left(\mathrm{g} \mathrm{C} \mathrm{m}^{-2} \mathrm{~d}^{-1}\right.$; top) and change in primary production from the default simulation ( $\mathrm{g} \mathrm{C} \mathrm{m}^{-2} \mathrm{~d}^{-1}$; bottom) for sensitivity simulations using default (red), equal (green) and reversed (blue; default) phytoplankton growth rates.

were used to spin-up the model, with analysis focusing on the final year (2005).

The results of these sensitivity simulations are presented in Figs. A1 to A7, and via summary statistics in Tables A1 and $\mathrm{A} 2$.

\section{A1 Phytoplankton growth rates}

In default MEDUSA, non-diatom phytoplankton are assumed to be representative of smaller phytoplankton and, correspondingly, have higher maximum growth rates $\left(0.53 \mathrm{~d}^{-1}>0.50 \mathrm{~d}^{-1}\right)$ than diatom phytoplankton (Furnas, 1990). Nonetheless, there are wide ranges in both phytoplankton cell size (large and small diatoms/non-diatoms) and in growth parameters. To examine the significance of the choice to assign non-diatom phytoplankton higher maximum growth rates than diatoms, two sensitivity simulations were performed:

- Both phytoplankton groups have the same maximum growth rate (i.e. $V_{\mathrm{Pn}}=V_{\mathrm{Pd}}=0.53 \mathrm{~d}^{-1}$ ).

- The growth differential is reversed between the phytoplankton groups (i.e. $V_{\mathrm{Pn}}=0.50 \mathrm{~d}^{-1}, V_{\mathrm{Pd}}=0.53 \mathrm{~d}^{-1}$ ).

\section{A1.1 Summary}

In the case of both simulations, change leads to increased diatom production (unsurprising since they are the beneficiary in both cases) but decreased total primary production, per
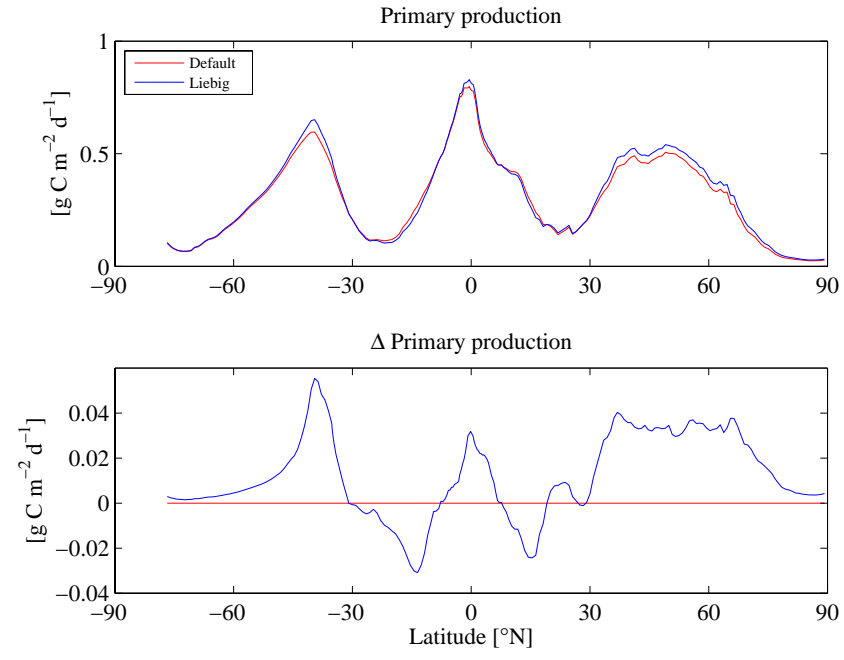

Fig. A2. Zonal average primary production $\left(\mathrm{g} \mathrm{C} \mathrm{m}^{-2} \mathrm{~d}^{-1}\right.$; top) and change in primary production from the default simulation ( $\mathrm{g} \mathrm{C} \mathrm{m}^{-2} \mathrm{~d}^{-1}$; bottom) for sensitivity simulations using multiplicative (red; default) and Liebig law of the minimum (blue) nutrient uptake.

Fig. A1. The changes are most pronounced in the case where growth rate disparity is reversed in favour of the diatoms.

However, the magnitude of change is small (at most $-1.3 \%$ for total primary production, and $+8.5 \%$ for diatom production), suggesting that total primary production MEDUSA is not particularly sensitive to the exact magnitudes of growth rates. Structural considerations (i.e. that diatoms are only grazed by mesozooplankton) are probably more significant.

\section{A2 Multiple nutrient limitation}

Default MEDUSA treats multiple nutrient limitation of phytoplankton in a multiplicative manner whereby individual limitation terms are multiplied together to determine overall nutrient limitation of growth (O’Neill et al., 1989).

$Q_{\text {multiplicative }}=\frac{\mathrm{N}}{k_{\mathrm{N}}+\mathrm{N}} \cdot \frac{\mathrm{F}}{k_{\mathrm{Fe}}+\mathrm{F}}$

A commonly-used alternative approach is to instead limit phytoplankton growth by the Michaelis-Menten term of the most limiting nutrient, the so-called Liebig law of the minimum (O’Neill et al., 1989).

$Q_{\text {liebig }}=\min \left(\frac{\mathrm{N}}{k_{\mathrm{N}}+\mathrm{N}}, \frac{\mathrm{F}}{k_{\mathrm{Fe}}+\mathrm{F}}\right)$

To examine the significance of the choice of multiplicative nutrient limitation, a sensitivity simulation was performed in 

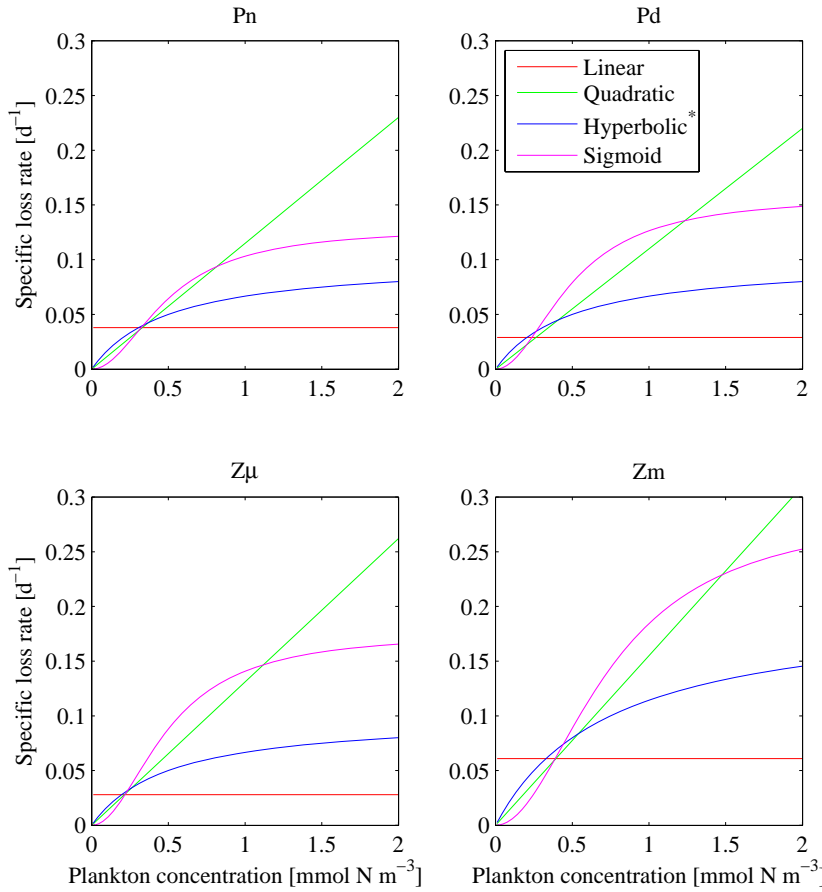

Fig. A3. Shape of specific mortality rate terms for each functional form for each plankton type. Parameter values used are described in the text.

which the relevant terms in the non-diatom and diatom phytoplankton equations were altered to a Liebig formulation.

\section{A2.1 Summary}

Switching from multiplicative to Liebig nutrient limitation leads to an increase in primary production $(+2.9 \%)$, per Fig. A2. This is not surprising given that the multiplicative form necessarily decreases nutrient uptake since each component term is $<1$. In terms of geographical distribution, productivity increases in equatorial upwelling and temperate regions, but decreases in the oligotrophic gyres. This is presumably due to a decline in the lateral transport of nutrients caused by the elevated consumption in adjacent regions. Productivity is changed least southwards of the Antarctic Front. All three nutrients experience declines, most noticeably nitrogen, as do surface concentrations of all plankton types, with the exception of diatoms.

However, overall change is still relatively slight, with diatom productivity experiencing the biggest "kick" from the adoption of Liebig limitation (+13.6\%; and a shift in phytoplankton community structure towards diatoms).

\section{A3 Density-dependent mortality}

Non-grazing mortality in all four plankton components of MEDUSA is divided into density-independent (= linear) and
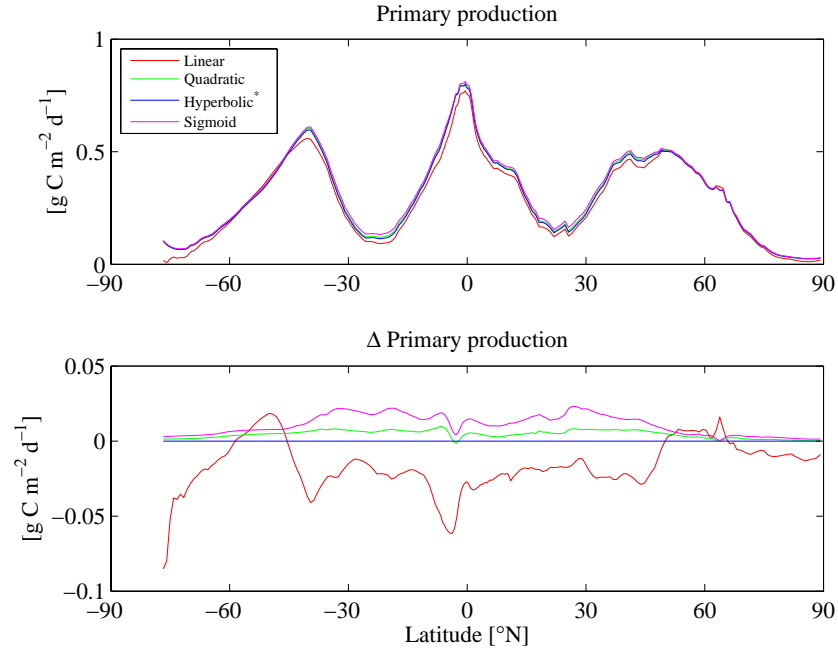

Fig. A4. Zonal average primary production $\left(\mathrm{g} \mathrm{C} \mathrm{m}^{-2} \mathrm{~d}^{-1}\right.$; top) and change in primary production from the default simulation ( $\mathrm{g} \mathrm{C} \mathrm{m}^{-2} \mathrm{~d}^{-1}$; bottom) for sensitivity simulations using linear (red), quadratic (green), hyperbolic (blue; default) and sigmoid (magenta) mortality terms.
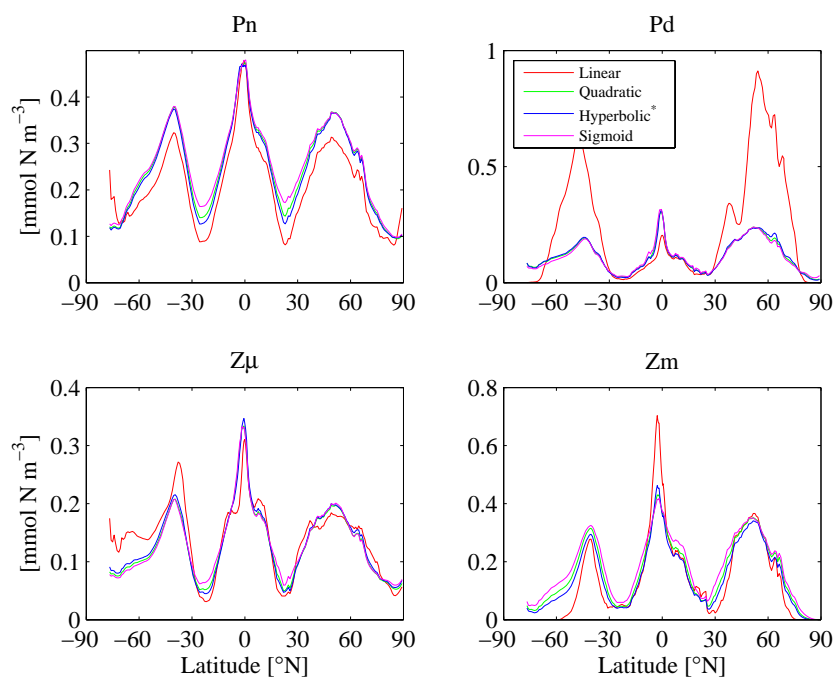

Fig. A5. Zonal average concentrations $\left(\mathrm{mmol} \mathrm{Nm}^{-3}\right)$ of nondiatom phytoplankton (top left), diatoms (top right), microzooplankton (bottom left) and mesozooplankton (bottom right) for sensitivity simulations using linear (red), quadratic (green), hyperbolic (blue; default) and sigmoid (magenta) mortality terms.

density-dependent (= non-linear) components. Following Fasham (1993), the latter terms in default MEDUSA are hyperbolic functions in which mortality is density-dependent at low plankton abundance, but saturates at high abundance. The form of such mortality in plankton ecosystem models 

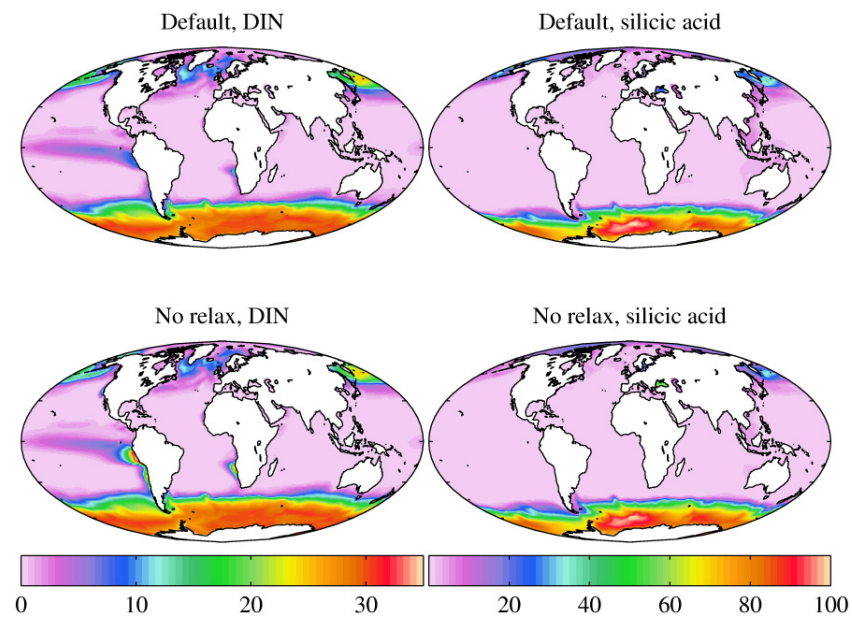

Fig. A6. Annual mean surface DIN $\left(\mathrm{mmol} \mathrm{N} \mathrm{m}^{-3}\right.$; left) and silicic acid ( $\mathrm{mmol} \mathrm{Si} \mathrm{m}{ }^{-3}$; right) concentrations for the default simulation (top), together with that for a sensitivity simulation with no coastal relaxation of nutrient concentrations.

is not well-constrained by observational evidence and has received considerable attention, particularly since this socalled "closure term" is the link to unmodelled higher predators (e.g. Steele and Henderson, 1992; Edwards and Yool, 2000; Fussmann and Blasius, 2005; Anderson et al., 2010).

To examine the significance of the choice of hyperbolic mortality terms for modelled plankton groups, three additional simulations were performed in which the mortality terms for all four groups were altered to linear, quadratic and sigmoid forms (as shown below; hyperbolic shown for comparison).

$$
\begin{array}{ll}
\text { Linear } & \mathrm{M} 2_{X}=\mu_{2, X} \cdot X \\
\text { Quadratic } & \mathrm{M} 2_{X}=\mu_{2, X} \cdot X^{2} \\
\text { Hyperbolic } & \mathrm{M} 2_{X}=\mu_{2, X} \cdot \frac{X}{k_{X}+X} \cdot X \\
\text { Sigmoid } & \mathrm{M} 2_{X}=\mu_{2, X} \cdot \frac{X^{2}}{k_{X}^{2}+X^{2}} \cdot X
\end{array}
$$

Of these, use of the linear term merely equates to a change in the value of the $\mu_{1, X}$ parameter in the $\mathrm{M} 1_{X}$ terms, and has only been performed here for completeness. The quadratic term is the most significantly different, since the mortality rate never saturates and instead continues to increase with abundance. The sigmoid term is similar to the hyperbolic term used in default MEDUSA, but exhibits a more gradual increase in mortality at low abundance that acts to create a "refuge" for scarce plankton.

In order that the sensitivity simulations were as comparable with one another as possible, the parameter values for
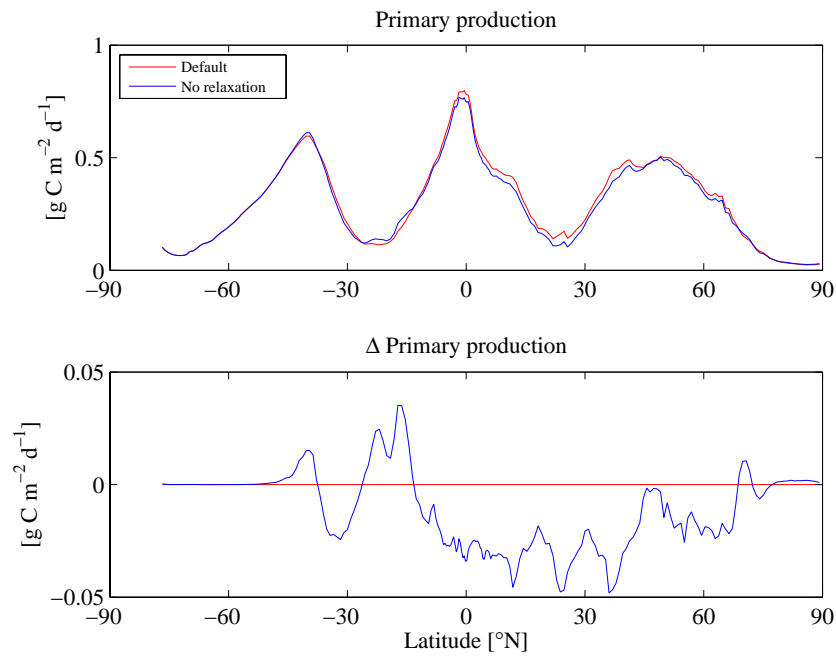

Fig. A7. Zonal average primary production $\left(\mathrm{g} \mathrm{C}^{-2} \mathrm{~d}^{-1}\right.$; top) and change in primary production from the default simulation ( $\mathrm{g} \mathrm{C} \mathrm{m}^{-2} \mathrm{~d}^{-1}$; bottom) for sensitivity simulations with (red; default) and without (blue) coastal nutrient relaxation.

$\mu_{2, X}$ used in each form for each plankton group $(X)$ were chosen such that total mortality matched that calculated using the hyperbolic form and annual average abundances from the default MEDUs A simulation. This approach results in the use of the following parameter values:

\begin{tabular}{ccccc}
\hline Plankton & Linear & Quadratic & Hyperbolic & Sigmoid \\
\hline $\mathrm{Pn}$ & 0.038 & 0.115 & 0.100 & 0.129 \\
$\mathrm{Pd}$ & 0.029 & 0.110 & 0.100 & 0.158 \\
$\mathrm{Z \mu}$ & 0.028 & 0.131 & 0.100 & 0.176 \\
$\mathrm{Zm}$ & 0.061 & 0.155 & 0.200 & 0.288 \\
\hline
\end{tabular}

In the case of sigmoid mortality, values of $k_{X}$ were unchanged from those of default hyperbolic mortality. Figure A3 illustrates the shape of specific loss rates for each of these functional forms for each plankton type.

\section{A3.1 Summary}

The adoption of alternative mortality schemes causes some of the largest and most diverse changes in Medusa behaviour in this sensitivity analysis. Figures A4 and A5 zonal averages of primary production and surface plankton concentrations for the three alternative schemes alongside default hyperbolic.

The replacement of density-dependent mortality terms with wholly linear ones causes the most significant changes but, as noted above, this mortality term was only used here for completeness, and these results should not be viewed as plausible. Use of the quadratic and sigmoid terms only results in relatively minor shifts from that of the default MEDUSA simulation. In general, both of these alternative 
Table A1. Sensitivity of Medus a state variables. The first row shows annual average surface concentrations of each state variable in mmol m${ }^{-3}$ (except Fe, which is in $\mu \mathrm{mol} \mathrm{m}{ }^{-3}$ ) for the year 2005. Subsequent rows list the percentage changes in these concentrations for each of the sensitivity simulations for the same year.

\begin{tabular}{lrrrrrrr}
\hline Experiment & $\mathrm{Pn}$ & $\mathrm{Pd}$ & $\mathrm{Z \mu}$ & $\mathrm{Zm}$ & $\mathrm{N}$ & $\mathrm{Si}$ & $\mathrm{Fe}$ \\
\hline Default & 0.263 & 0.114 & 0.143 & 0.168 & 6.083 & 10.77 & 0.509 \\
Equal Vp & $-0.4 \%$ & $+3.4 \%$ & $-0.9 \%$ & $+0.3 \%$ & $-0.5 \%$ & $-1.9 \%$ & $-0.2 \%$ \\
Reverse $\mathrm{Vp}$ & $-1.3 \%$ & $+6.7 \%$ & $-2.9 \%$ & $-0.7 \%$ & $+0.2 \%$ & $-2.9 \%$ & $+0.1 \%$ \\
Liebig & $-7.1 \%$ & $+4.3 \%$ & $-8.9 \%$ & $-1.3 \%$ & $-4.0 \%$ & $-1.5 \%$ & $-2.2 \%$ \\
Linear & $-13.9 \%$ & $+78.2 \%$ & $+4.6 \%$ & $-1.5 \%$ & $-3.2 \%$ & $-4.5 \%$ & $-1.4 \%$ \\
Quadratic & $+2.8 \%$ & $-0.2 \%$ & $-1.1 \%$ & $+9.2 \%$ & $+0.6 \%$ & $-0.0 \%$ & $+0.3 \%$ \\
Sigmoid & $+5.9 \%$ & $+1.1 \%$ & $+0.6 \%$ & $+21.3 \%$ & $+1.6 \%$ & $+0.7 \%$ & $+0.7 \%$ \\
No relax & $-3.2 \%$ & $-5.8 \%$ & $-4.4 \%$ & $-5.6 \%$ & $+2.9 \%$ & $-0.2 \%$ & $+1.2 \%$ \\
\hline
\end{tabular}

Table A2. Sensitivity of Medus a biogeochemical fluxes. The first row shows annual integrals of each flux in $\mathrm{GtC}^{-1}$ (except opal production, which is in $\mathrm{Tmol} \mathrm{Si} \mathrm{yr}^{-1}$ ) for the year 2005. Subsequent rows list the percentage changes in these fluxes for each of the sensitivity simulations for the same year.

\begin{tabular}{lrrrrrr}
\hline Experiment & Total PP & Pd PP & UML PP & Opal & Slow D & Fast D \\
\hline Default & 46.66 & 7.76 & 34.91 & 225.1 & 22.25 & 8.18 \\
Equal Vp & $-0.0 \%$ & $+4.7 \%$ & $+0.1 \%$ & $+3.1 \%$ & $-0.5 \%$ & $+1.3 \%$ \\
Reverse Vp & $-1.3 \%$ & $+8.5 \%$ & $-1.5 \%$ & $+5.1 \%$ & $-2.6 \%$ & $+0.5 \%$ \\
Liebig & $+2.9 \%$ & $+13.6 \%$ & $-1.7 \%$ & $+3.4 \%$ & $+2.1 \%$ & $+9.1 \%$ \\
Linear & $-5.1 \%$ & $+22.7 \%$ & $-4.8 \%$ & $+25.7 \%$ & $-4.5 \%$ & $+3.9 \%$ \\
Quadratic & $+1.5 \%$ & $+0.0 \%$ & $+1.6 \%$ & $-0.9 \%$ & $-0.7 \%$ & $+0.9 \%$ \\
Sigmoid & $+3.7 \%$ & $+0.3 \%$ & $+3.9 \%$ & $-2.8 \%$ & $-1.0 \%$ & $+0.9 \%$ \\
No relax & $-4.2 \%$ & $-6.7 \%$ & $-4.0 \%$ & $-16.3 \%$ & $-3.7 \%$ & $-4.7 \%$ \\
\hline
\end{tabular}

terms slightly increase productivity (particular that of nondiatoms), particularly in the fringes of oligotrophic regions. The largest changes occur in mesozooplankton, but even then are relatively minor. The close correspondence in MEDUSA between simulations using quadratic and sigmoid forms is perhaps unsurprising given the broad overlap between both forms that can be seen in Fig. A3. Until quite large plankton concentrations, both forms result in similar magnitude specific mortality rates, and both have lower mortality than the default hyperbolic term at low plankton concentrations.

In general, while the use of different mortality terms causes spatio-temporal changes in model behaviour, these are (with the exception of linear mortality) minor in scale. However, given the method of parameterisation employed here (i.e. chosen to produce an equal magnitude of mortality given the same annual average plankton field), this is perhaps to be expected. Nonetheless, the findings suggest that MEDUSA is not particularly sensitive to the default choice of hyperbolic mortality.

\section{A4 Coastal nutrient relaxation}

In the default Medus a simulation dissolved inorganic nitrogen and silicic acid concentrations are relaxed towards World Ocean Atlas climatology values in grid cells within $100 \mathrm{~km}$ of land to simulate unresolved coastal processes such as riverine fluxes of these nutrients. To examine the significance of this for the wider ocean, an additional simulation was performed in which no relaxation occurred. No other changes were implemented in this simulation.

\section{A4.1 Summary}

Figure A6 shows surface nutrient fields for both the default, relaxed simulation and the corresponding no relaxation simulation. Unsurprisingly, the largest differences occur in coastal waters, most notably off the western margin of South America where strong upwelling introduces high nutrient concentrations to surface waters. Perhaps more surprisingly is that the main effect of relaxation is to lower 
nutrient concentrations back towards those values in the forcing WOA climatology. While nutrient concentrations are elevated as intended in other areas, this is somewhat at odds with the intention to emulate the addition of nutrients by rivers. In the case of silicic acid, the global effect of relaxation is to marginally decrease surface concentrations $(-0.2 \%)$, and the most significant deviation in the no relaxation simulation is a marked $(-16.3 \%)$ drop in biogenic opal production. Figure A7 shows the corresponding changes in zonal primary production. Because coastal areas, and thus relaxation, is not evenly distributed, a simple pattern is not immediately discernible, although in common with the nutrient fields, the changes are both positive and negative.

Nonetheless, in general the change from the default simulation is still relatively modest. But the operation of relaxation in the opposite sense from that intended does point to it being of less utility than originally envisaged, though it may still be important in regions where riverine supply of nutrients is significant such as the Arctic Ocean (cf. Popova et al., 2010).

\section{Appendix B}

\section{Code structure}

The following provides a structural outline of the computer code that accompanies this description of MEdusA. This code does not encompass the entire NEMO model, but includes those modules that either include MEDUSA's calculations, or those in which MEDUSA makes an appearance for operational reasons.

The MEdusa model is organised in a similar manner to other passive tracer modules in the NEMO model. The majority of the code directly associated with MEDUsa is located within the NEMO/TOP_SRC/MEDUSA directory, with one minor exception that is described later. The actual model code is distributed across 9 separate routines as follows.

- par_medusa.F90

this routine declares the tracer and diagnostic arrays required for MEDUSA ,

- sms_medusa.F90

this routine declares the parameters required for MEDUSA ,

- trcct 1 medusa.F90

this routine checks that the correct number of passive tracers is specified,
- trcini_medusa.F90

this routine initialises the passive tracers to default values unless they are provided by a restart file,

- trclsm_medusa.F90

this routine initialises the parameters to the values specified in namelist.trc.sms,

- trcsms medusa.F90

this routine is called by the NEMO model during a simulation and in turn calls the MEDUSA routines that calculate biogeochemical sources and sinks,

- trcopt_medusa.F90

this routine calculates the submarine light field,

- trcbio_medusa.F90

this is the main model routine and includes (almost) all of the ecosystem equations used for the biogeochemical sources and sinks for tracers,

- trcsed_medusa.F90

this routine both initialises the aeolian iron deposition and $\Omega_{\text {calcite }}$ CCD fields and calculates the sinking of the slow detritus tracer.

Aside from these routines, MEDUSA includes a further modification to the passive tracer damping routine, trcdmp. F 90. In MEDUSA, an existing tracer damping subroutine is altered such that dissolved inorganic nitrogen and silicic acid are damped globally but only within $100 \mathrm{~km}$ of the coast. This damping relaxes nitrogen and silicon nutrients towards World Ocean Atlas values (Garcia et al., 2006), and aims to emulate the supply of these macronutrients to coastal regions from riverine sources. Since no corresponding climatology exists for the iron micronutrient, its concentrations experience no relaxation anywhere within the model ocean.

\section{Supplementary material related to this article is available online at: http://www.geosci-model-dev.net/4/381/2011/ gmd-4-381-2011-supplement.zip.}

Acknowledgements. The authors are grateful to the NEMO development team at NOCS for their technical support of this work. In particular, the assistance of Andrew Coward, Beverly de Cuevas and Steven Alderson has been invaluable in the development and simulation of MEDUSA. We are especially indebted to Steven for his patient and thorough detective work that uncovered, and resolved, a serious and cryptic bug deep within the NEMO physical code. 
The authors would like to acknowledge the assistance of Mick Follows and Stephanie Dutkiewicz (MIT) with MEDUSA's iron cycle submodel, and for supplying a spun-up initialising field of dissolved iron. The authors are also grateful to Keith Moore (UC Irvine), Eric Galbraith (McGill University), John Dunne and Rob Armstrong (Princeton University) for their assistance with MEDUSA's ballast submodel.

The authors are especially grateful to our two anonymous referees for their many helpful criticisms of MEDUSA, and for their diligence in pinpointing errors in our manuscript's description of it. Dorothy Dunford (Environment Canada) additionally uncovered a number of mistakes in our equations.

The authors gratefully acknowledge the financial support of the Natural Environmental Research Council (NERC). This work was performed as part of Themes 2 and 9 of the NERC Oceans 2025 strategic marine science programme.

Edited by: A. Ridgwell

\section{References}

Anderson, T. R.: Plankton functional type modelling: running before we can walk?, J. Plankton Res., 27, 1073-1081, doi:10.1093/plankt/fbi076, 2005.

Anderson, T. R.: Progress in marine ecosystem modelling and the "unreasonable effectiveness of mathematics", J. Mar. Syst., 81, 4-11, doi:10.1016/j.jmarsys.2009.12.015, 2010.

Anderson, T. R. and Hessen, D. O.: Carbon or nitrogen limitation of marine copepods?, J. Plankton Res., 17, 317-331, 1995.

Anderson, T. R. and Pondaven, P.: Non-redfield carbon and nitrogen cycling in the Sargasso Sea: pelagic imbalances and export flux, Deep-Sea Res. I, 50, 573-591, 2003.

Anderson, T. R., Ryabchenko, V. A., Fasham, M. J. R., and Gorchakov, V. A.: Denitrification in the Arabian Sea: A 3-D ecosystem modeling study, Deep-Sea Res. I, 54, 2082-2119, 2007.

Anderson, T. R., Gentleman, W. C., and Sinha, B.: Influence of grazing formulations on the emergent properties of a complex ecosystem model in a global ocean general circulation model, Prog. Oceanogr., 87, 201-213, doi:10.1016/j.pocean.2010.06.003, 2010.

Antonov, J. I., Locarnini, R. A., Boyer, T. P., Mishonov, A. V., and Garcia, H. E.: World Ocean Atlas 2005, Volume 2: Salinity, NOAA Atlas NESDIS 62, US Government Printing Office, Washington, DC, USA, edited by: Levitus, S., 182 pp., 2006.

Armstrong, R. A., Lee, C., Hedges, J. I., Honjo, S., and Wakeham, S. G.: A new, mechanistic model for organic carbon fluxes in the ocean: based on the quantitative association of POC with ballast minerals, Deep-Sea Res. II, 49, 219-236, 2002.

Aumont, O., Maier-Reimer, E., Blain, S., and Monfray, P.: An ecosystem model of the global ocean including $\mathrm{Fe}$, $\mathrm{Si}$, P colimitations, Global Biogeochem. Cy, 17, 1060, doi:10.1029/2001GB001745, 2003.

Azam, F., Fenchel, T., Field, J. G., Gray, J. S., Meyer-Reil, L. A., and Thingstad, F.: The Ecological Role of Water-Column Microbes in the Sea, Mar. Ecol. Prog. Ser., 10, 257-263, 1983.

Baird, M. E. and Suthers, I. M.: A size-resolved pelagic ecosystem model, Ecol. Modelling, 203, 185-203, doi:10.1016/j.ecolmodel.2006.11.025, 2007.
Barnier, B., Madec, G., Penduff, T., Molines, J.-M., Treguier, A.M., Le Sommer, J., Beckmann, A., Boning, C., Dengg, J., Derval, C., Durand, E., Gulev, S., Remy, E., Talandier, C., Theerren, S., Maltrud, M., McClean, J., and de Cuevas, B.: Impact of partial steps and momentum advection schemes in a global ocean circulation model at eddy-permitting resolution, Ocean Dynam., 56, 543-567, doi:10.1007/s10236-006-0082-1, 2006.

Behrenfeld, M. J. and Falkowski, P. G.: Photosynthetic rates derived from satellite-based chlorophyll concentration, Limnol. Oceanogr., 42, 1-20, 1997.

Blain, S., Leynaert, A., Tréguer, P., Chretiennot-Dinet, M. C., and Rodier, M.: Biomass, growth rates and limitation of equatorial Pacific diatoms, Deep-Sea Res. I, 44, 1255-1275, 1997.

Bopp, L., Aumont, O., Cadule, P., Alvain, S., and Gehlen, M.: Response of diatoms distribution to global warming and potential implications: A global model study, Global Biogeochem. Cy., 32, L19606, doi:10.1029/2005GL023653, 2005.

Boye, M., Aldrich, A. P., van den Berg, C. M. G., de Jong, J. T. M., Veldhuis, M., and de Baar, H. J. W.: Horizontal gradient of the chemical speciation of iron in surface waters of the northeast Atlantic Ocean, Mar. Chem., 80, 129-143, 2003.

Brzezinski, M. A., Villareal, T. A., and Lipschultz, F.: Silica production and the contribution of diatoms to new and primary production in the central North Pacific, Mar. Ecol. Prog. Ser., 167, 89-104, 1998.

Buesseler, K. O., Lamborg, C. H., Boyd, P. W., Lam, P. J., Trull, T. W., Bidigare, R. R., Bishop, J. K. B., Casciotti, K. L., Dehairs, F., Elskens, M., Honda, M., Karl, D. M., Siegel, D. A., Silver, M. W., Steinberg, D. K., Valdes, J., Van Mooy, B., and Wilson, S.: Revisiting Carbon Flux Through the Ocean's Twilight Zone, Science, 316, 567-570, doi:10.1126/science.1137959, 2007.

Burd, A. B. and Jackson, G. A.: Particle aggregation, Annu. Rev. Mar. Sci., 1, 65-90, 2009.

Caldeira, K. and Wickett, M. E.: Anthropogenic carbon and ocean pH, Nature, 425, 365-365, doi:10.1038/425365a, 2003.

Capone, D. G., Burns, J. A., Montoya, J. P., Subramaniam, A., Mahaffey, C., Gunderson, T., Michaels, A. F., and Carpenter, E. J.: Nitrogen fixation by Trichodesmium spp.: An important source of new nitrogen to the tropical and subtropical North Atlantic Ocean, Global Biogeochem. Cy., 19, GB2024, doi:10.1029/2004GB002331, 2005.

Carlson, C. A., Hansell, D. A., Nelson, N. B., Siegel, D. A., Smethie, W. M., Khatiwala, S., Meyers, M. M., and Halewood, E.: Dissolved organic carbon export and subsequent remineralisation in the mesopelagic and bathypelagic realms of the North Atlantic basin, Deep-Sea Res. II, 57, 1433-1445, 2010.

Carr, M.-E.: Estimation of potential productivity in Eastern Boundary Currents using remote sensing, Deep-Sea Res. II, 49, 59-80, 2002.

Carr, M.-E., Friedrichs, M. A. M., Schmeltz, M., Aita, M. N., Noguchi, M., Campbell, J., Ciotti, A., Dierssen, H., Dowell, M., Dunne, J., Esaias, W., Gentili, B., Gregg, W., Groom, S., Hoepffner, N., Ishizaka, J., Kameda, T., Le Quéré, C., Lohrenz, S., Marra, J., Mélin, F., Moore, K., Morel, A., Reddy, T. E., Ryan, J., Scardi, M., Smyth, T., Turpie, K., Tilstone, G., Waters, K., and Yamanaka, Y.: A comparison of global estimates of marine primary production from ocean color, Deep-Sea Res. II, 53, 741-770, 2006.

Charria, G., Dadou, I., Llido, J., Drévillon, M., and Garçon, V.: 
Importance of dissolved organic nitrogen in the north Atlantic Ocean in sustaining primary production: a 3-D modelling approach, Biogeosciences, 5, 1437-1455, doi:10.5194/bg-5-14372008, 2008.

Christian, J. R. and Anderson, T. R.: Modeling DOM biogeochemistry, in: Biogeochemistry of marine dissolved organic, edited by: Hansell, D. A. and Carlson, C. A., Academic Press, USA, 717-756,2002.

Christian, J. R., Feeley, R. A., Ishii, M., Murtugudde, R., and Wang, X.: Testing an ocean carbon model with observed sea surface $\mathrm{pCO}_{2}$ and dissolved inorganic carbon in the tropical Pacific Ocean, J. Geophys. Res., 113, C07047, doi:10.1029/2007/JC004428, 2008.

Cox, P. M., Betts, R. A., Jones, C. D., Spall, S. A., and Totterdell, I. J.: Acceleration of global warming due to carbon-cycle feedbacks in a coupled climate model, Nature, 408, 184-187, 2000.

Dai, A. and Trenberth, K. E.: Estimates of freshwater discharge from continents: latitudinal and seasonal variations, J. Hydrometeorol., 3, 660-687, 2002.

Deutsch, C., Sarmiento, J. L., Sigman, D. M., Gruber, N., and Dunne, J. P.: Spatial coupling of nitrogen inputs and losses in the ocean, Nature, 445, 163-167, doi:10.1038/nature05392, 2007.

DRAKKAR Group: Eddy-permitting Ocean Circulation Hindcasts of past decades, CLIVAR Exchanges No. 42, 12, 8-10, 2007.

Dugdale, R. C. and Wilkerson, F. P.: Silicate regulation of new production in the equatorial Pacific upwelling, Nature, 391, 270273, 1998

Dunne, J. P., Armstrong, R. A., Gnanadesikan, A., and Sarmiento, J. L.: Empirical and mechanistic models for the particle export ratio, Global Biogeochem. Cy., 19, GB4026, doi:10.1029/2004GB002390, 2005.

Dunne, J. P., Sarmiento, J. L., and Gnanadesikan, A.: A synthesis of global particle export from the surface ocean and cycling through the ocean interior and on the seafloor, Global Biogeochem. Cy., 21, GB4006, doi:10.1029/2006GB002907, 2007.

Dutkiewicz, S., Follows, M. J., and Parekh, P.: Interactions of the iron and phosphorus cycles: A threedimensional model study, Global Biogeochem. Cy., 19, GB1021, doi:10.1029/2004GB002342, 2005.

Edwards, A. M. and A. Yool: The role of higher predation in plankton population models, J. Plankton Res., 22, 1085-1112, 2000.

Eppley, R. W.: Temperature and phytoplankton growth in the sea, Fish. Bull. Nat. Ocean. Atmos. Adm., 70, 1063-1085, 1972.

Fasham, M. J. R.: Modelling the marine biota, in: The Global Carbon Cycle, Springer-Verlag, New York, USA, edited by: Heimann, M., 457-504, 1993.

Fasham, M. J. R., Ducklow, H. W., and McKelvie, S. M.: A nitrogen-based model of plankton dynamics in the oceanic mixed layer, J. Mar. Res., 48, 591-639, 1990.

Feely, R. A., Sabine, C. L., Lee, K., Berelson, W., Kleypas, J., Fabry, V. J., and Millero, F. J.: Impact of anthropogenic $\mathrm{CO}_{2}$ on the $\mathrm{CaCO}_{3}$ system in the oceans, Science, 305, 362-366, 2004.

Fichefet, T. and Morales Maqueda, M. A.: Sensitivity of a global sea ice model to the treatment of ice thermodynamics and dynamics, J. Geophys. Res., 102, 12609-12646, 1997.

Flynn, K. J.: A mechanistic model for describing dynamic multinutrient, light, temperature interactions in phytoplankton, J. Plankton Res., 23, 977-997, 2001.

Flynn, K. J.: Castles built on sand: dysfunctionality in plankton models and the inadequacy of dialogue between biologists and modellers, J. Plankton Res., 27, 1205-1210, 2005.

Furnas, M. J.: In situ growth rates of marine phytoplankton: approaches to measurement, community and species growth rates, J. Plankton Res., 12, 1117-1151, 1990.

Fussmann, G. F. and Blasius, B.: Community response to enrichment is highly sensitive to model structure, Biol. Lett., 1, 9-12, doi:10.1098/rsbl.2004.0246, 2005.

Galbraith, E. D., Gnanadesikan, A., Dunne, J. P., and Hiscock, M. R.: Regional impacts of iron-light colimitation in a global biogeochemical model, Biogeosciences, 7, 1043-1064, doi:10.5194/bg-7-1043-2010, 2010.

Garcia, H. E., Locarnini, R. A., Boyer, T. P., and Antonov, J. I.: World Ocean Atlas 2005, Volume 4: Nutrients (phosphate, nitrate, silicate), NOAA Atlas NESDIS 64, edited by: Levitus, S., US Government Printing Office, Washington, DC, USA, 396 pp., 2006.

Gaspar, P., Grégoris, Y., and Lefevre, J.-M.: A simple eddy kinetic energy model for simulations of the oceanic vertical mixing Tests at station papa and long-term upper ocean study site, J. Geophys. Res, 95, 16179-16193, 1990.

Gehlen, M., Gangstø, R., Schneider, B., Bopp, L., Aumont, O., and Ethe, $\mathrm{C} .:$ The fate of pelagic $\mathrm{CaCO}_{3}$ production in a high $\mathrm{CO}_{2}$ ocean: a model study, Biogeosciences, 4, 505-519, doi:10.5194/bg-4-505-2007, 2007.

Gledhill, M. and van den Berg, C.: Determination of complexation of iron (III) with natural organic complexing ligands in seawater using cathodic stripping voltammetry, Mar. Chem., 47, 41-54, 1994.

Greenwood, J.: Shallow water dissolution of settling calcite at Station ALOHA, Limnol. Oceanogr., 54, 1420-1424, 2009.

Gregg, W. W., Ginoux, P., Schopf, P. S., and Casey, N. W.: Phytoplankton and iron: validation of a global three-dimensional ocean biogeochemical model, Deep-Sea Res. II, 50, 3143-3169, 2003.

Gruber, N., Sarmiento, J. L., and Stocker, T. F.: An improved method for detecting anthropogenic $\mathrm{CO}_{2}$ in the oceans, Global Biogeochem. Cy., 10, 809-837, 1996.

Harris, R. P.: Zooplankton grazing on the coccolithophore Emiliania huxleyi and its role in inorganic carbon flux, Mar. Biol., 119, 431-439, 1994.

Hibler, W. D.: A dynamic thermodynamic sea ice model, J. Phys. Oceanogr., 9, 815-846, 1979.

Hood, R. R., Laws, E. A., Armstrong, R. A., Bates, N. R., Brown, C. W., Carlson, C. A., Chai, F., Doney, S. C., Falkowski, P. G., Feely, R. A., Friedrichs, M. A. M., Landry, M. R., Moore, J. K., Nelson, D. M., Richardson, T. L., Salihoglu, B., Schartau, M., Toole, D. A., and Wiggert, J. D.: Pelagic functional group modeling: Progress, challenges and prospects, Deep-Sea Res. II, 53, 459-512, 2006.

Iglesias-Rodriguez, M. D., Halloran, P. R., Rickaby, R. E. M., Hall, I. R., Colmenero-Hidalgo, E., Gittins, J. R., Green, D. R. H., Tyrrell, T., Gibbs, S. J., von Dassow, P., Rehm, E., Armbrust, E. V., and Boessenkool, K. P.: Phytoplankton Calcification in a High- $\mathrm{CO}_{2}$ World, Science, 320, 336-340, doi:10.1126/science.1154122, 2008.

Jourdan, D., Balopoulos, E., Garcia-Fernandez, M.-J., and Maillard, C.: Objective analysis of temperature and salinity historical data set over the Mediterranean basin, OCEANS '98 Conference Proceedings, 1, 82-87, doi:10.1109/OCEANS.1998.725649, 1998. 
Kahler, P. and Koeve, W.: Marine dissolved organic matter: can its C:N ratio explain carbon overconsumption?, Deep-Sea Res. I, 48, 49-62, 2001.

Kelly-Gerreyn, B. A., Martin, A. P., Tyrrell, T., and Somavilla, R.: Part 2, Calcification model user guide, in: MEECE EU Framework 7 project no. 212085: D2.2 Sub-model acidificationsensitive calcification rate, including user guide, edited by: Blackford, J., Artioli, Y., Kelly-Gerreyn, B. A., Martin A. P., Tyrrell, T., and Somavilla, R., 10-30, 2009.

Key, R. M., Kozyr, A., Sabine, C. L., Lee, K., Wanninkhof, R., Bullister, J. L., Feely, R. A., Millero, F. J., Mordy, C., and Peng, T.-H.: A global ocean carbon climatology: Results from Global Data Analysis Project (GLODAP), Global Biogeochem. Cy., 18, GB4031, doi:10.1029/2004GB002247, 2004.

Klaas, C. and Archer, D.: Association of sinking organic matter with various types of mineral ballast in the deep sea: Implications for the rain ratio, Global Biogeochem. Cy., 16, 1116, doi:10.1029/2001GB001765, 2002.

Kneip, C., Lockhart, P., Voß, C., and Maier, U.: Nitrogen fixation in eukaryotes - New models for symbiosis, BMC Evol. Biol., 7, 55, doi:10.1186/1471-2148-7-55, 2007.

Kriest, I. and Evans, G. T.: Representing phytoplankton aggregates in biogeochemical models, Deep-Sea Res. I, 46, 1841-1859, 1999.

Kwok, R. and Rothrock, D. A.: Decline in Arctic sea ice thickness from submarine and ICESat records: 1958-2008, Geophys. Res. Lett., 36, L15501, doi:10.1029/2009GL039035, 2009.

Lancelot, C., de Montety, A., Goosse, H., Becquevort, S., Schoemann, V., Pasquer, B., and Vancoppenolle, M.: Spatial distribution of the iron supply to phytoplankton in the Southern Ocean: a model study, Biogeosciences, 6, 2861-2878, doi:10.5194/bg6-2861-2009, 2009.

Large, W. and Yeager, S.: Diurnal to decadal global forcing for ocean and sea-ice models: the data sets and flux climatologies, CGD Division of the National Center for Atmospheric Research, NCAR Technical Note: NCAR/TN-460+STR, 2004.

Le Quéré, C., Harrison, S. P., Prentice, C., Buitenhuis, E., Aumont, O., Bopp, L., Claustre, H., Cotrim Da Cunha, L., Geider, R., Giraud, X., Klaas, C., Kohfeld, K. E., Legendre, L., Manizza, M., Platt, T., Rivkin, R. B., Sathyendranath, S., Uitz, J., Watson, A. J., and Wolf-Gladrow, D.: Ecosystem dynamics based on plankton functional types for global ocean biogeochemistry models, Glob. Change Biol., 11, 2016-2040, 2005.

Liu, G. and Chai, F.: Seasonal and interannual variation of physical and biological processes during 1994-2001 in the Sea of Japan/East Sea: A three-dimensional physical-biogeochemical modeling study, J. Mar. Syst. 78, 265-277, 2009.

Locarnini, R. A., Mishonov, A. V., Antonov, J. I., Boyer, T. P., and Garcia, H. E.: World Ocean Atlas 2005, Volume 1: Temperature, NOAA Atlas NESDIS 61, edited by: Levitus, S., US Government Printing Office, Washington, DC, USA, 182 pp., 2006.

Lyman, J. M., Good, S. A., Gouretski, V. V., Ishii, M., Johnson, G. C., Palmer, M. D., Smith, D. M., and Willis, J. K.: Robust warming of the global upper ocean, Nature, 465, 334-337, doi:10.1038/nature09043, 2010.

Madec, G.: NEMO reference manual, ocean dynamic component: NEMO-OPA, Note du Pole de modélisation, Institut Pierre Simon Laplace, Technical Report 27, Note du Pole de modélisation, Institut Pierre Simmon Laplace, France, No. 27,
2008.

Madec, G., Delecluse, P., Imbard, M., and Lévy, C.: OPA 8.1 ocean general circulation model reference manual, Note du Pole de modélisation, Institut Pierre Simon Laplace, France, Technical Report 11, 91 pp., 1998.

Mann, D. G.: The species concept in diatoms, Phycologia, 38, 437495, 1999.

Marra, J., Ho, C., and Trees, C. C.: An alternative algorithm for the calculation of primary productivity from remote sensing data, Lamont-Doherty Earth Observatory, Technical Report \#LDEO2003-1, 27 pp. (unpublished manuscript), 2003.

Martin, J. H., Knauer, G. A., Karl, D. M., and Broenkow, W. W.: VERTEX: Carbon cycling in the northeastern Pacific, Deep-Sea Res. I, 34, 267-285, 1987.

Martin-Jézéquel, V., Hildebrand, M., and Brzezinski, M. A.: Silicon metabolism in diatoms : implications for growth, J. Phycol., 36, 821-840, 2000.

McGillicuddy, D. J., Anderson, L. A., Doney, S. C., and Maltrud, M. A.: Eddy-driven sources and sinks of nutrients in the upper ocean: Results from a $0.1^{\circ}$ resolution model of the North Atlantic, Global Biogeochem. Cy., 17, 1035, doi:10.1029/2002GB001987, 2003.

Milliman, J. D., Troy, P. J., Balch, W. M., Adams, A. K., Li, Y.H., and Mackenzie, F. T.: Biologically mediated dissolution of calcium carbonate above the chemical lysocline, Deep-Sea Res. I, 46, 1653-1669, 1999.

Mongin, M., Nelson, D. M., Pondaven, P., and Tréguer, P.: Simulation of upper-ocean biogeochemistry with a flexible-composition phytoplankton model: $\mathrm{C}, \mathrm{N}$ and Si cycling and Fe limitation in the Southern Ocean, Deep-Sea Res. II, 53, 601-619, 2006.

Monteiro, F. M., Follows, M. J., and Dutkiewicz, S.: Distribution of diverse nitrogen fixers in the global ocean, Global Biogeochem. Cy., GB3017, doi:10.1029/2009GB003731, 2010.

Moore, J. K. and Doney, S. C.: Iron availability limits the ocean nitrogen inventory stabilizing feedbacks between marine denitrification and nitrogen fixation, Global Biogeochem. Cy., 21, GB2001, doi:10.1029/2006GB002762, 2007.

Moore, J. K., Doney, S. C., Kleypas, J. A., Glover, D. M., and Fung, I. Y.: An intermediate complexity marine ecosystem model for the global domain, Deep-Sea Res. II, 49, 403-462, 2002.

Moore, J. K., Doney, S. C., and Lindsay, K.: Upper ocean ecosystem dynamics and iron cycling in a global threedimensional model, Global Biogeochem. Cy., 18, GB4028, doi:10.1029/2004GB002220, 2004.

Nelson, D. M. and Brzezinski, M. A.: Diatom growth and productivity in an oligotrophic mid-ocean gyre: a 3-year record from the Sargasso Sea near Bermuda, Limnol. Oceanogr., 42, 473486, 1997.

O’Neill, R. V., Angelis, D. L., Pastor, J. J., Jackson, B. J., and Post, W. M.: Multiple nutrient limitation in ecological models, Ecol. Model., 46, 147-163, 1989.

O'Reilly, J. E., Maritorena, S., Mitchell, B. G., Siegal, D. A., Carder, K. L., Garver, S. A., Kahru, M., and McClain, C.: Ocean color chlorophyll algorithms for SeaWiFS, J. Geophys. Res., 103, 24937-24953, 1998.

Oka, A., Kato, S., and Hasumi, H.: Evaluating effect of ballast mineral on deep-ocean nutrient concentration by using an ocean general circulation model, Global Biogeochem. Cy., 22, GB3004, doi:10.1029/2007GB003067, 2008. 
Okunishi, T., Kishi, M. J., Ono, Y., and Yamashita, T.: A lower trophic ecosystem model including iron effects in the Okhotsk Sea, Cont. Shelf Res., 27, 2080-2098, 2007.

Orr, J. C., Fabry, V. J., Aumont, O., Bopp, L., Doney, S. C., Feely, R. A., Gnanadesikan, A., Gruber, N., Ishida, A., Joos, F., Key, R. M., Lindsay, K., Maier-Reimer, E., Matear, R., Monfray, P., Mouchet, A., Najjar, R. G., Plattner, G.-K., Rodgers, K. B., Sabine, C. L., Sarmiento, J. L., Schlitzer, R., Slater, R. D., Totterdell, I. J., Weirig, M.-F., Yamanaka, Y., and Yool, A.: Anthropogenic ocean acidification over the twenty-first century and its impact on calcifying organisms, Nature, 437, 681-686, 2005.

Oschlies, A. and Schartau, M.: Basin-scale performance of a locally optimized marine ecosystem model, J. Mar. Res., 63, 335-358, doi:10.1357/0022240053693680, 2005.

Östlund, G. and Stuiver, M.: GEOSECS Pacific radiocarbon, Radiocarbon, 22, 25-53, 1980.

Palmer, J. R. and Totterdell, I. J.: Production and export in a global ocean ecosystem model, Deep-Sea Res., 48, 1169-1198, 2001.

Parekh, P., Follows, M. J., and Boyle, E. A.: Decoupling of iron and phosphate in the global ocean, Global Biogeochem. Cy., 19, GB2020, doi:10.1029/2004GB002280, 2005.

Penduff, T., Le Sommer, J., Barnier, B., Treguier, A.-M., Molines, J.-M., and Madec, G.: Influence of numerical schemes on current-topography interactions in $1 / 4^{\circ}$ global ocean simulations, Ocean Sci., 3, 509-524, doi:10.5194/os-3-509-2007, 2007.

Penduff, T., Juza, M., Brodeau, L., Smith, G. C., Barnier, B., Molines, J.-M., Treguier, A.-M., and Madec, G.: Impact of global ocean model resolution on sea-level variability with emphasis on interannual time scales, Ocean Sci., 6, 269-284, doi:10.5194/os6-269-2010, 2010.

Pomeroy, L. R.: The Ocean's Food Web, a Changing Paradigm, Bioscience, 24, 499-504, 1974.

Pond, D. W., Harris, R. P., and Brownlee, C. A.: Microinjection technique using a $\mathrm{pH}$-sensitive dye to determine the gut $\mathrm{pH}$ of Calanus helgolandicus, Mar. Biol., 123, 75-79, 1995.

Popova, E. E. and Anderson, T. R.: Impact of including dissolved organic matter in a global ocean box model on simulated distributions and fluxes of carbon and nitrogen, Geophys. Res. Lett., 29, 1303, doi:10.1029/2001GL014274, 2002.

Popova, E. E., Coward, A. C., Nurser, G. A., de Cuevas, B., Fasham, M. J. R., and Anderson, T. R.: Mechanisms controlling primary and new production in a global ecosystem model - Part I: Validation of the biological simulation, Ocean Sci., 2, 249-266, doi:10.5194/os-2-249-2006, 2006.

Popova, E. E., Yool, A., Coward, A. C., Aksenov, Y. K., Alderson, S. G., de Cuevas, B. A., and Anderson, T. R.: Control of primary production in the Arctic by nutrients and light: insights from a high resolution ocean general circulation model, Biogeosciences, 7, 3569-3591, doi:10.5194/bg-7-3569-2010, 2010.

Prowe, F., Thomas, H., Pätsch, J., Kühn, W., Bozec, Y., Schiettecatte, L. S., Borges, A. V., and de Baar, H. J. W.: Mechanisms controlling the air-sea $\mathrm{CO}_{2}$ flux in the North Sea Cont. Shelf Res., 29, 1801-1808, doi:10.1016/j.csr.2009.06.003, 2009.

Raven, J. A. and Falkowski, P. G.: Oceanic sinks for atmospheric $\mathrm{CO}_{2}$, Plant Cell Environ., 22, 741-755, 1999.

Raven, J. A., Caldeira, K., Elderfield, H., Hoegh-Guldberg, O., Liss, P., Riebesell, U., Shepherd, J., Turley, C., and Watson, A.: Ocean acidification due to increasing atmospheric carbon dioxide, Royal Society of London, UK, 2005.
Redfield, A. C.: On the proportions of organic derivatives in seawater and their relation to the composition of plankton, in: James Johnstone Memorial Volume, edited by: Daniel, R. J., University of Liverpool, UK, 176-192, 1934.

Ridgwell, A., Zondervan, I., Hargreaves, J. C., Bijma, J., and Lenton, T. M.: Assessing the potential long-term increase of oceanic fossil fuel $\mathrm{CO}_{2}$ uptake due to $\mathrm{CO}_{2}$-calcification feedback, Biogeosciences, 4, 481-492, doi:10.5194/bg-4-481-2007, 2007.

Riebesell, U., Zondervan, I., Rost, B., Tortell, P. D., Zeebe, R. E., and Morel, F. M. M.: Reduced calcification of marine plankton in response to increased atmospheric $\mathrm{CO}_{2}$, Nature, 407, 364-367, doi:10.1038/35030078, 2000.

Rose, A. L. and Waite, T. D.: Kinetics of iron complexation by dissolved natural organic matter in coastal waters, Mar. Chem., 84, 85-103, 2003.

Roussenov, V., Williams, R. G., Mahaffey, C., and Wolff, G. A.: Does the transport of dissolved organic nutrients affect export production in the Atlantic Ocean? Global Biogeochem. Cy., 20, GB3002, doi:10.1029/2005GB002510, 2006.

Sarmiento, J. L., Slater, R. D., Fasham, M. J. R., Ducklow, H. W., Toggweiler, J. R., and Evans, G. T.: A seasonal threedimensional ecosystem model of nitrogen cycling in the North Atlantic euphotic zone, Global Biogeochem. Cy., 7, 417-450, 1993.

Schmittner, A., Oschlies, A., Giraud, X., Eby, M., and Simmons, H. L.: A global model of the marine ecosystem for long-term simulations: Sensitivity to ocean mixing, buoyancy forcing, particle sinking, and dissolved organic matter cycling, Global Biogeochem. Cy., 19, GB3004, doi:10.1029/2004GB002283, 2005.

Semtner, A. J.: A model for the thermodynamic growth of sea ice in numerical investigation of climate, J. Phys. Oceanogr., 6, 376389, 1976.

Six, K. D. and Maier-Reimer, E.: Effects of plankton dynamics on seasonal carbon fluxes in an ocean general circulation model, Global Biogeochem. Cy., 10, 559-583, 1996.

Smetacek, V. S.: Role of sinking in diatom life-history cycles: ecological, evolutionary and geological significance, Mar. Biol., 84, 239-251, 1985.

Smith, S. L., Yamanaka, Y., Pahlow, M., and Oschlies, A.: Optimal uptake kinetics: physiological acclimation explains the pattern of nitrate uptake by phytoplankton in the ocean, Mar. Ecol. Prog. Ser., 384, 1-12, doi:10.3354/meps08022, 2009.

Steele, J. H. and Henderson, E. W.: The role of predation in plankton models, J. Plankton Res., 14, 157-172, 1992.

Steele, M., Morley, R., and Ermold, W.: PHC: a global ocean hydrography with a high quality Artic Ocean, J. Climate, 14, 2079 2087, 2001.

Taylor, A. H., Geider, R. J., and Gilbert, F. J. H.: Seasonal and latitudinal dependencies of phytoplankton carbon-to-chlorophyll a ratios: results of a modelling study, Mar. Ecol. Prog. Ser., 152, 51-66, 1997.

Timmermann, R., Goosse, H., Madec, G., Fichefet, T., Ethe, C., and Duliere, V.: On the representation of high latitude processes in the ORCA-LIM global coupled sea ice-ocean model, Ocean Model., 8, 175-201, doi:10.1016/j.ocemod.2003.12.009, 2005.

Tréguer, P., Nelson, D. M., Van Bennekom, A. J., DeMaster, D. J., Leynaert, A., and Quéguiner, B.: The silica balance in the world ocean: a reestimate, Science, 268, 375-379, 1995. 
Tyrrell, T.: The relative influences of nitrogen and phosphorus on oceanic primary production, Nature, 400, 525-531, 1999.

Tyrrell, T. and Taylor, A. H.: A modelling study of Emiliania huxleyi in the NE Atlantic, J. Mar. Syst., 9, 83-112, 1996.

Westberry, T., Behrenfeld, M. J., Siegel, D. A., and Boss, E.: Carbon-based primary productivity modeling with vertically resolved photoacclimation, Global Biogeochem. Cy., 22, GB2024, doi:10.1029/2007GB003078, 2008.

Yool, A. and Tyrrell, T.: The role of diatoms in regulating the ocean's silicon cycle, Global Biogeochem. Cy., 17, 1103, doi:10.1029/2002GB002018, 2003.
Yool, A., Oschlies, A., Nurser, A. J. G., and Gruber, N.: A modelbased assessment of the TrOCA approach for estimating anthropogenic carbon in the ocean, Biogeosciences, 7, 723-751, doi:10.5194/bg-7-723-2010, 2010.

Zahariev, K., Christian, J. R., and Denman, K. L.: Preindustrial, historical, and fertilization simulations using a global ocean carbon model with new parameterizations of iron limitation, calcification, and $\mathrm{N}_{2}$ fixation, Prog. Oceanogr., 77, 56-82, 2008.

Zeebe, R. E. and Wolf-Gladrow, D. A.: $\mathrm{CO}_{2}$ in Seawater: Equilibrium, Kinetics, Isotopes, Elsevier, Amsterdam, Netherlands, 2001. 